\title{
Biotinylated Platinum(II) Ferrocenylterpyridine Complexes for Targeted Photoinduced Cytotoxicity
}

Koushambi Mitra, Abhijith Shettar, Paturu Kondaiah," and Akhil R. Chakravarty

\section{SUPPORTING INFORMATION}




\section{Table of contents}

Synthetic procedures - Preparation and characterization of the ligands

Experimental Section - Methods

\section{Schemes -}

Scheme S1 - Preparation of the ligands $\mathrm{HL}^{1}, \mathrm{HL}^{2}, \mathrm{HL}^{3}$

Scheme S2 - Preparation of the complexes 1-6

Scheme S3 - Plausible pathways for photodecomposition of complex 1

\section{Figures -}

Figure S1. ${ }^{1} \mathrm{H}$ NMR and ${ }^{13} \mathrm{C}$ NMR spectra of the ligand $\mathrm{HL}^{1}$

Figure S2. ${ }^{1} \mathrm{H}$ NMR and ${ }^{13} \mathrm{C}$ NMR spectra of the ligand $\mathrm{HL}^{3}$

Figures S3. Mass spectra of the ligand $\mathrm{HL}^{1}$

Figure S4. HPLC chromatograms for purity check for complexes 1-6

Figures S5-S7. ${ }^{1} \mathrm{H}$ spectra of the complexes 1-6

Figures S8-S13.Mass spectra of the complexes 1-6

Figure S14. UV-visible spectra of the complexes 1-6

Figure S15. Luminescence spectra of the complexes

Figure S16. IR spectra of the complexes 1-6

Figure S17. Cyclic voltammograms of the complexes 1-6

Figure S18. Cyclic voltammograms of the Fc, Fc-tpy and Ph-tpy

FigureS19. Energy-minimized structures of complexes 1-3

Figures S20-S21. Molecular orbital diagrams involved in transitions

Figure S22. Photostability of complexes in 10\% DMSO-DPBS

Figure S23. Photostability of the complexes in pure DMSO

Figure S24. Effect of addition of phen complexes 1-3 and light exposure 
Figure S25. Mass spectra of photo-exposed samples containing complex and phen

Figure S26. UV-visible absorption spectra of ferric chloride and phen

Figure S27. Photostability in 10\% DMSO-DPBS in presence of excess GSH

Figure S28. Changes in the ${ }^{1} \mathrm{H}$ nmr of complex 2 on light exposure

Figure S29. Changes in the ${ }^{1} \mathrm{H}$ nmr of complex 3 on light exposure

Figure S30. Mass spectra analysis of photo-exposed ferrocene derivative

Figure S31. NMR spectra of photo-exposed ferrocene derivative

Figure S32. Mass spectra complexes 1-3 after photoexposure

Figure S33. DNA melting and viscosity curves

Figure S34. Luminescence intensity of complexes 4-6 in DNA-buffer solution

FiguresS35. Cell viability plots for MTT assay of the complexes and ligands

Figures S36. ROS plots as obtained from DCFDA assay in BT474 cells

Figures S37. Annexin-V/FITC-PI assay of the complexes in BT474 cells

Figures S38. Cell cycle analysis of the complexes in BT474 cells

\section{Tables -}

Table S1 - Coordinates for the energy minimized structures

Table S2 - Selected transitions in the visible region as calculated from TDDFT

Table S3 - Platinum amount in ct-DNA

\section{References -}




\section{Experimental Section}

\section{Preparation and Characterization of the Ligands}

General procedure for ligands synthesis. The corresponding acid [6-biotinylaminocaproic acid (586 mg, $1.64 \mathrm{mmol})$ for $\mathrm{HL}^{1}$, acetic acid $(100 \mu \mathrm{L}, 1.64 \mathrm{mmol})$ for $\left.\mathrm{HL}^{3}\right]$ and 2-propyn1-amine (176 $\mu \mathrm{L}, 1.64 \mathrm{mmol})$ was suspended in aq. $\mathrm{MeCN}(50 \%, 18 \mathrm{~mL})$ and cooled in an ice bath for 15 mins. Anhydrous HOBt (336 mg, $1.64 \mathrm{mmol}$ ) and EDCI (492 mg, $1.64 \mathrm{mmol}$ ) were added and the solution was stirred at room temperature. The solvent was evaporated using a rotavac and the yellow oily residue was purified using column chromatography on neutral alumina $(\mathrm{DCM} / \mathrm{MeOH})$ to obtain a white solid which was characterised as the desired product.

$\mathrm{HL}^{1}$. (Yield: $300 \mathrm{mg}, 46 \%$ ). Anal.Calcd for $\mathrm{C}_{19} \mathrm{H}_{30} \mathrm{~N}_{4} \mathrm{O}_{3} \mathrm{~S}\left(\mathrm{HL}^{1}\right.$ ): C, 57.84; H, 7.66; N, 14.20 . Found: C, 57.23; H, 7.85; N, 13.98. ESI-MS in MeOH: $m / z 395.2117[\mathrm{M}+\mathrm{H}]^{+}(100 \%) .{ }^{1} \mathrm{H}$ NMR $\left(400 \mathrm{MHz}\right.$, DMSO- $\left.d_{6}\right): \delta(\mathrm{ppm})=8.20(\mathrm{t}, 1 \mathrm{H}), 7.72(\mathrm{t}, 1 \mathrm{H}), 6.41(\mathrm{~s}, 1 \mathrm{H}), 6.30(\mathrm{~s}, 1 \mathrm{H})$, $4.30(\mathrm{t}, 1 \mathrm{H}), 4.14(\mathrm{~m}, 1 \mathrm{H}) 3.83(\mathrm{~m}, 2 \mathrm{H}), 3.09(\mathrm{~m}, 2 \mathrm{H}), 3.00(\mathrm{~m}, 2 \mathrm{H}), 2.83(\mathrm{~m}, 1 \mathrm{H}), 2.59(\mathrm{~m}$, 1H), $2.05(\mathrm{~s}, 4 \mathrm{H}), 1.49-1.21(\mathrm{~b}, 12 \mathrm{H}) .{ }^{13} \mathrm{C}$ NMR $\left(100 \mathrm{MHz}, \mathrm{DMSO}-d_{6}\right): \delta(\mathrm{ppm})=172.75$, $163.63,82.27,73.67,61.96,60.11,56.34,35.91,29.86,29.12,28.94,28.61$.

$\mathrm{HL}^{3}$. (Yield: $133 \mathrm{mg}, 84 \%$ ). Anal.Calcd for $\mathrm{C}_{5} \mathrm{H}_{7} \mathrm{NO}\left(\mathrm{HL}^{3}\right)$ : C, 61.84; H, 7.27; N, 14.42 . Found: C, 49.95; H, 4.89; N, 9.40. ESI-MS in MeOH: $m / z 98.0606[\mathrm{M}+\mathrm{H}]^{+}(100 \%) .{ }^{1} \mathrm{H}$ $\operatorname{NMR}\left(400 \mathrm{MHz}, \mathrm{CDCl}_{3}\right): \delta(\mathrm{ppm})=5.82(\mathrm{~b}, 1 \mathrm{H}), 4.04(\mathrm{~m}, 2 \mathrm{H}), 2.23(\mathrm{~s}, 1 \mathrm{H}), 2.01(\mathrm{~s}, 3 \mathrm{H})$.

${ }^{13} \mathrm{C} \operatorname{NMR}\left(100 \mathrm{MHz}, \mathrm{CDCl}_{3}\right): \delta(\mathrm{ppm})=170.40,79.83,72.12,29.79,23.39$. 


\section{DNA binding studies}

Two identical sets of calf thymus (ct) DNA $(5 \mathrm{ml}, 500 \mu \mathrm{M})$ were treated with the complexes 1-6 $(50 \mu \mathrm{M})$ in $10 \%$ DMSO-DPBS $(\mathrm{pH}=7.2)$. One set was incubated in the dark while the other set of samples was photo-irradiated (400-700 nm, Luzchem photo-reactor, Model: LZC-1, Ontario, Canada) for $1 \mathrm{~h}$. The DNA was then precipitated by treating with excess ethanol $(10 \mathrm{~mL})$ and centrifuged at $4000 \mathrm{rpm}$ at $4{ }^{\circ} \mathrm{C}$. The precipitate was washed with ethanol twice to remove any unbound platinum and then dissolved in $2 \% \mathrm{HNO}_{3}$. The solutions were then subjected to ICPMS along with known standards to evaluate the platinum content (covalently bound to ct-DNA) in the dark and on photo-irradiated conditions. The DNA thermal denaturation experiments were performed using a Cary 300 bio UV-visible spectrometer fitted with a Cary temperature controller. Absorbance was measured at $260 \mathrm{~nm}$ at intervals of $0.1{ }^{\circ} \mathrm{C}$ rise in temperature. The maxima of the melting plots gave the melting temperatures $\left(\mathrm{T}_{\mathrm{m}}\right)$ of ct-DNA. Ethidium bromide (EB) was used as a standard. The DNA viscosity experiments were carried out by addition of $100 \mu \mathrm{L}$ of the complexes in DMF $(200 \mu \mathrm{M})$ in DPBS buffer, $\mathrm{pH}=7.2$ to ct-DNA $(100 \mu \mathrm{M})$. The average flow times of the homogenous solutions were obtained using Schott Gerate AVS 310 Automated Viscometer. The specific relative viscosities were determined from the flow time of ct-DNA containing solutions $(t)$ duly corrected for that of the buffer alone $\left(t_{0}\right)$, applying the formula, $\eta=\left(t-t_{0}\right) / t_{0}$.

\section{Photoinduced DNA cleavage and mechanistic studies}

The samples after incubation in a dark chamber were added to the loading buffer containing $0.25 \%$ bromophenol blue, $0.25 \%$ xylene cyanol, $30 \%$ glycerol $(3 \mu \mathrm{L})$ and the solution was finally loaded on $1 \%$ agarose gel containing $1.0 \mu \mathrm{g} \mathrm{mL} \mathrm{m}^{-1}$ ethidium bromide (EB). The gelelectrophoresis completed inabout $2 \mathrm{~h}$ at $60 \mathrm{~V}$ in TAE (Tris-acetate EDTA) buffer. Bands were visualized by UV light and photographed. The extent of plasmid DNA cleavage was measured from the intensities of the bands using UVITEC Gel Documentation System. Due corrections were made for the low level of nicked circular (NC) form present in the original supercoiled (SC) DNA sample and for the low affinity of EB binding to SC compared to NC and linear forms of DNA. The concentrations of the complexes and additives corresponded to that in the $20 \mu \mathrm{L}$ final 
volume of the sample using Tris buffer. The observed error in measuring the band intensities was $\sim 5 \%$.

\section{Theoretical Calculations}

The geometries of the complexes were initially optimized [basis sets B3LYP/LanL2dz] which were further employed to run the time-dependent density functional theory (TDDFT) calculations. $^{\mathrm{S} 1}$

\section{Cell Viability Assay.}

Cytotoxicity of the complexes were assessed from the MTT, 3-(4,5-dimethylthiazole-2-yl)-2,5diphenyltetrazolium bromide, assay. The formazan formed in this assay was dissolved in DMSO for quantification by spectral method. Photo-irradiation with visible light of 400-700 nm was done for $1 \mathrm{~h}$ using a Luzchem Photoreactor (Model LZC-1, Ontario, Canada, $10 \mathrm{~J} \mathrm{~cm}^{-2}$ ). Approximately, 8000 BT474 (human breast epithelial carcinoma) and HBL-100 (human normal breast epithelial) cells were plated in 96 wells culture plate in Dulbecco's Modified Eagle Medium (DMEM) containing 10\% FBS (Fetal Bovine Serum) and were allowed to grow for $24 \mathrm{~h}$ in a $\mathrm{CO}_{2}$ incubator maintained at $37{ }^{\circ} \mathrm{C}$. Various concentrations of complexes 1-6 and ligands were added to the cells varying concentrations from 50 to $5 \mu \mathrm{M}$ and incubation was continued for $24 \mathrm{~h}$ in dark. The medium after replacing with DPBS (Dulbecco's phosphate buffer solution) was photo-irradiated with visible light of 400-700 $\mathrm{nm}$ for $1 \mathrm{~h}$ using a Luzchem Photoreactor (Model LZC-1, Ontario, Canada, $10 \mathrm{~J} \mathrm{~cm}^{-2}$ ). After photo-exposure, DPBS was replaced with DMEM$10 \% \mathrm{FBS}$ and incubation was continued for further $20 \mathrm{~h}$ in dark. After incubation, a $25 \mu \mathrm{L}$ of 4 $\mathrm{mg} \mathrm{mL}^{-1}$ of MTT was added to each well and incubation was done for another $4 \mathrm{~h}$. The culture medium was then discarded and $200 \mu \mathrm{L}$ of DMSO was added to dissolve the formazan. Its absorbance at $540 \mathrm{~nm}$ was measured using a TECAN microplate reader. Cytotoxicity of the complexes was measured as the percentage ratio of the absorbance of the complex treated cells to the untreated controls. The $\mathrm{IC}_{50}$ values were obtained by nonlinear regression analysis using GraphPad Prism5. The errors were calculated from three independent set of experiments, each performed in triplicates. 


\section{Cell Cycle Analysis}

The complexes 1-6 (concentration $=\mathrm{IC}_{50}$ values in light) were added to the BT474 cells $(\sim 2 \mathrm{x}$ $\left.10^{5}\right)$, incubated in the dark for $24 \mathrm{~h}$ and photo-irradiated in visible light $(400-700 \mathrm{~nm}, 1 \mathrm{~h})$ after replacing media with DPBS. Cells were further kept in the dark for $12 \mathrm{~h}$, trypsinized and centrifuged. After washing with cold DPBS, cells were fixed by adding $500 \mu \mathrm{L}$ of cold $70 \%$ ethanol. The cell suspensions were then kept for $\sim 6 \mathrm{~h}$ at $-20{ }^{\circ} \mathrm{C}$. The cell pellets, obtained by DPBS washing and centrifugation, were re-suspended for $12 \mathrm{~h}$ at $37^{\circ} \mathrm{C}$ in $200 \mu \mathrm{L}$ of DPBS containing $10 \mu \mathrm{g} \mathrm{mL}^{-1}$ DNAse-free RNAse. After digestion of cellular RNA, propidium iodide (PI, $20 \mu \mathrm{L}$ of $1 \mathrm{mg} \mathrm{mL}^{-1}$ ) was added and incubated for $10 \mathrm{~min}$ at room temperature. FACS analysis was done with these samples (in duplicates) along with dark and untreated controls. Percentage of cells in each cell-cycle phase was obtained by data analysis using WinMDI version 2.8 .

\section{Cellular Uptake from Pt Estimation}

To measure the total platinum uptake, about $10^{6}$ BT474 and HBL-100 cells were seeded in 60 mm tissue culture dishes, allowed to attach for $24 \mathrm{~h}$, treated with complexes 1-6 $(50 \mu \mathrm{M})$ for 24 h. After incubation, medium was aspirated and the dishes were washed with sterile DPBS. One set was used for platinum estimation in whole cell, while its similar treatment counterpart was subjected to Bradford assay for determination of protein content ( $415 \mu \mathrm{g}$ in $10^{6}$ cells).Cells were trypsinized and suspended in $500 \mu \mathrm{L}$ of DPBS. Cells were pelleted down at $12000 \mathrm{~g}$ at $4^{\circ} \mathrm{C}$ for $10 \mathrm{~min}$. This cellular pellet was then treated with $70 \% \mathrm{HNO}_{3}$ and $\mathrm{H}_{2} \mathrm{O}_{2}$ for $\sim 3 \mathrm{~h}$ at $55{ }^{\circ} \mathrm{C}$. After incubation, lysates were diluted to $10 \mathrm{~mL}\left(2 \% \mathrm{HNO}_{3}\right)$ and used for ICP analysis. The samples were run using ICP-MS for platinum content along with the standards $(0.01-1 \mathrm{ppm}$, and a blank sample fitted in a linear plot with a correlation of 0.99). Platinum content obtained in ppb units was then expressed as ng of $\mathrm{Pt} / \mu \mathrm{g}$ of protein. All the experiments were performed in triplicates and with untreated controls. 


\section{Reference:}

S1. M. J. Frisch, G. W. Trucks, H. B. Schlegel, G. E. Scuseria, M. A. Robb, J. R. Cheeseman, G. Scalmani, V. Barone, B. Mennucci, G. A. Petersson, H. Nakatsuji, M. Caricato, X. Li, H. P. Hratchian, A. F. Izmaylov, J. Bloino, G. Zheng, J. L. Sonnenberg, M. Hada, M. Ehara, K. Toyota, R. Fukuda, J. Hasegawa, M. Ishida, T. Nakajima, Y. Honda, O. Kitao, H. Nakai, T. Vreven, J. A. Montgomery Jr., J. E. Peralta, F. Ogliaro, M. Bearpark, J. J. Heyd, E. Brothers, K. N. Kudin, V. N. Staroverov, R. Kobayashi, J. Normand, K. Raghavachari, A. Rendell, J. C. Burant, S. S. Iyengar, J. Tomasi, M. Cossi, N. Rega, J. M. Millam, M. Klene, J. E. Knox, J. B. Cross, V. Bakken, C. Adamo, J. Jaramillo, R. Gomperts, R. E. Stratmann, O. Yazyev, A. J. Austin, R. Cammi, C. Pomelli, J. W. Ochterski, R. L. Martin, K. Morokuma, V. G. Zakrzewski, G. A. Voth, P. Salvador, J. J. Dannenberg, S. Dapprich, A. D. Daniels, Ö. Farkas, J. B. Foresman, J. V. Ortiz, J. Cioslowski and D. J. Fox, GAUSSIAN 09 (Revision A.1), Gaussian, Inc., Wallingford, CT, 2009. 


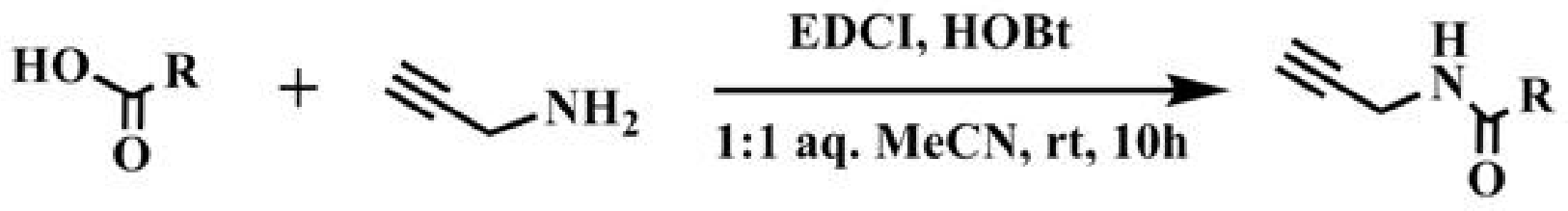<smiles>[R]=C=CCCCNC(=O)CCCCC1SCC2NC(=O)NC21</smiles>

$\mathrm{HL}^{1}$

$\mathrm{HL}^{2}$

$\mathrm{HL}^{3}$

Scheme S1. Preparation of the ligands $\mathrm{HL}^{1}, \mathrm{HL}^{2}$ and $\mathrm{HL}^{3}$.
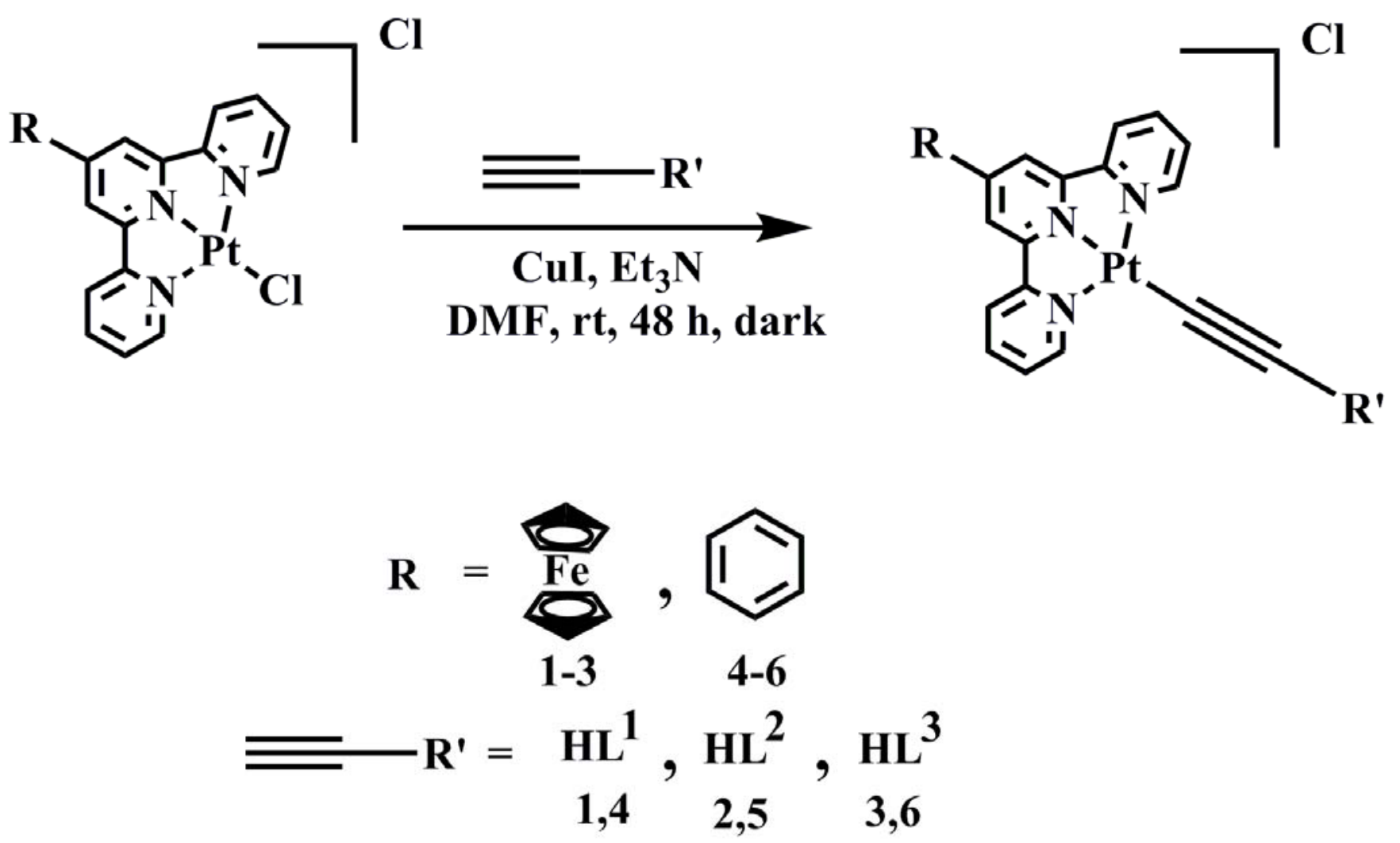

Scheme S2. Preparation of the complexes 1-6. 


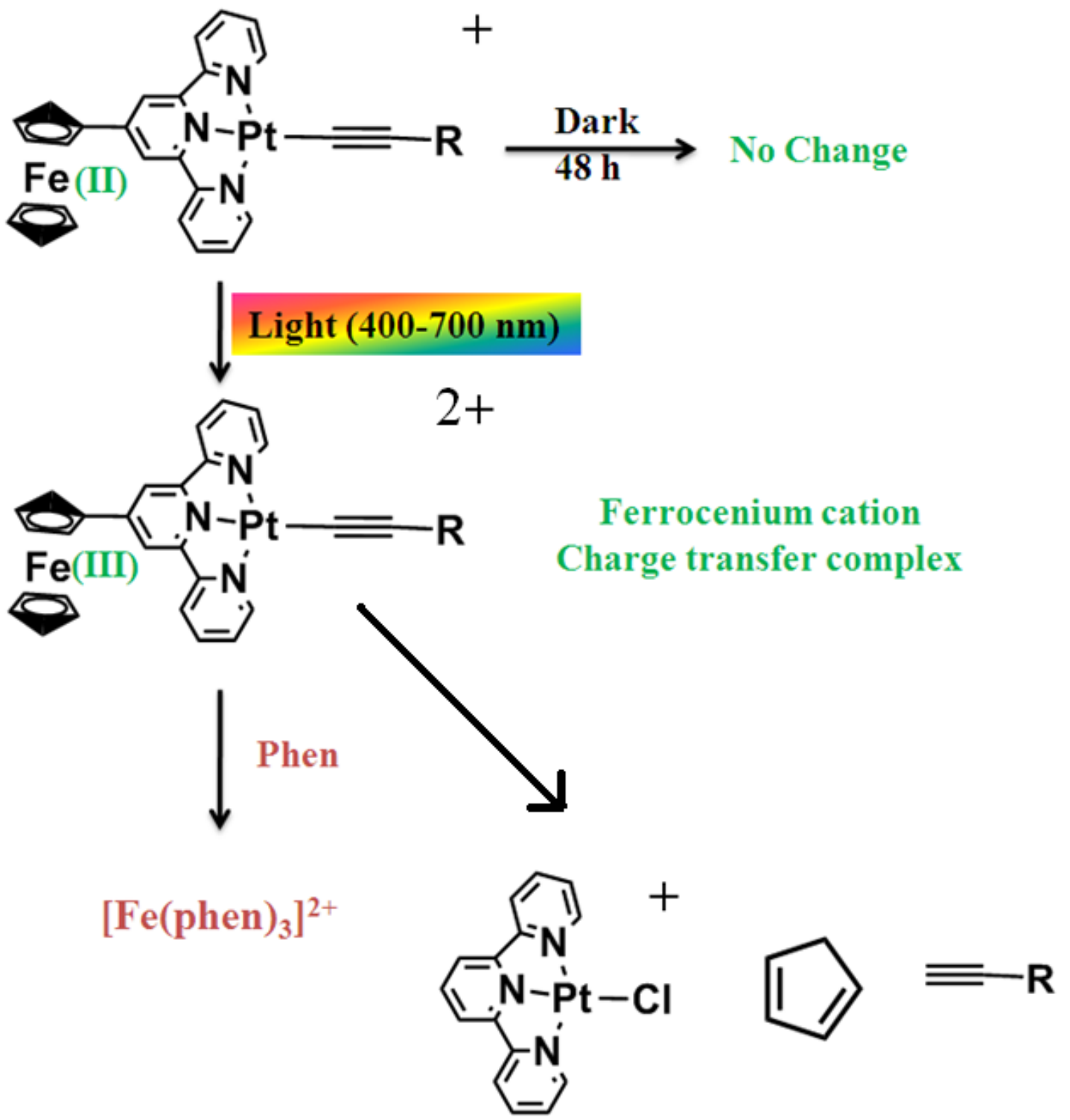

Scheme S3. Proposed mechanistic aspects of the complexes 1-3 on photoirradiation (400 - $700 \mathrm{~nm}, 10 \mathrm{~J}$ $\mathrm{cm}^{-2}$ ). 


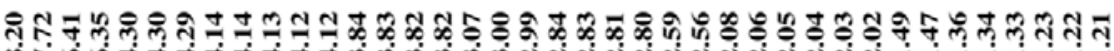

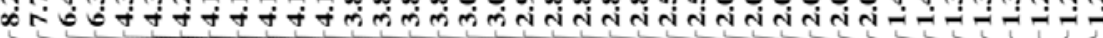

(a)

a)
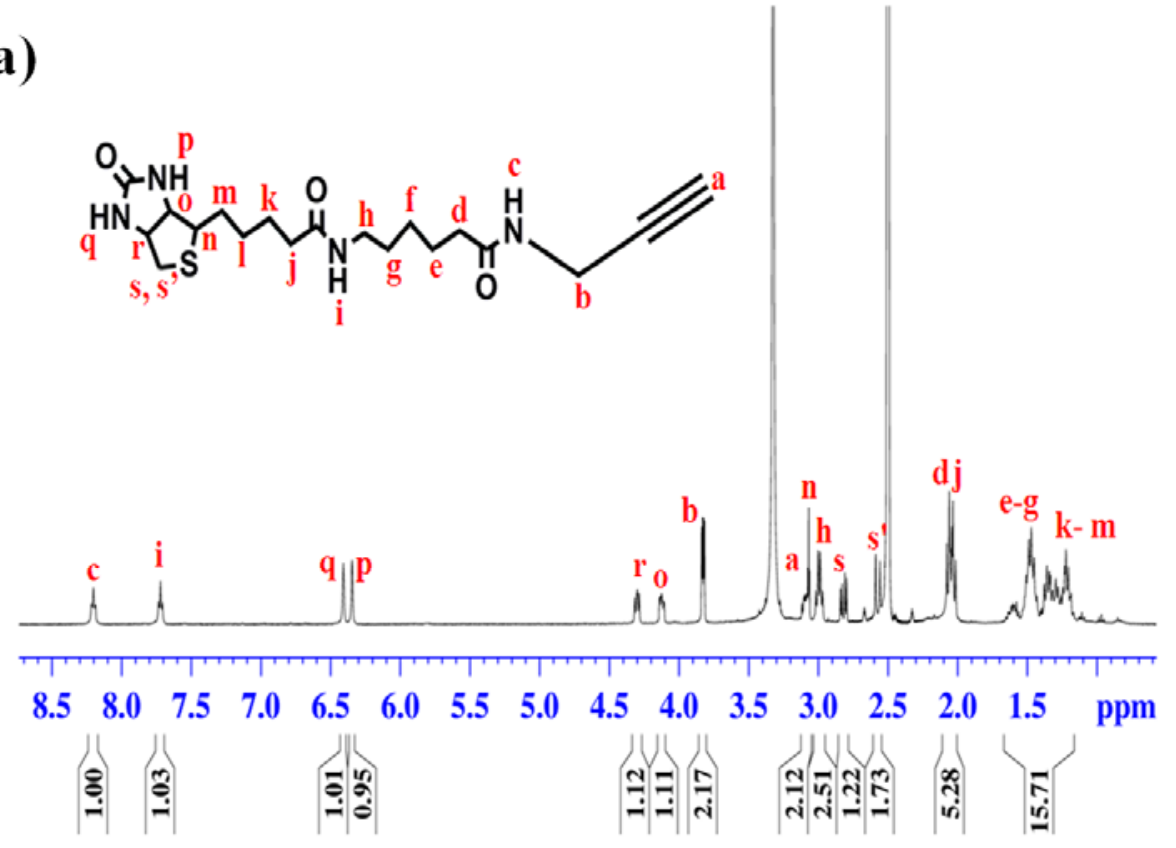

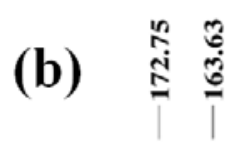
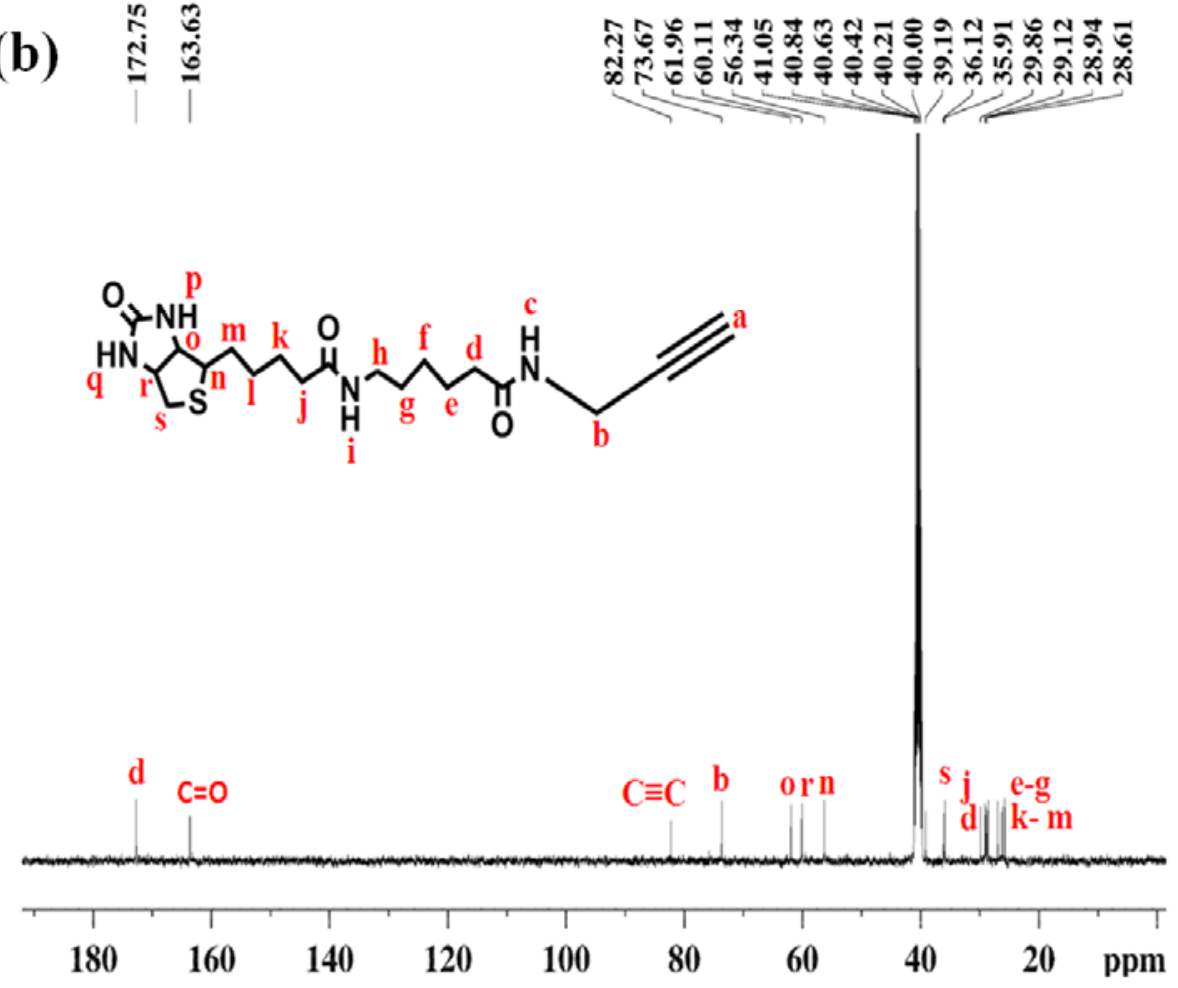

Figure S1. ${ }^{1} \mathrm{H}$ (a) and ${ }^{13} \mathrm{C}$ NMR (b) spectra of the $\mathrm{HL}^{1}$ recorded in $\mathrm{d}_{6}$-DMSO solvent. 

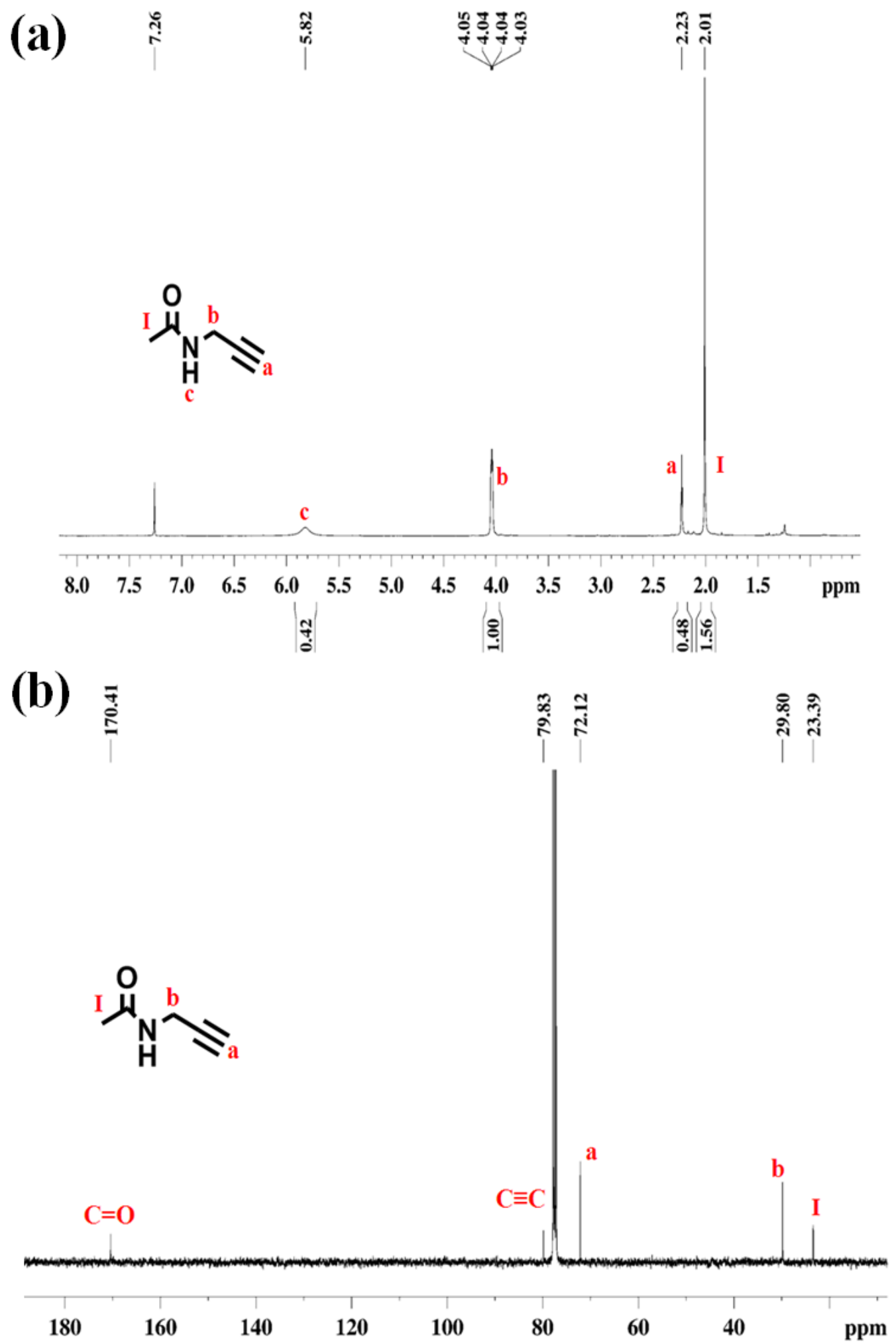

Figure S2. ${ }^{1} \mathrm{H}$ and ${ }^{13} \mathrm{C}$ NMR spectra of the ligand $\mathrm{HL}^{3}$ recorded in $\mathrm{CDCl}_{3}$. 


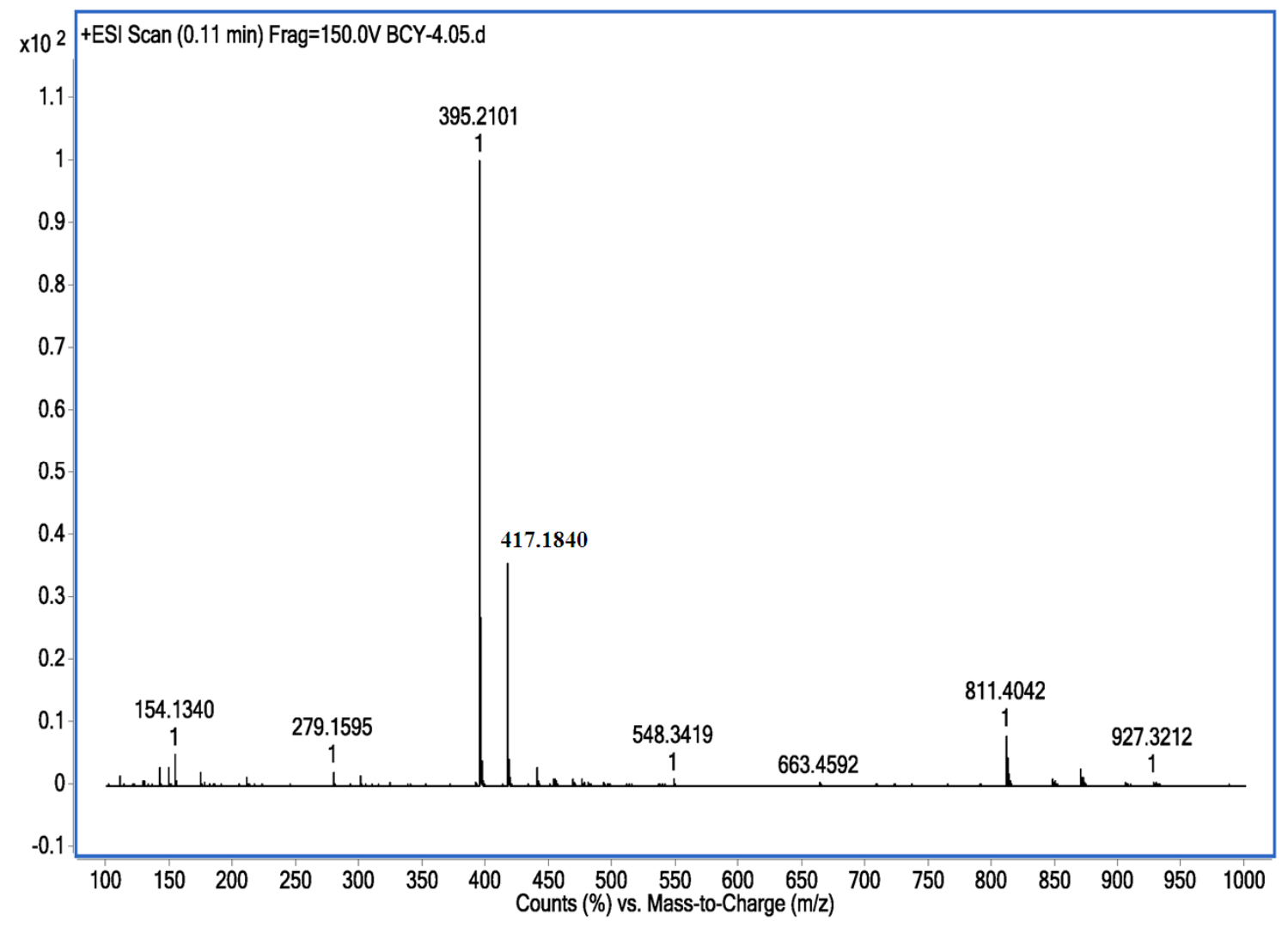

Figure S3. Mass spectrum of $\mathrm{HL}^{1}$ in $\mathrm{MeOH}$ with peak corresponding to $[\mathrm{M}+\mathrm{H}]^{+}(\mathrm{m} / \mathrm{z})$ at 395.2101 and $[\mathrm{M}+\mathrm{Na}]^{+}(\mathrm{m} / \mathrm{z})$ at 417.1840 . 

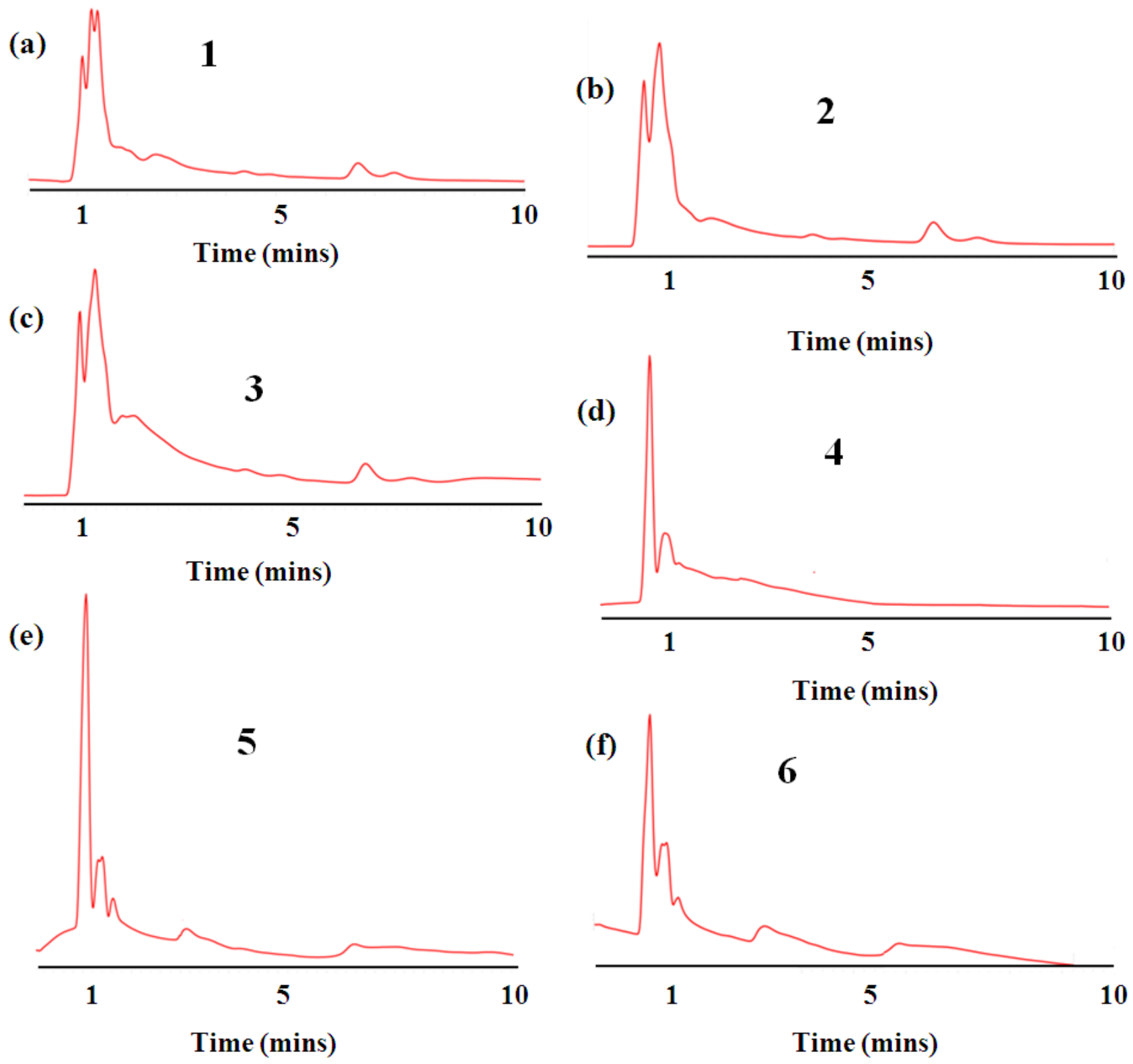

Figure S4. HPLC-chromatograms of the complexes 1-6. 


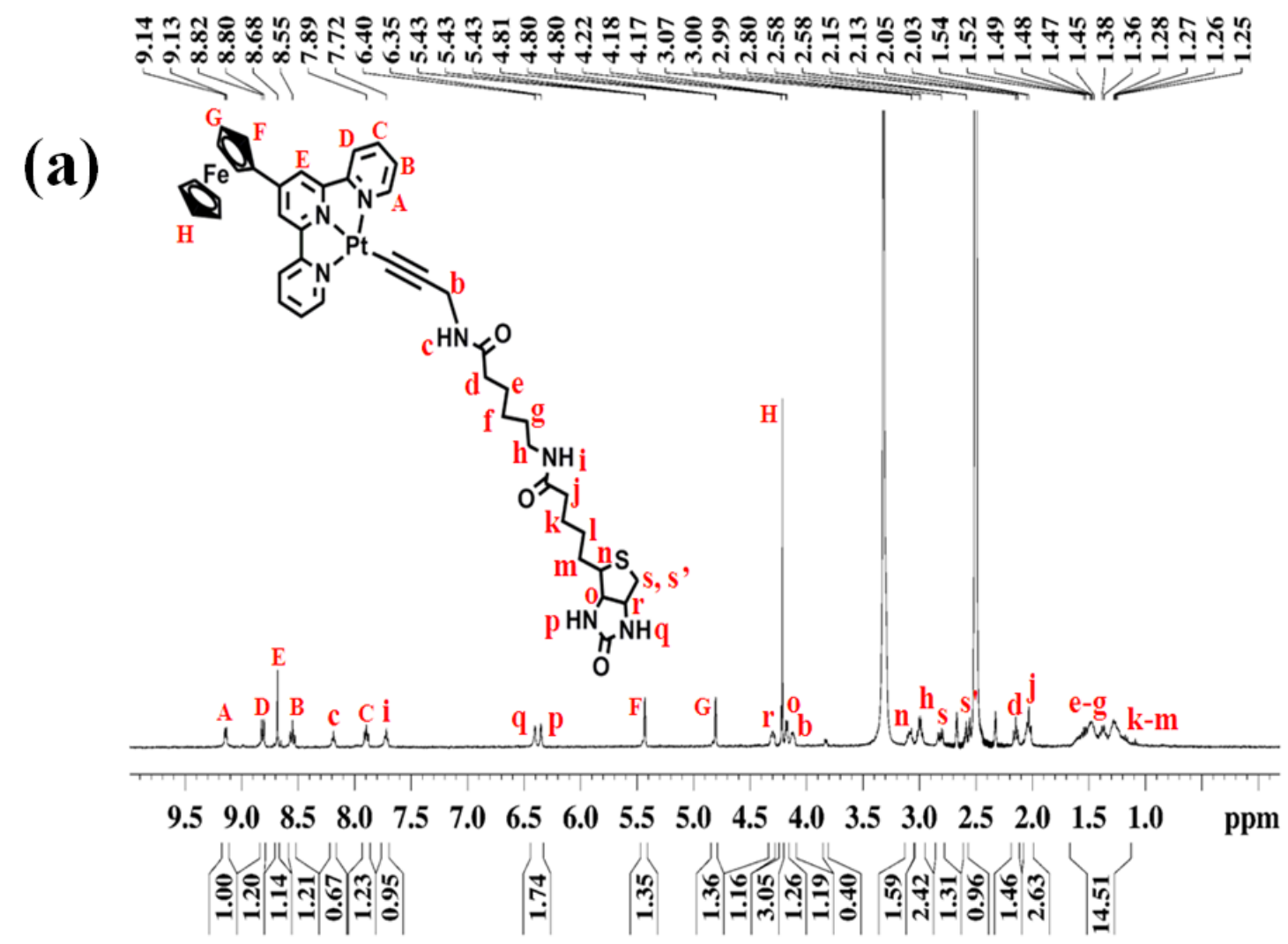

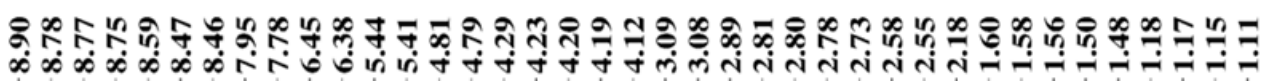

(b)

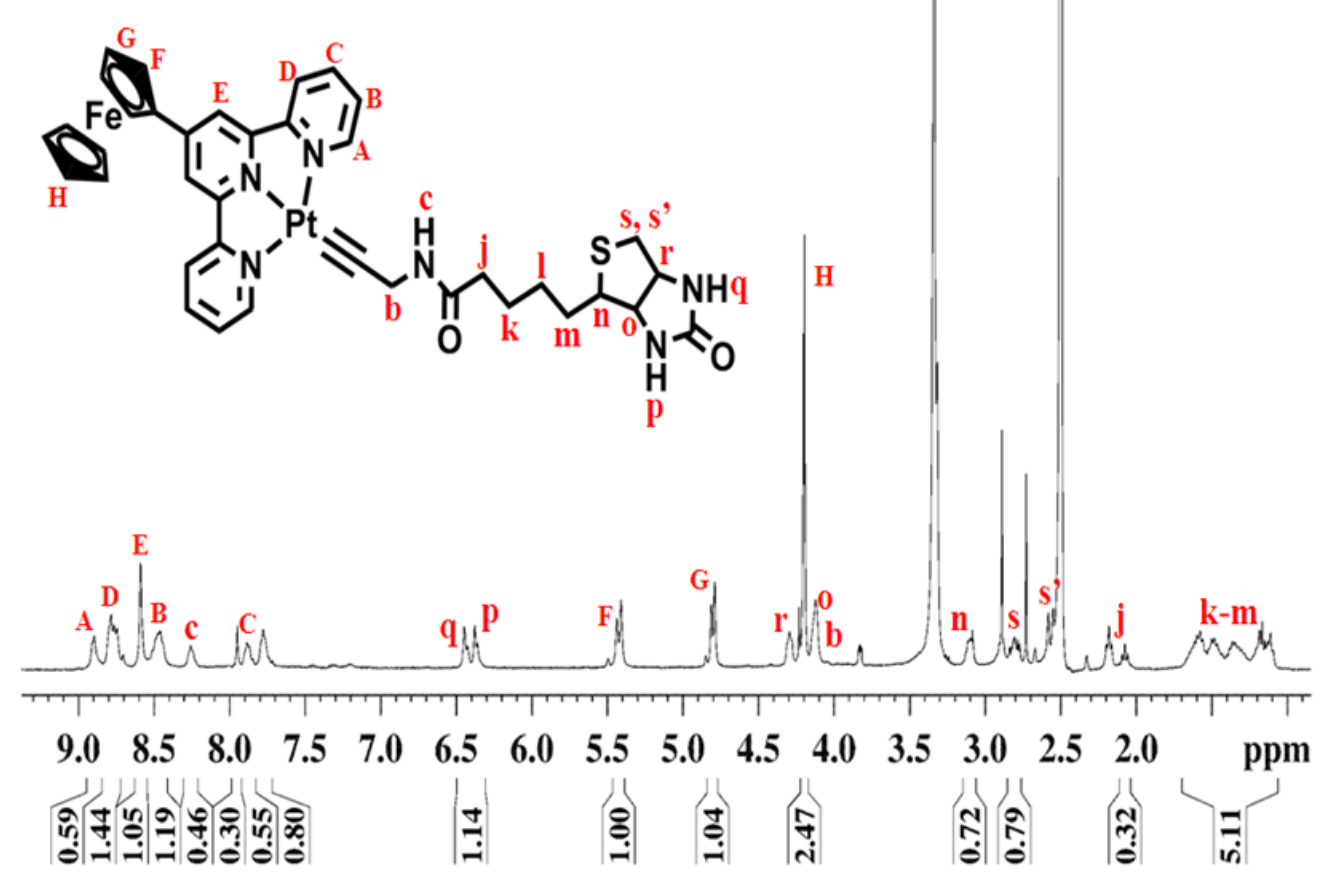

Figure S5. ${ }^{1} \mathrm{H}$ NMR spectra of the complexes (a) 1 and (b) 2 recorded in $\mathrm{d}_{6}$-DMSO. 

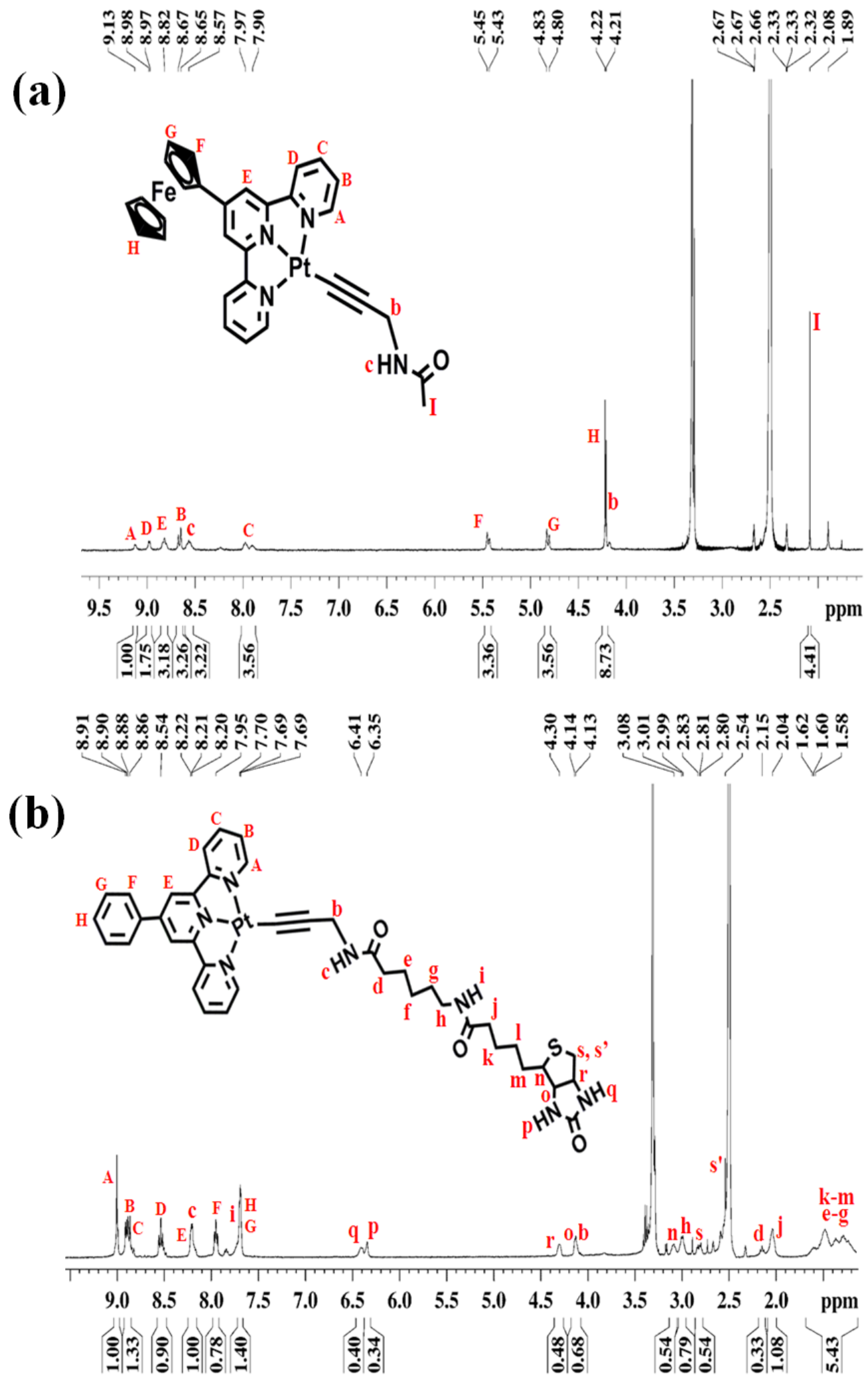

Figure S6. ${ }^{1} \mathrm{H}$ NMR spectra of the complexes (a) 3 and (b) 4 recorded in $\mathrm{d}_{6}$-DMSO. 


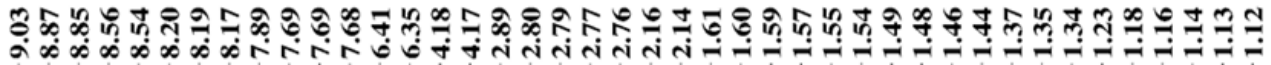

(a)
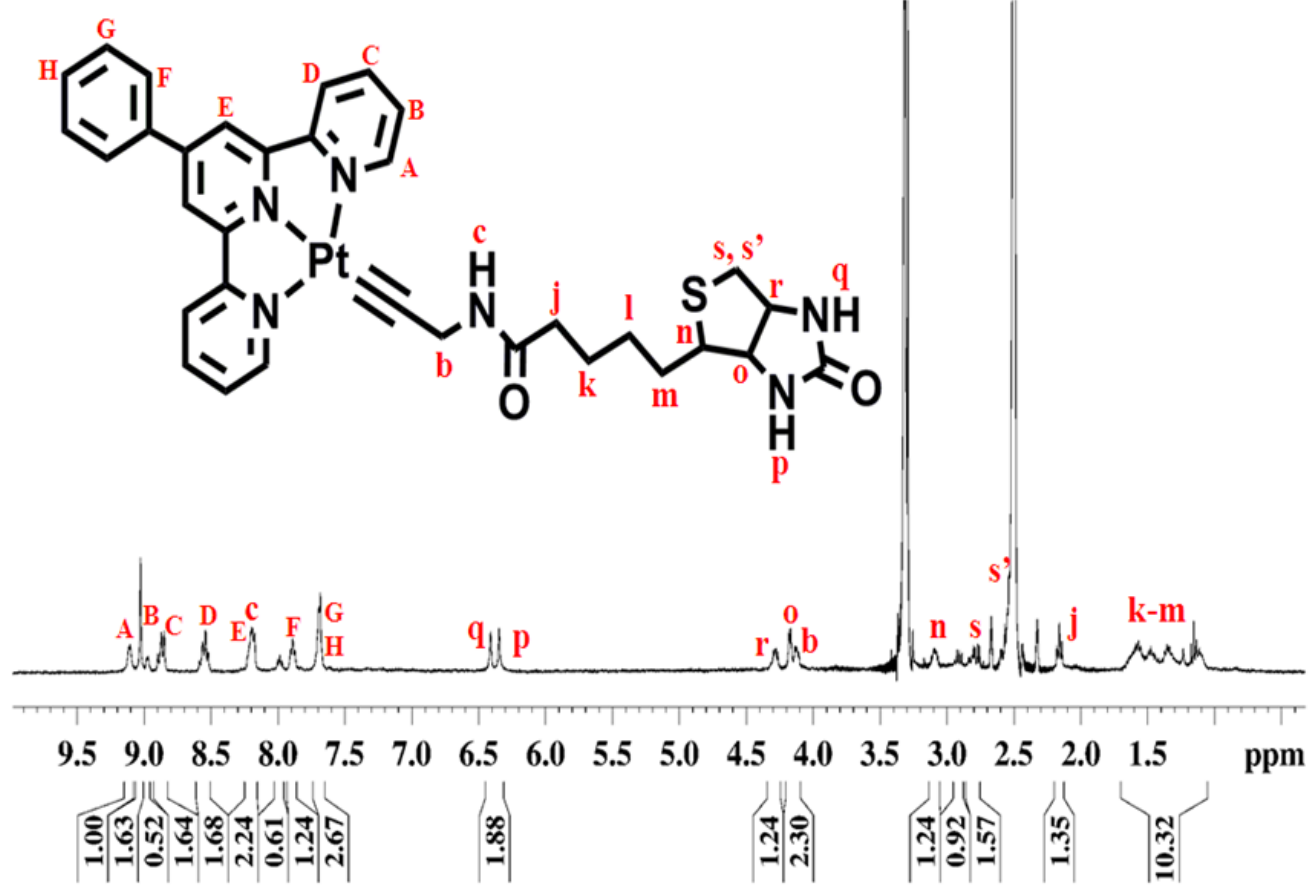

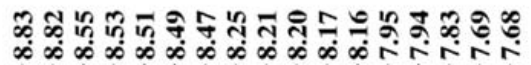

(b)

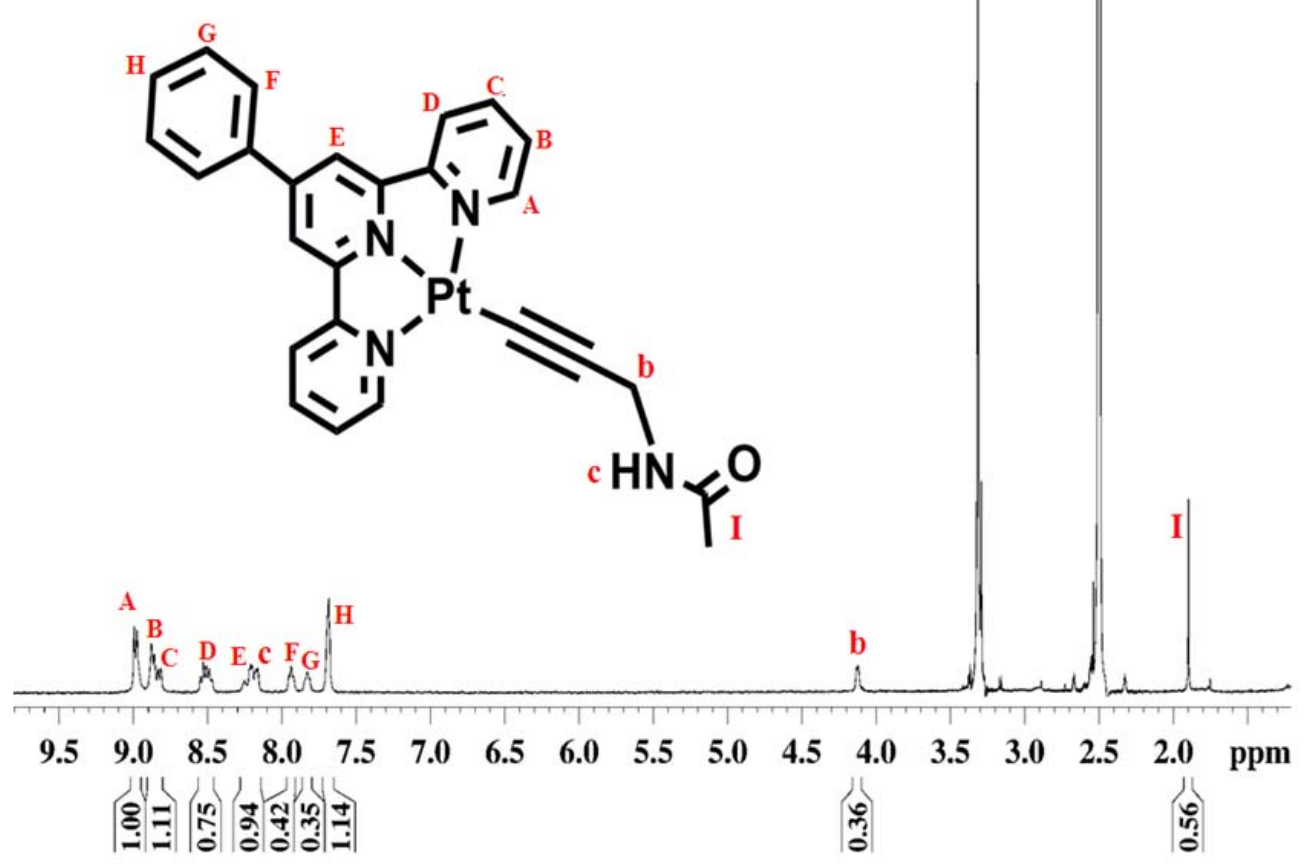

Figure S7. ${ }^{1} \mathrm{H}$ NMR spectra of the complexes (a) 5 and (b) 6 recorded in $\mathrm{d}_{6}$-DMSO. 


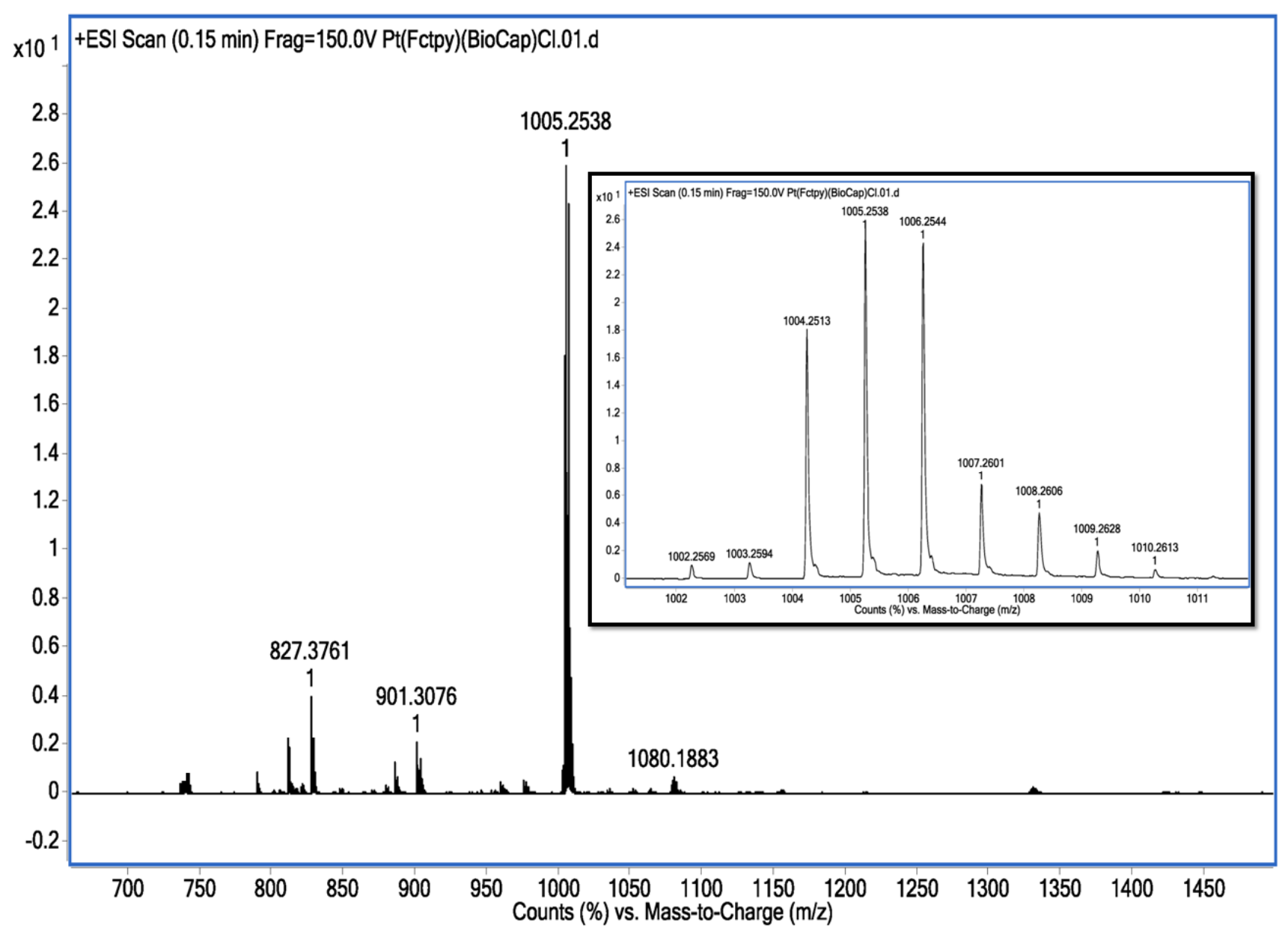

Figure S8. Mass spectrum of complex 1 in $\mathrm{MeOH}$ showing a peak corresponding to $[\mathrm{M}-\mathrm{Cl}]^{+}(\mathrm{m} / \mathrm{z}$ found = 1005.2538). Inset shows the isotopic distribution for the platinum in the ionic fragment. 


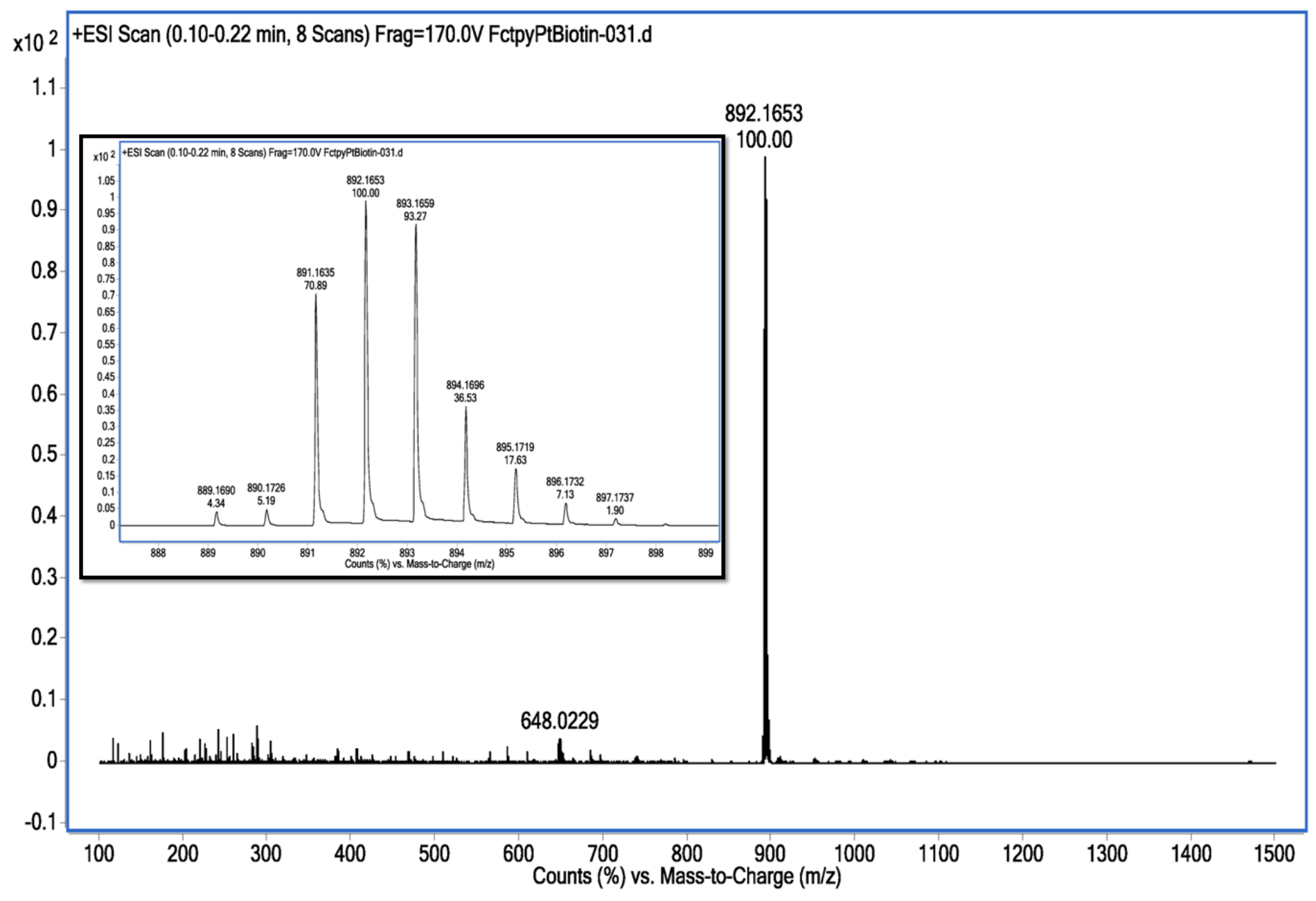

Figure S9. Mass spectrum of complex 2 in $\mathrm{MeOH}$ showing a peak corresponding to $[\mathrm{M}-\mathrm{Cl}]^{+}(\mathrm{m} / \mathrm{z}$ found $=$ 892.1653). Inset shows the isotopic distribution for the platinum in the ionic fragment. 


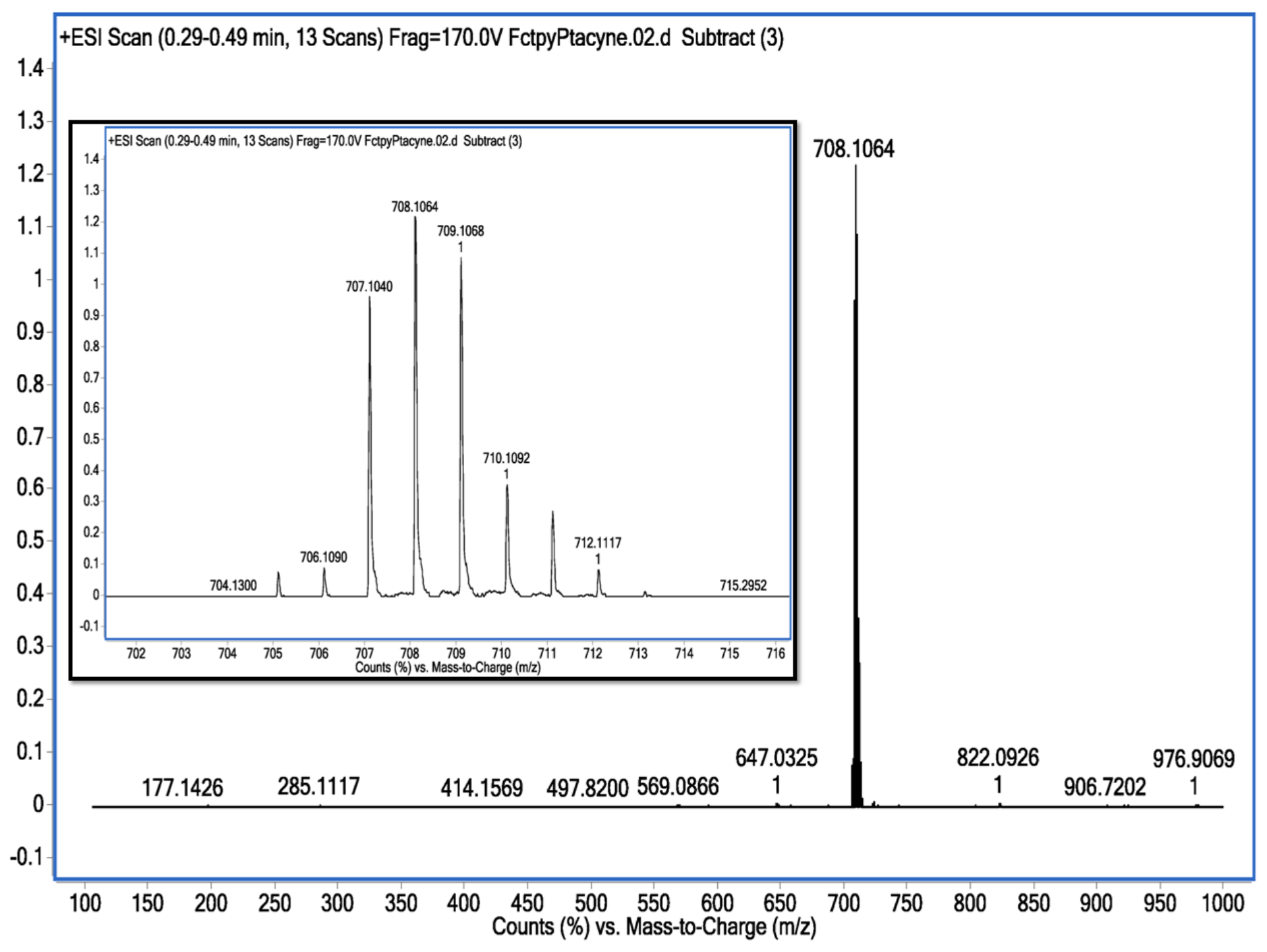

Figure S10. Mass spectrum of complex 3 in $\mathrm{MeOH}$ showing a peak corresponding to $[\mathrm{M}-\mathrm{Cl}]^{+}$(m/z found = 708.1064). Inset shows the isotopic distribution for the platinum in the ionic fragment. 


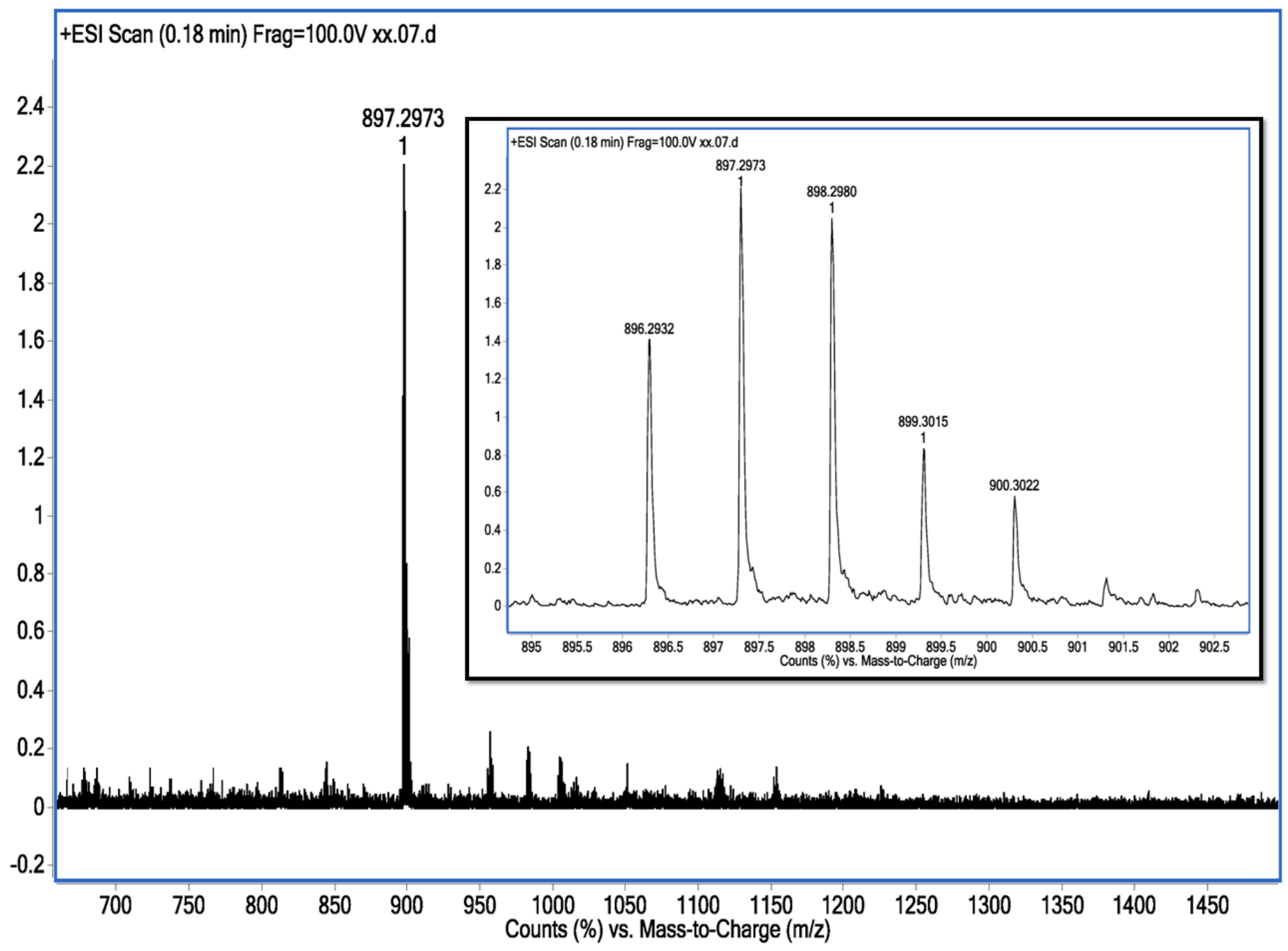

Figure S11. Mass spectrum of complex 4 in $\mathrm{MeOH}$ showing a peak corresponding to $[\mathrm{M}-\mathrm{Cl}]^{+}(\mathrm{m} / \mathrm{z}$ found $=$ 897.2973). Inset shows the isotopic distribution for the platinum in the ionic fragment. 


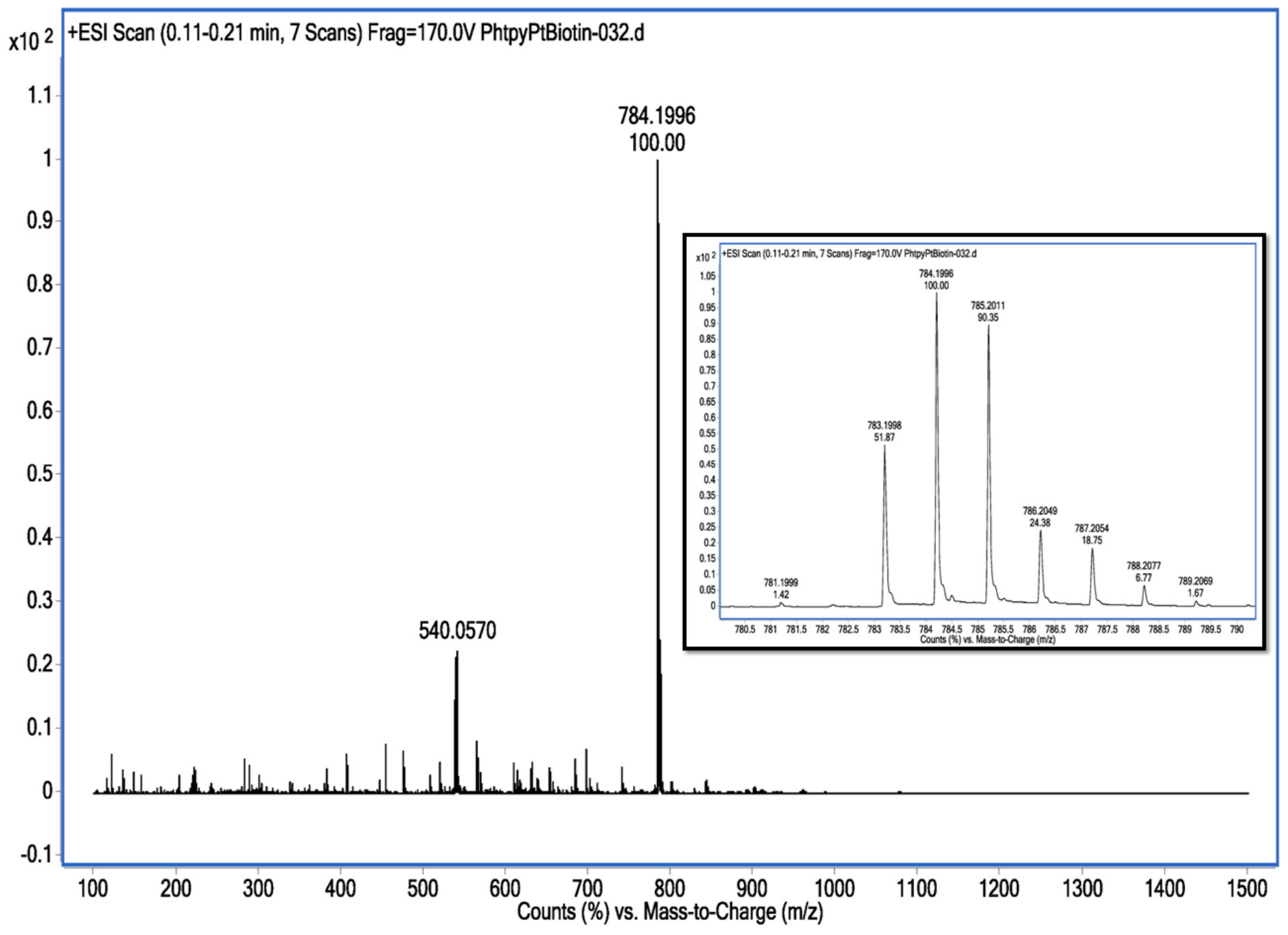

Figure S12. Mass spectrum of complex 5 in $\mathrm{MeOH}$ showing a peak corresponding to $[\mathrm{M}-\mathrm{Cl}]^{+}(\mathrm{m} / \mathrm{z}$ found = 784.1996). Inset shows the isotopic distribution for the platinum in the ionic fragment. 


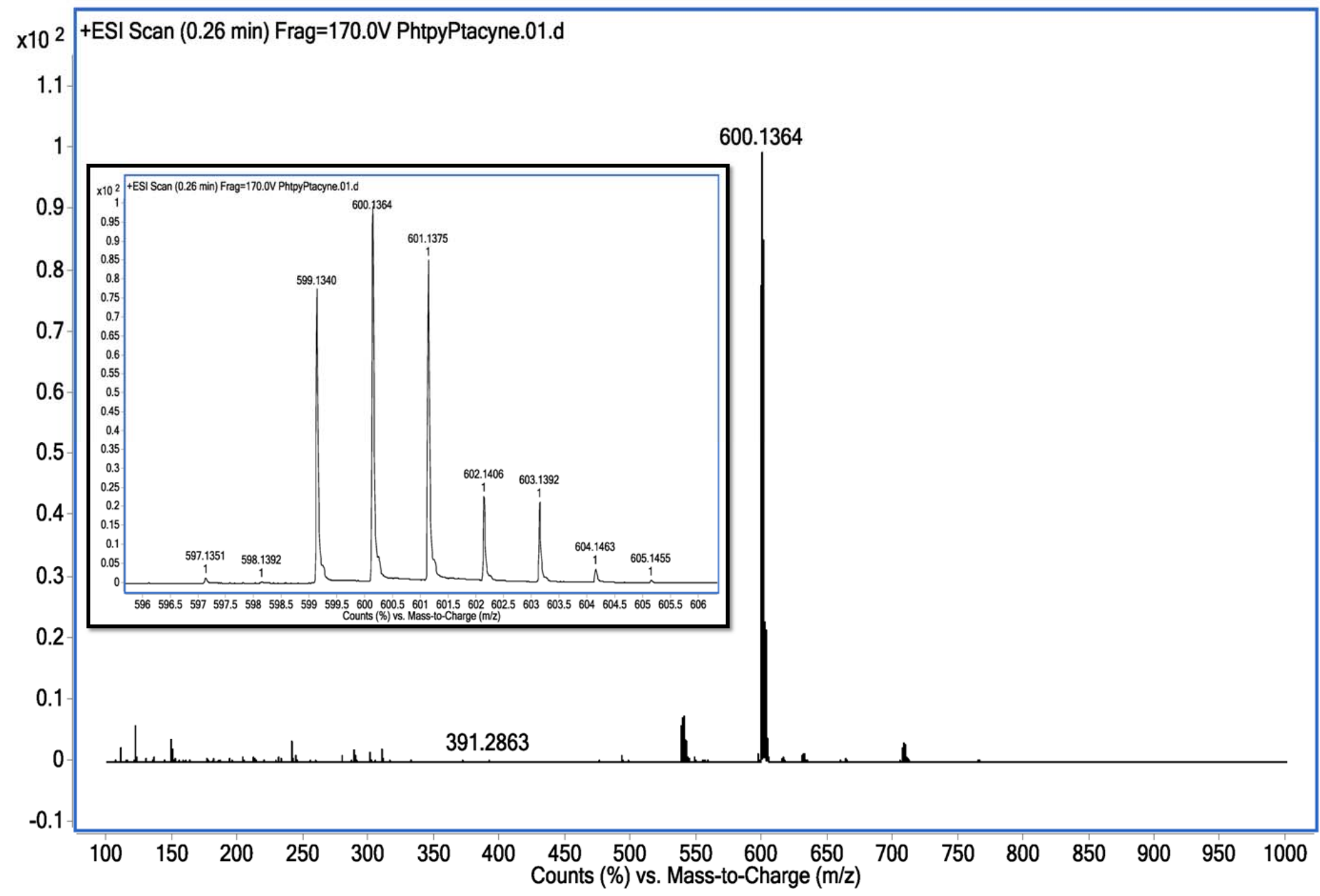

Figure S13. Mass spectrum of complex 6 in $\mathrm{MeOH}$ showing a peak corresponding to $[\mathrm{M}-\mathrm{Cl}]^{+}(\mathrm{m} / \mathrm{z}$ found = 600.1364). Inset shows the isotopic distribution for the platinum in the ionic fragment. 


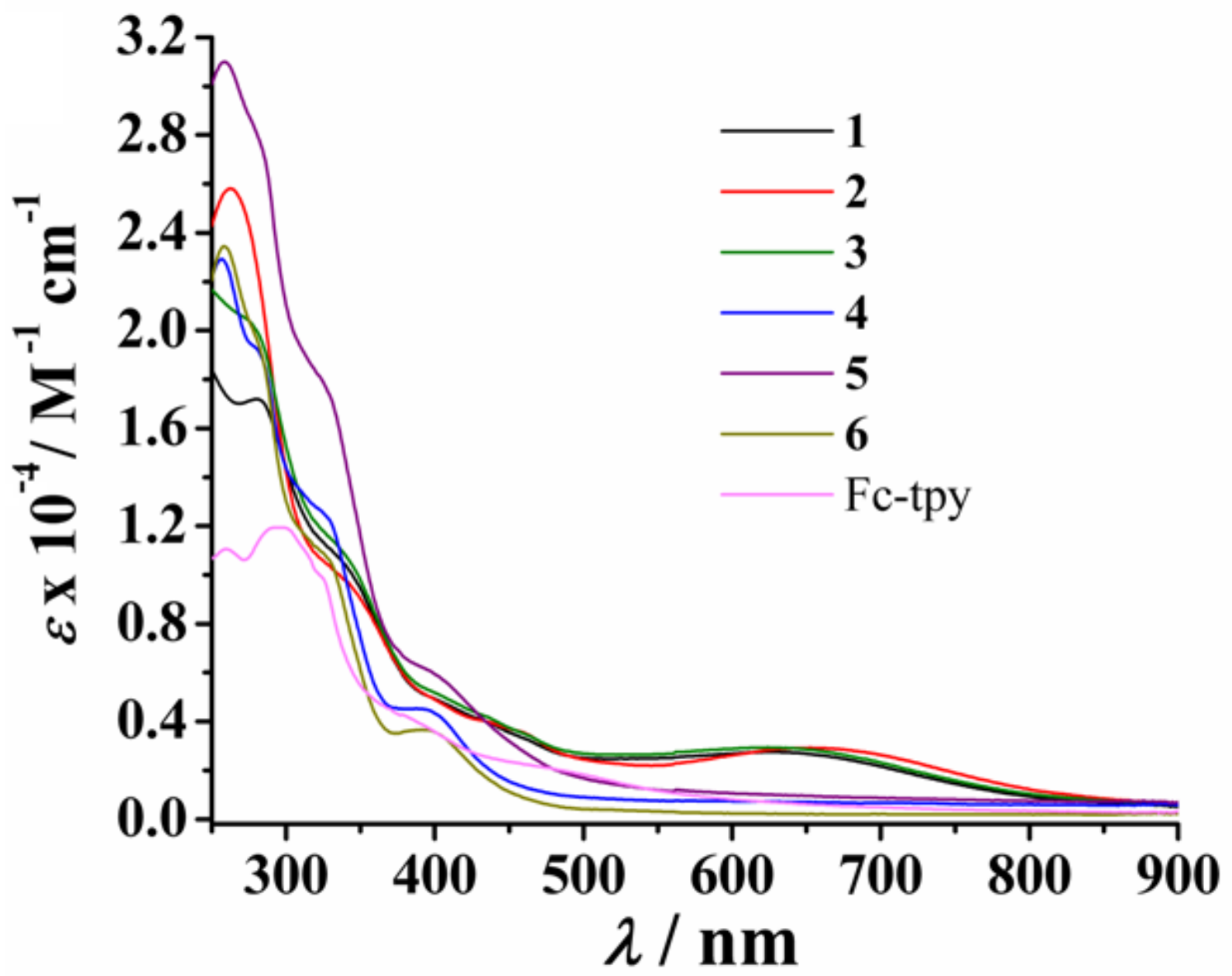

Figure S14. UV-visible spectra of the complexes 1-6 and Fc-tpy $(50 \mu \mathrm{M})$ in 10\% DMSO-DPBS at pH 7.2. 

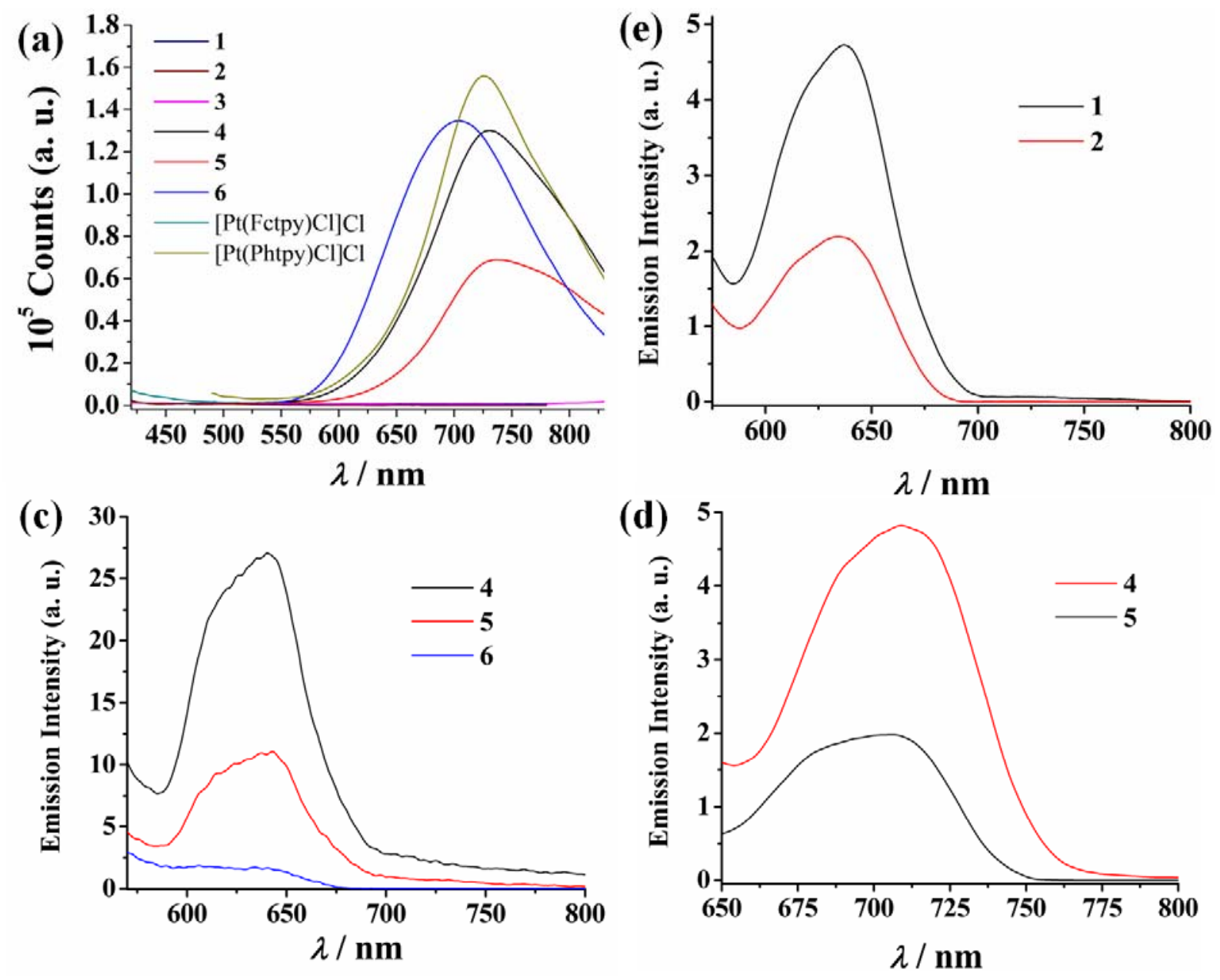

Figure S15. Luminescence spectra of the complexes 1-6. (a) In solid state (298 K, excitation wavelength $=450 \mathrm{~nm}$ ). (b) and (c) In DCM, excitation wavelength $=470 \mathrm{~nm}$. (d) $\mathrm{In}$ DCM, excitation wavelength $=550 \mathrm{~nm}$. 

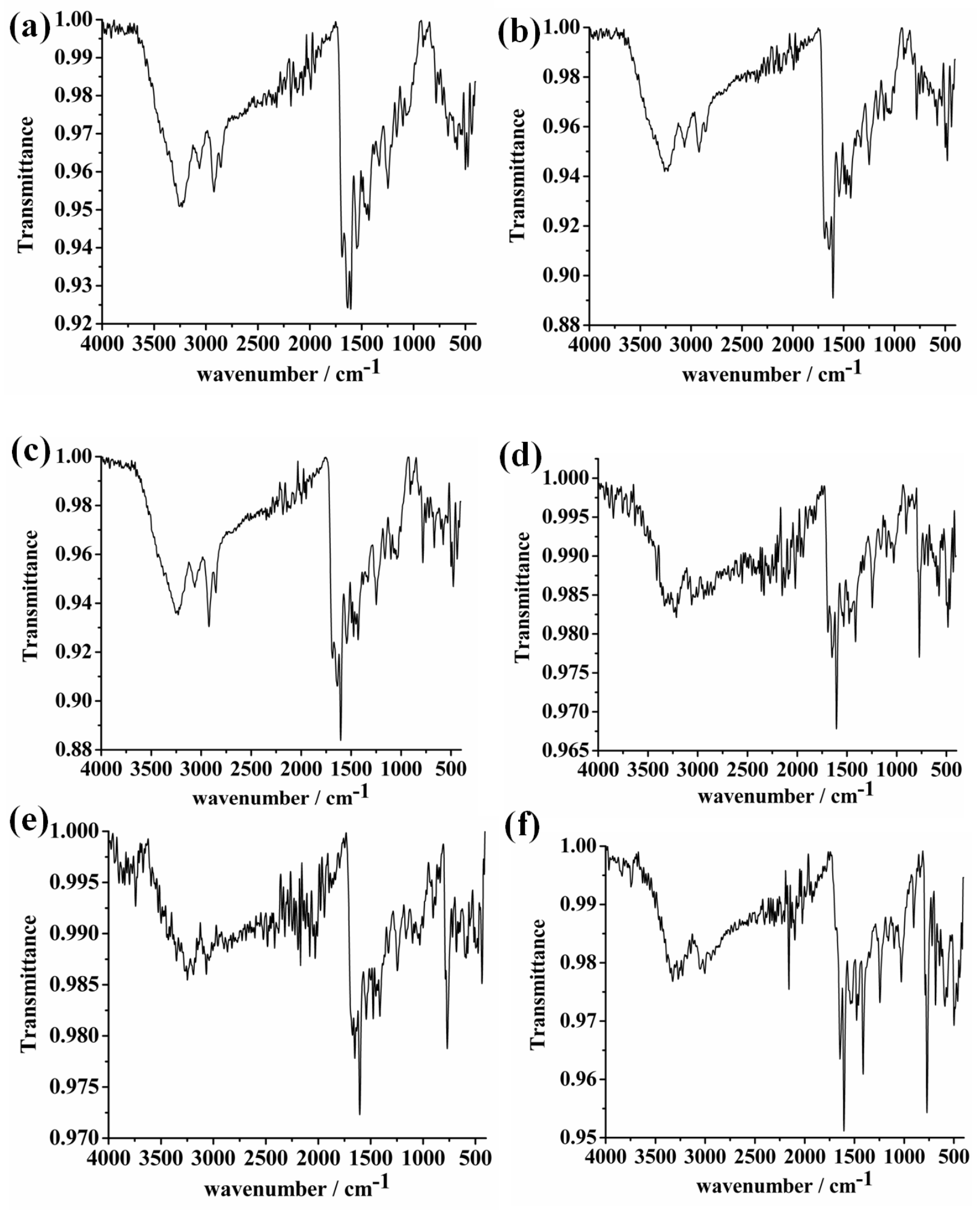

(f)

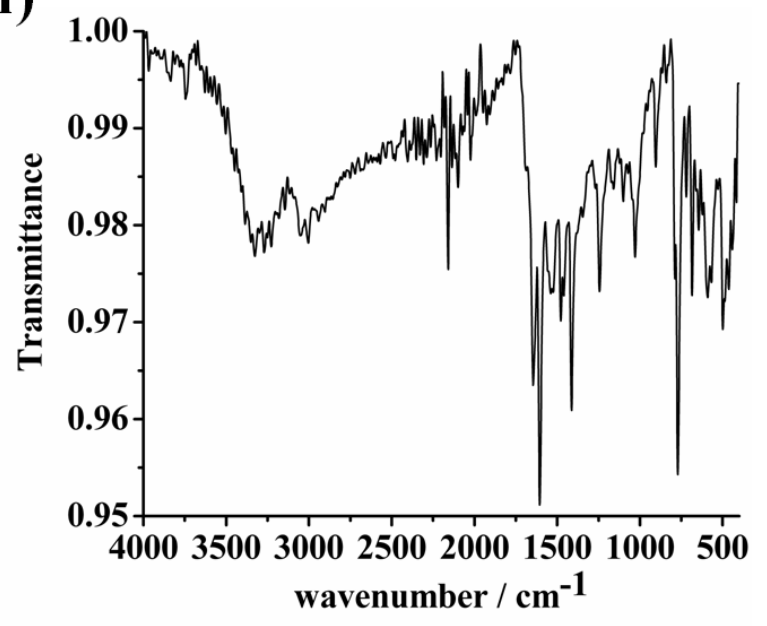

Figure S16. IR spectra of the complexes (a) 1;(b) 2; (c) 3; (d) 4; (e) 5; (f) 6 . 

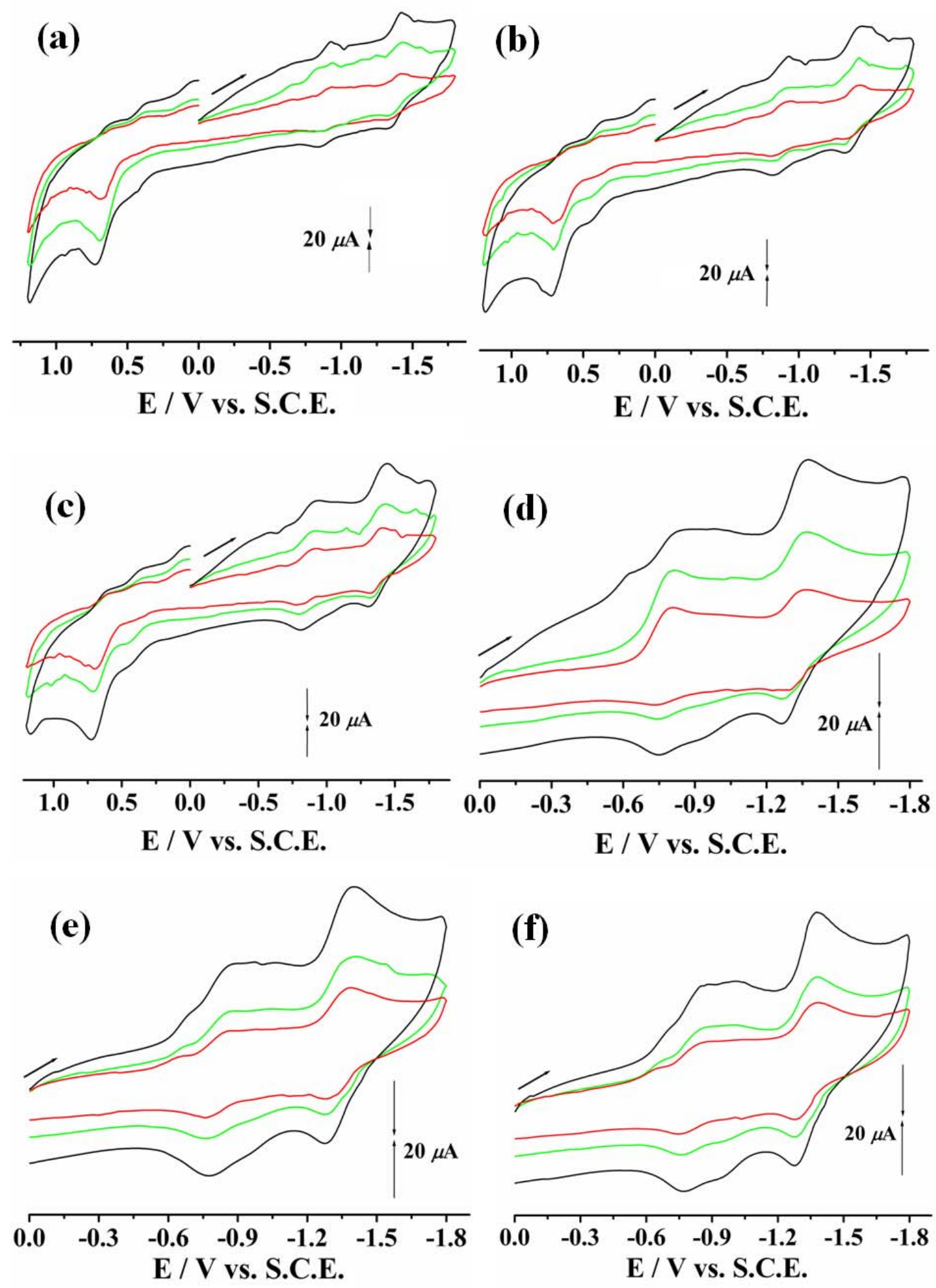

Figure S17. Cyclic voltammograms of $1 \mathrm{mM}$ of complexes 1 (a), 2 (b), 3 (c), 4 (d), 5 (e) and 6 (f) in DMF (0.1 M TBAP as supporting electrolyte) at various scan rates of $200 \mathrm{mV} \mathrm{sec}^{-1}$ (black), $100 \mathrm{mV} \mathrm{sec}^{-1}$ (green) and $200 \mathrm{mV} \mathrm{sec}^{-1}$ (red). 
(a)
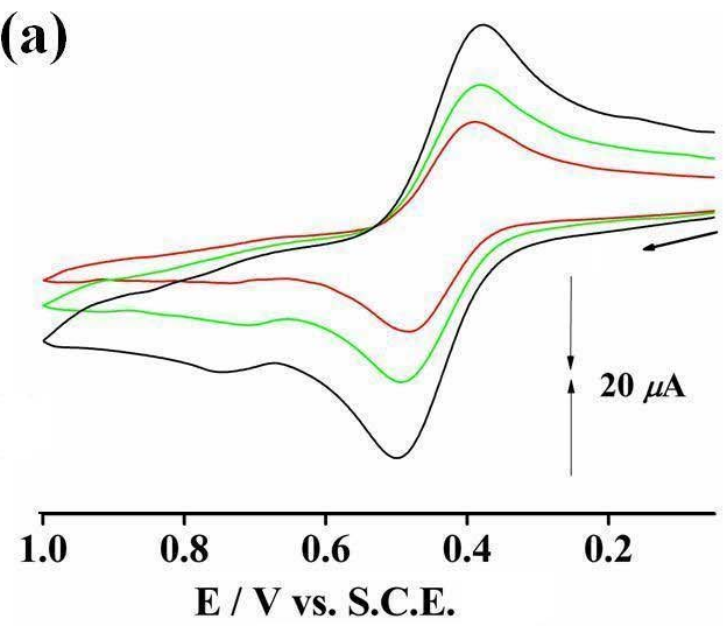

(c)

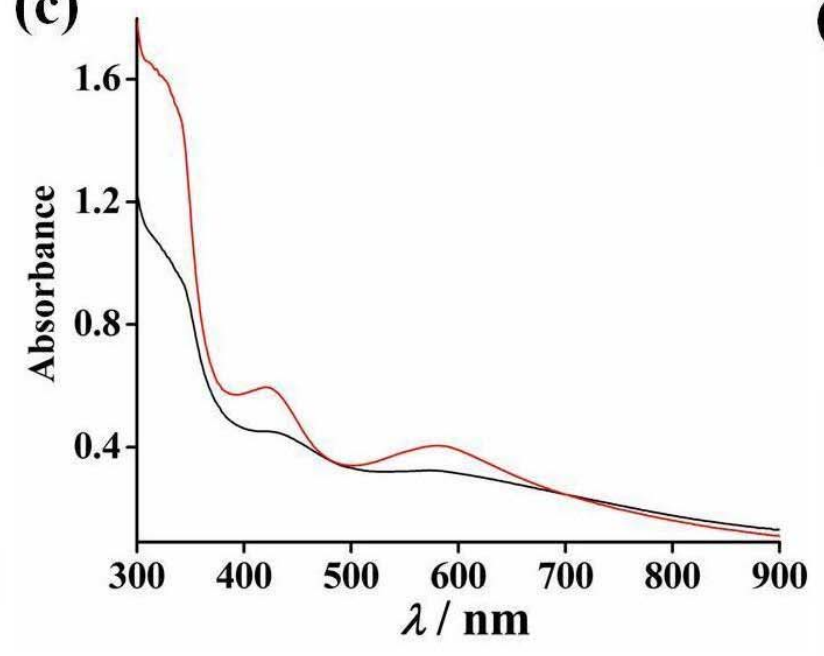

(b)
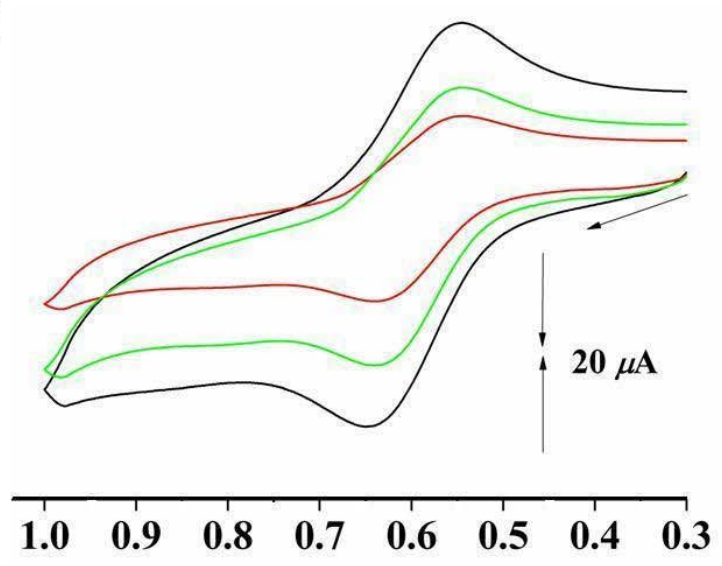

E / V vs. S.C.E.

(d)

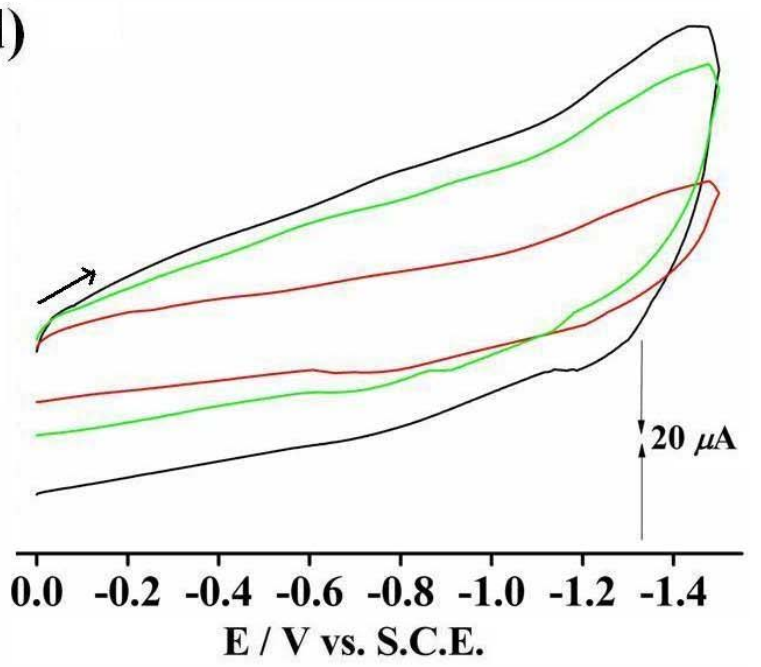

Figure S18. Cyclic voltammograms of $1 \mathrm{mM}$ of (a), Ferrocene (Fc) (b), Ferrocenyl-terpyridine (Fctpy), (d), Ph-tpy or Fc-tpy in DMF (0.1 M TBAP as supporting electrolyte) at various scan rates of 200 $\mathrm{mV} \mathrm{sec}{ }^{-1}$ (black), $100 \mathrm{mV} \mathrm{sec}{ }^{-1}$ (green) and $200 \mathrm{mV} \mathrm{sec}{ }^{-1}$ (red). (c) UV-visible absorption spectra of solution of complex 1 before (red line) and after subjection (black line) to chronoamperometry at $+0.85 \mathrm{~V}$ for $5 \mathrm{~h}$. Loss of intensity and flattening of bands indicates instability of oxidized species. 

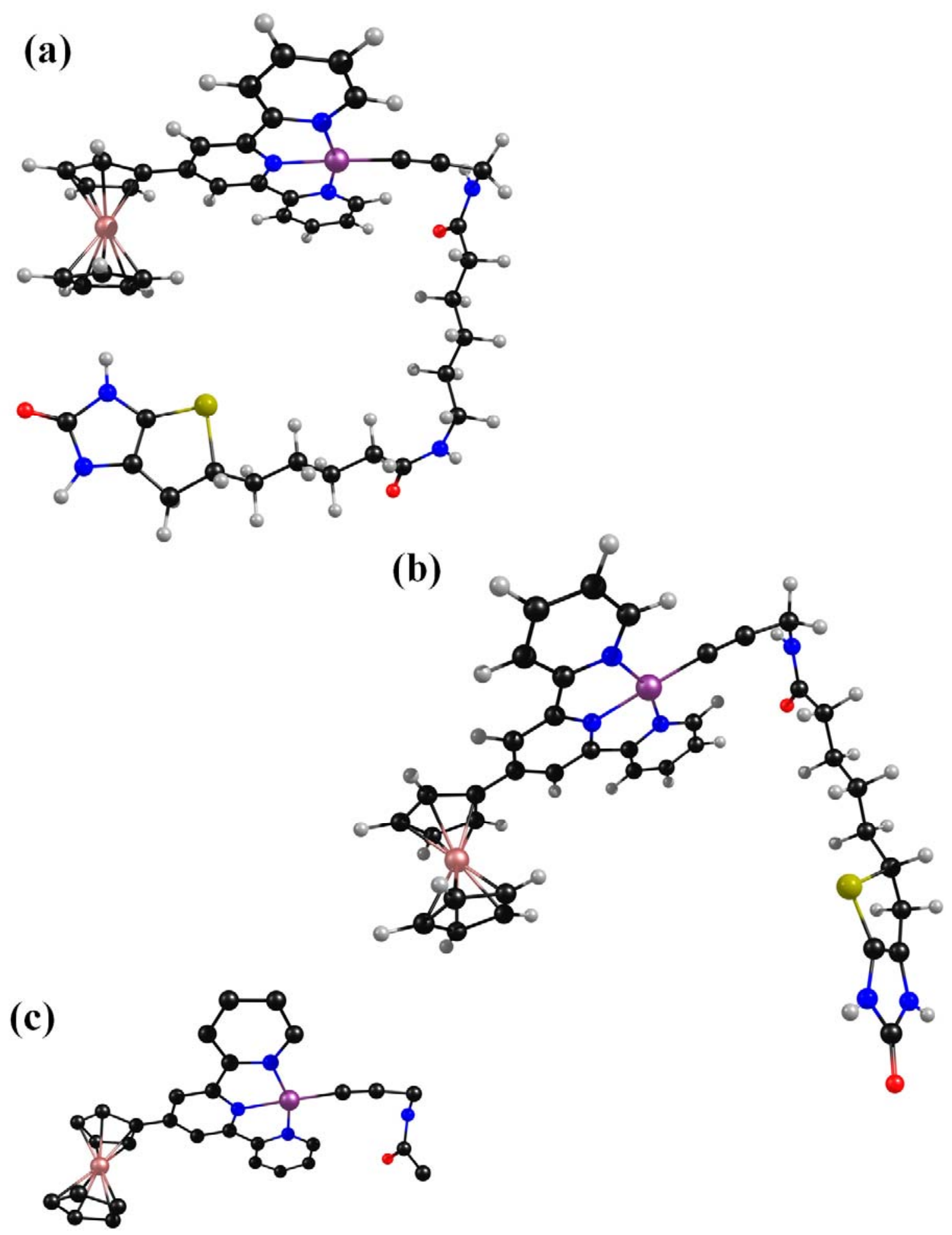

Figure S19. Energy-minimized structures of complexes 1 (a), 2 (b) and 3 (c) using B3LYP/LanL2DZ level of theory. Color codes: Purple, Pt; Brown, Fe; Red, O; Black, C; Grey, H. 

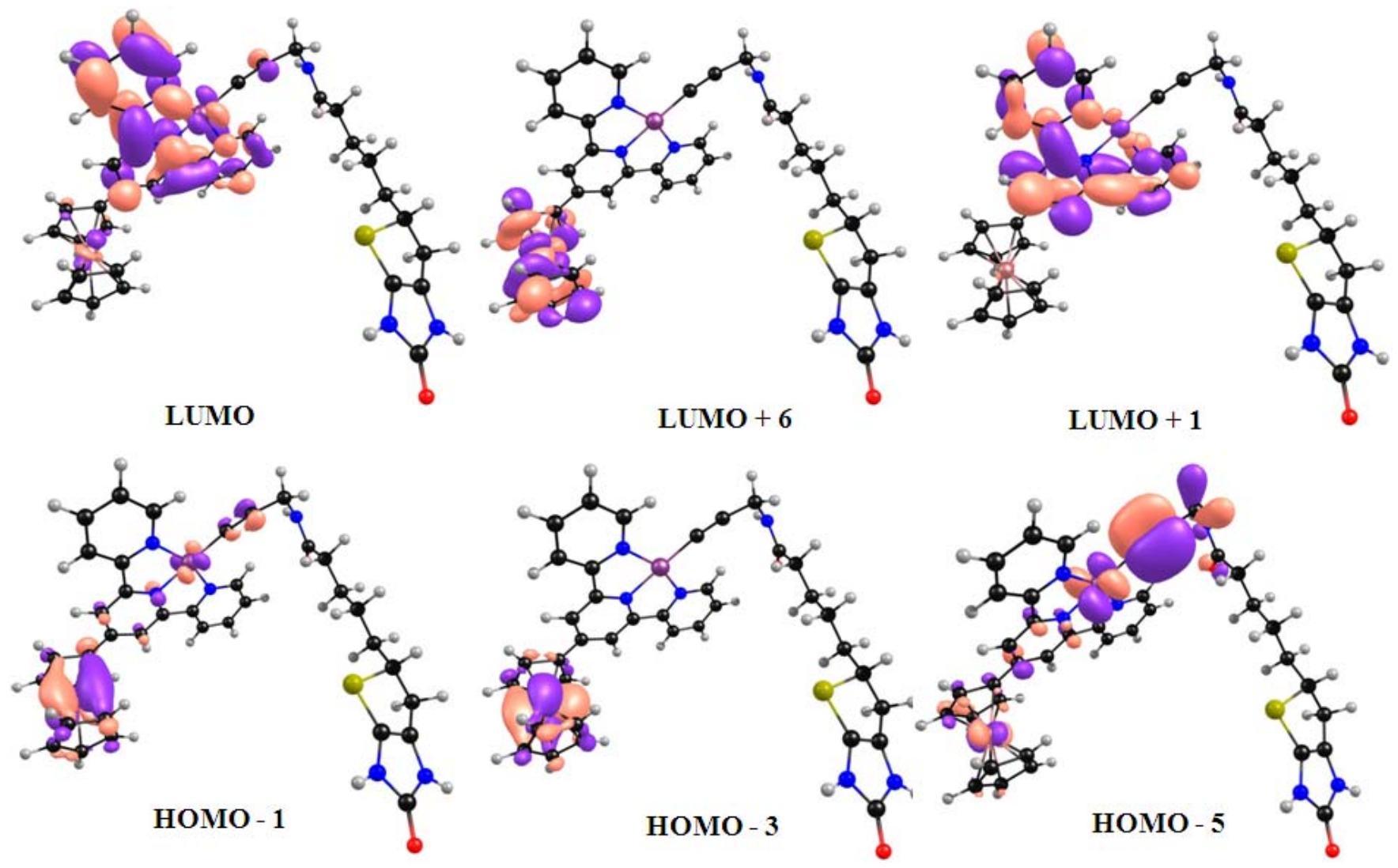

Figure S20. Frontier molecular orbitals of complex 2 involved in the transitions in visible region as obtained from TDDFT calculations using B3LYP/LanL2DZ level of theory. Color codes: Purple, Pt; Brown, Fe; Red, $\mathrm{O}$; Black, C; Grey, H. Contour value $=0.03$. 


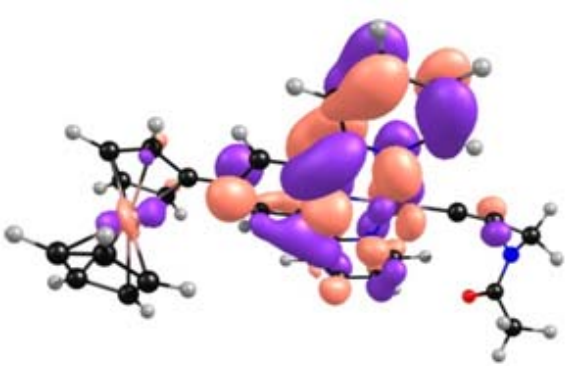

LUMO

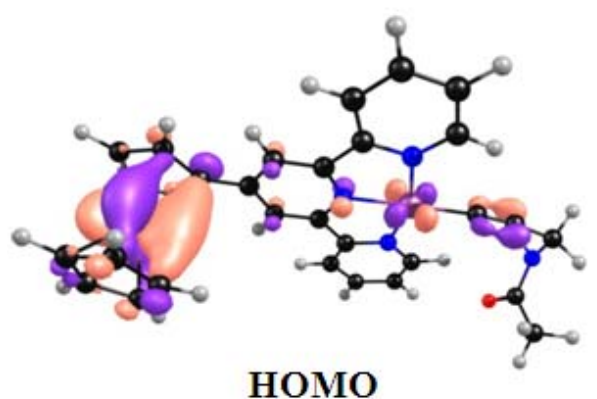

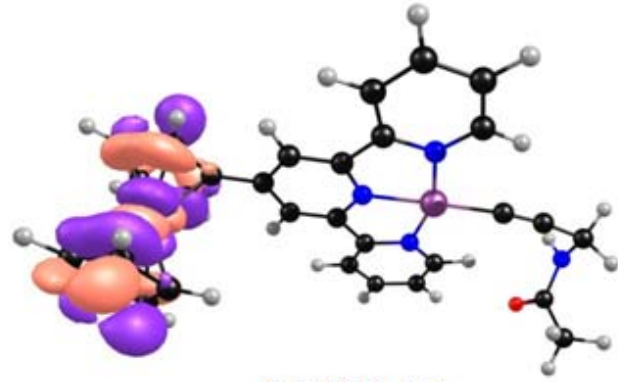

LUMO + 6

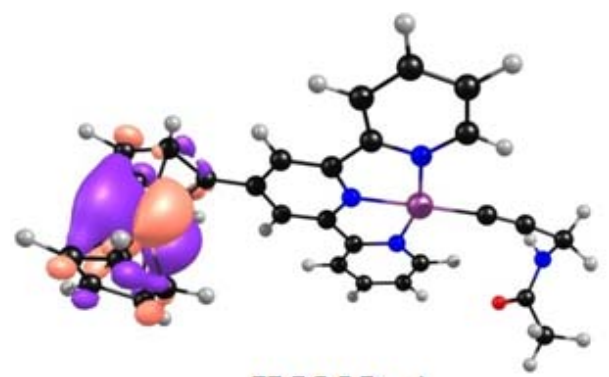

HOMO - 1
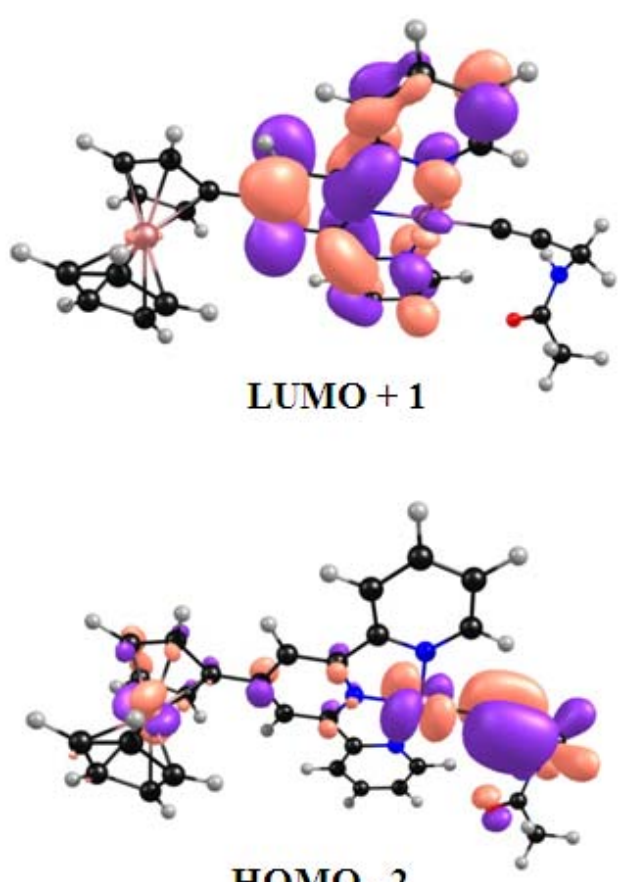

HOMO - 2

Figure S21. Frontier molecular orbitals of complex 3 involved in the transitions in visible region as obtained from TDDFT calculations using B3LYP/LanL2DZ level of theory. Color codes: Purple, Pt; Brown, Fe; Red, O; Black, C; Grey, H. Contour value $=0.03$. 

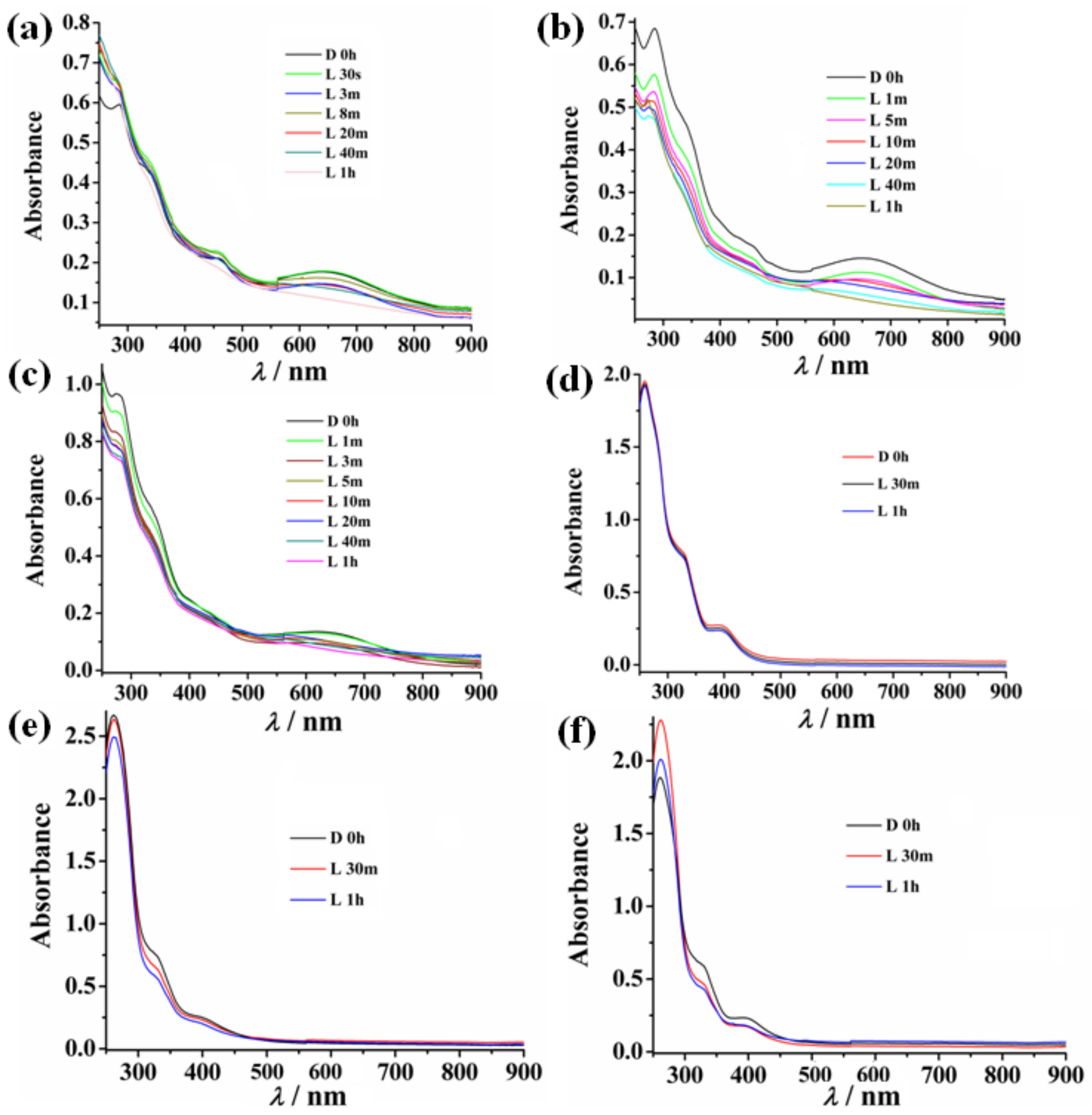

Figure S22. Changes in the UV-visible absorption bands of (50 $\mu \mathrm{M})$ complexes 1 (a), 2 (b), 3 (c), 4 (d), 5 (e) and 6 (f) in 10\% DMSO-DPBS ( $\mathrm{pH}=7.2)$ on exposure to visible light of $400-700 \mathrm{~nm}$ at different time intervals as depicted in the figure. $\mathrm{D}=$ dark, $\mathrm{L}=$ Light, $\mathrm{s}=\mathrm{sec}, \mathrm{m}=\mathrm{min}, \mathrm{h}=$ hour. The ferrocenyl complexes 1-3 show decrease in intensity at $640 \mathrm{~nm}$ on photoexposure, while the phenyl counterparts 4-6 are photostable. 

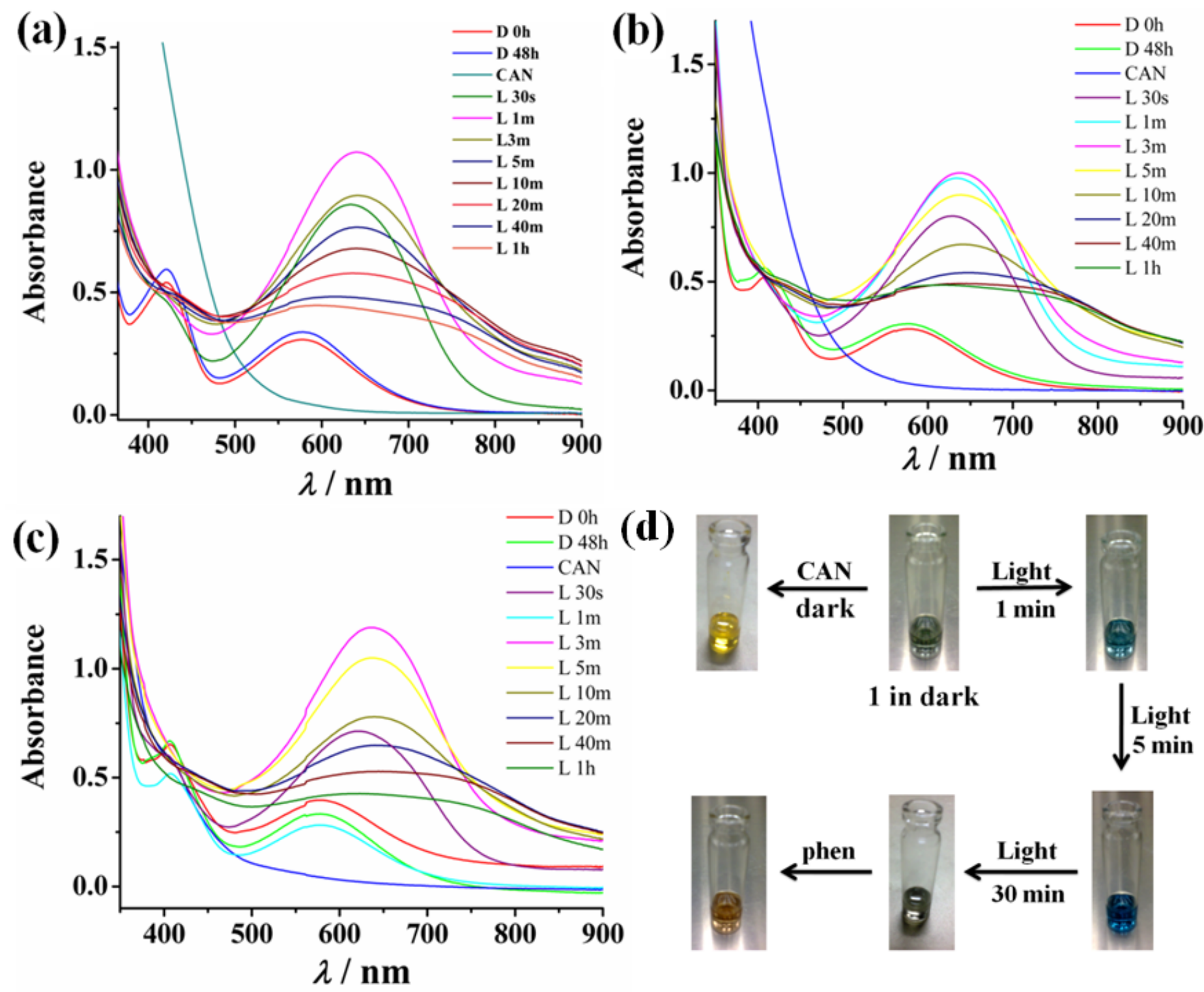

Figure S23. Changes in the UV-visible absorption bands of $(50 \mu \mathrm{M})$ complexes 1 (a), 2 (b), 3 (c), in pure DMSO solvent on exposure to visible light of 400-700 $\mathrm{nm}$ at different time intervals as depicted in the figure. $\mathrm{D}=$ dark, $\mathrm{L}$ $=$ Light, $\mathrm{s}=\mathrm{sec}, \mathrm{m}=$ min, $\mathrm{h}=$ hour. (d) Gradual changes in color observed for complex 1 (50 $\mu \mathrm{M}$ in DMSO or $\mathrm{DMF}$ ) on photo-irradiation (400-700 $\mathrm{nm}$ ) from deep green (in the dark) to light blue (after $1 \mathrm{~min}$ ) to deep blue (after $5 \mathrm{~min}$ ) and finally black (after $30 \mathrm{~min}$ ). It turned red on addition of excess of 1,10-phenanthroline (phen) and on exposure to light. Complex 1 when treated with excess ceric ammonium nitrate (CAN) in dark turned yellow in color due to oxidation. 

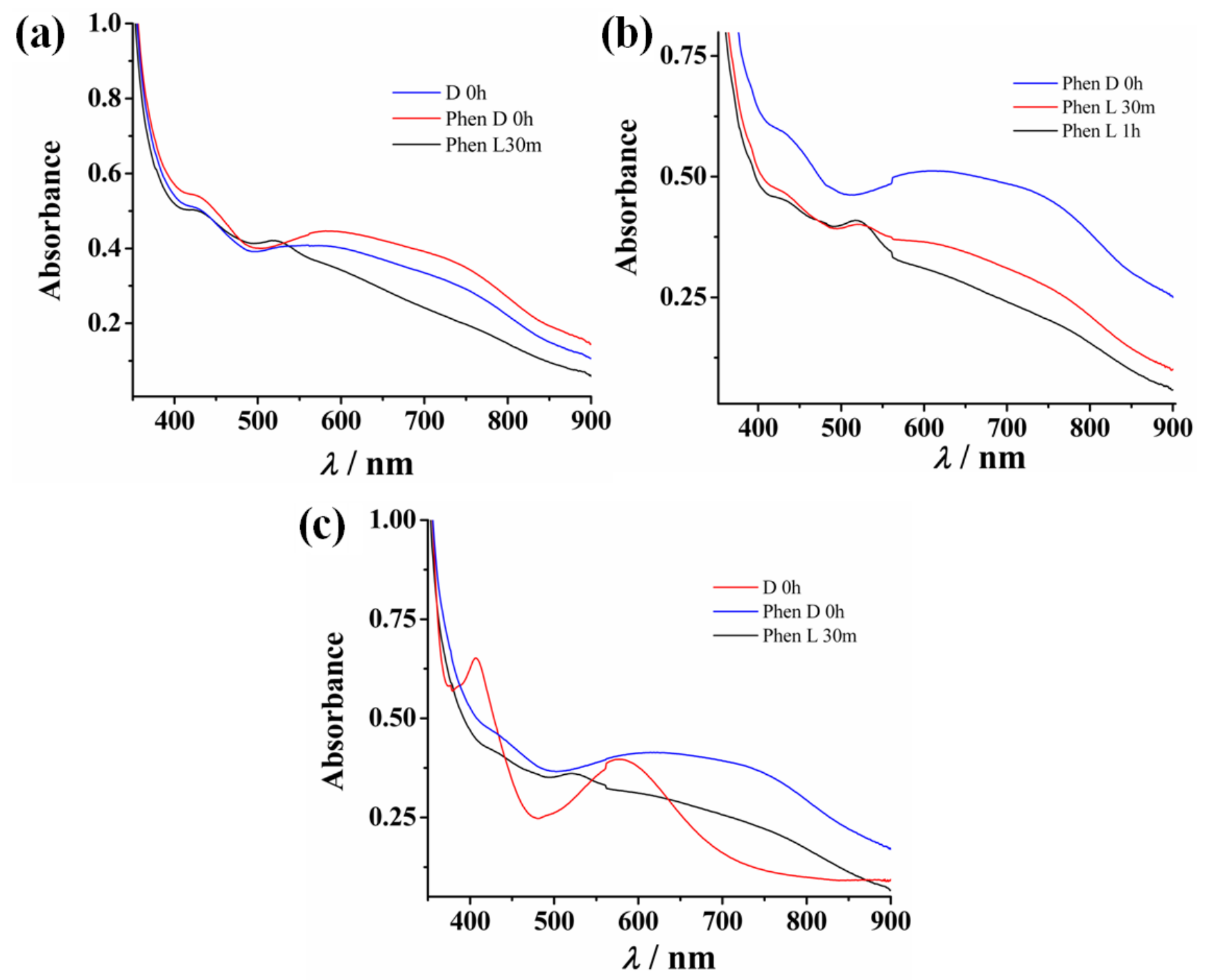

Figure S24. Changes in the UV-visible absorption bands of (50 $\mu \mathrm{M})$ complexes 1 (a), 2 (b), 3 (c), in pure DMSO solvent in presence of excess 1,10-phenanthroline (phen, $1 \mathrm{mM}$ ) on exposure to visible light of 400-700 $\mathrm{nm}$ at different time intervals as depicted in the figure. $\mathrm{D}=$ dark, $\mathrm{L}=$ Light, $\mathrm{m}=\mathrm{min}, \mathrm{h}$ $=$ hour. 


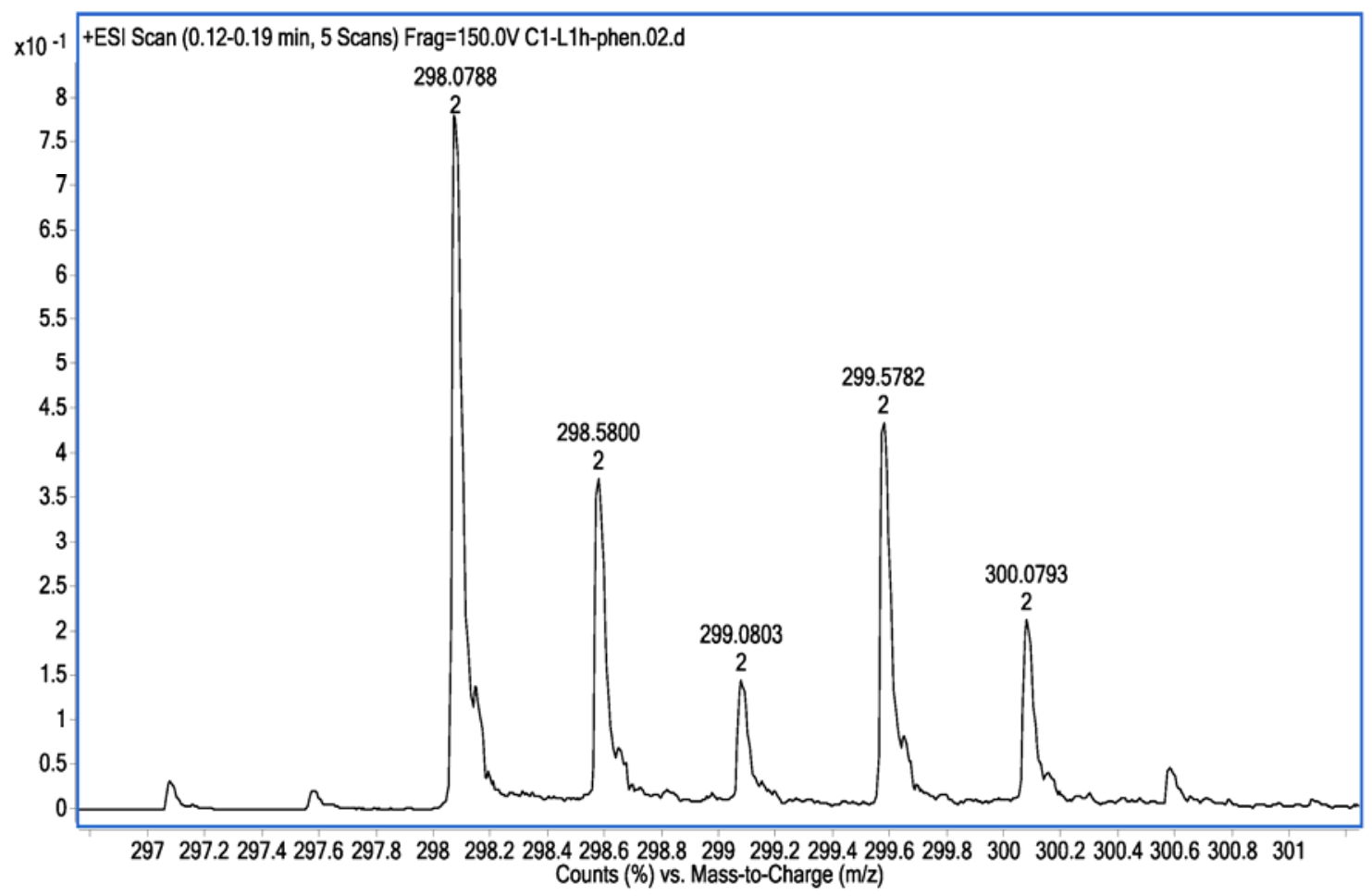

Figure S25. Mass spectra of irradiated samples $(400-700 \mathrm{~nm}, 1 \mathrm{~h})$ containing complexes 1 or 2 or 3 and excess 1,10-phenanthroline (phen) showing the formation of $\left[\mathrm{Fe}(\mathrm{phen})_{2}\right]^{2+}$ at $\mathrm{m} / \mathrm{z}=298.0788$.

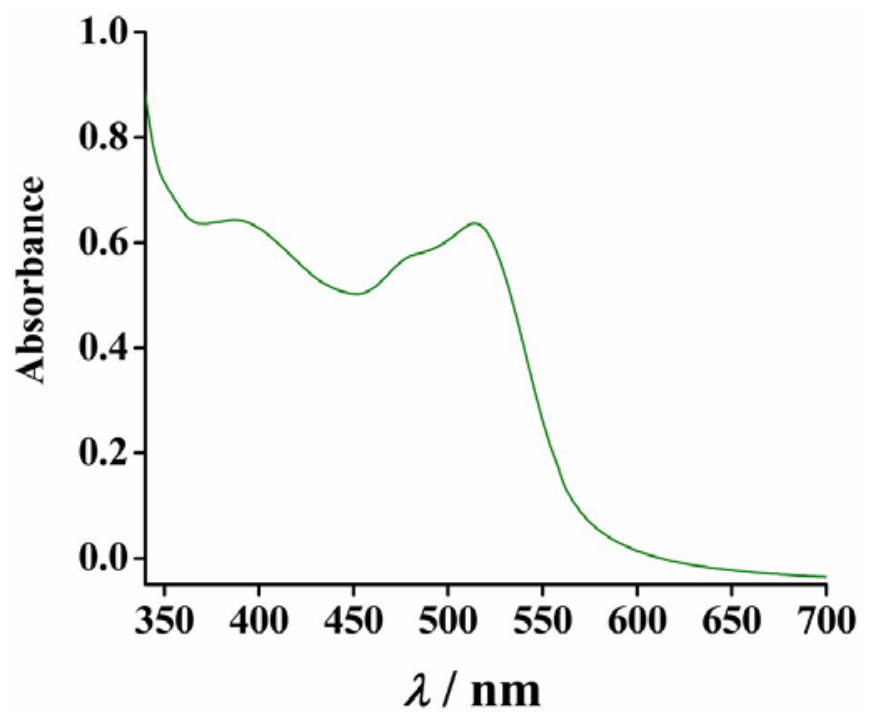

Figure S26. Appearance of absorption bands at 515 and $480 \mathrm{~nm}$ on treating ferric chloride $(200 \mu \mathrm{M})$ with excess of 1,10-phenanthroline (phen, $1 \mathrm{mM}$ ) for $1 \mathrm{~h}$ in dark in 10\% DMSObuffer solution. 

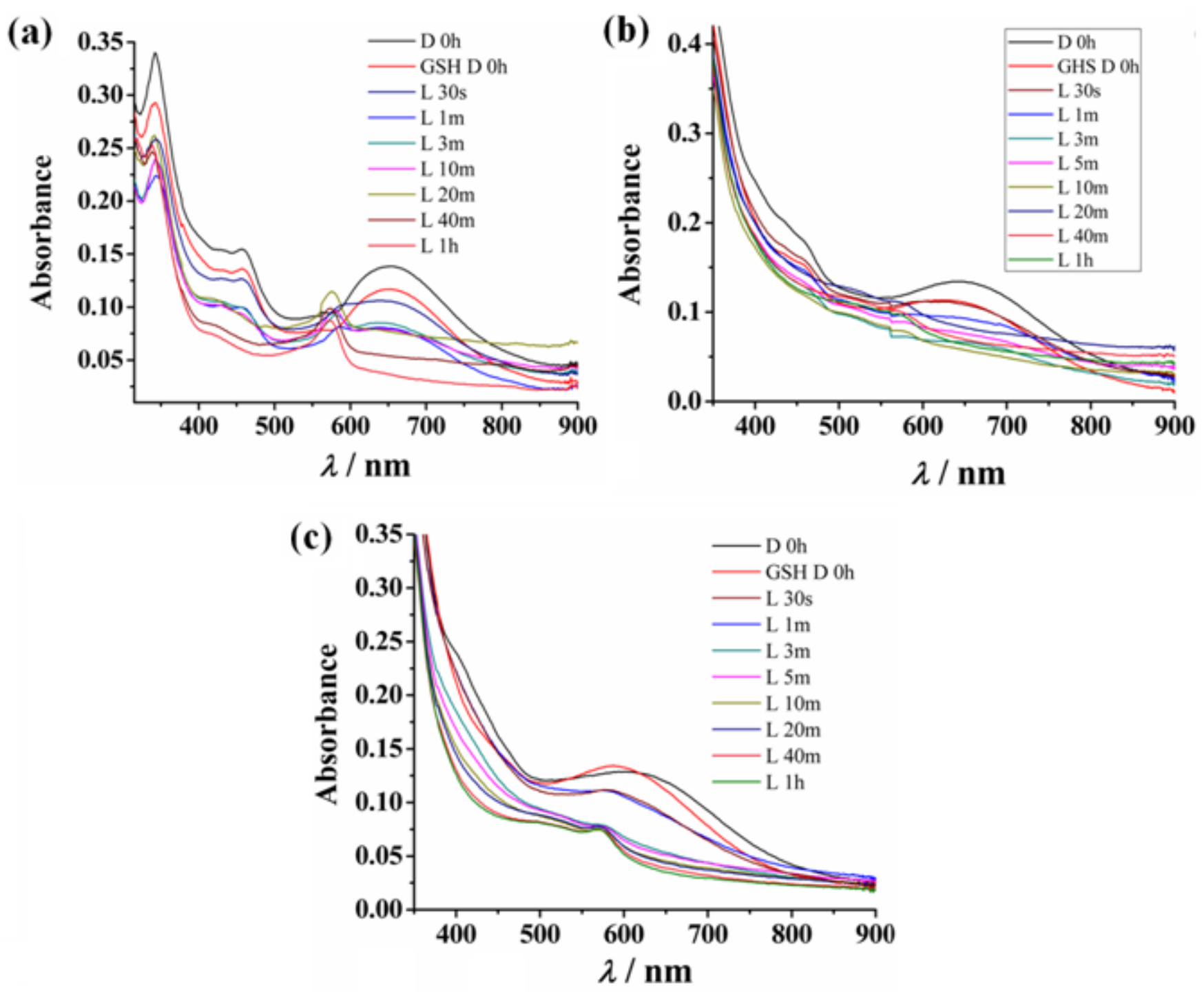

Figure S27. Changes in the UV-visible absorption bands of (50 $\mu \mathrm{M})$ complexes 1 (a), 2 (b), 3 (c), in 10\% DMSO-DPBS solvent in presence of excess glutathione (GSH, $5 \mathrm{mM}$ ) on exposure to visible light of 400$700 \mathrm{~nm}$ at different time intervals as depicted in the figure. $\mathrm{D}=$ dark, $\mathrm{L}=$ Light, $\mathrm{s}=\mathrm{sec}, \mathrm{m}=\mathrm{min}, \mathrm{h}=$ hour. 


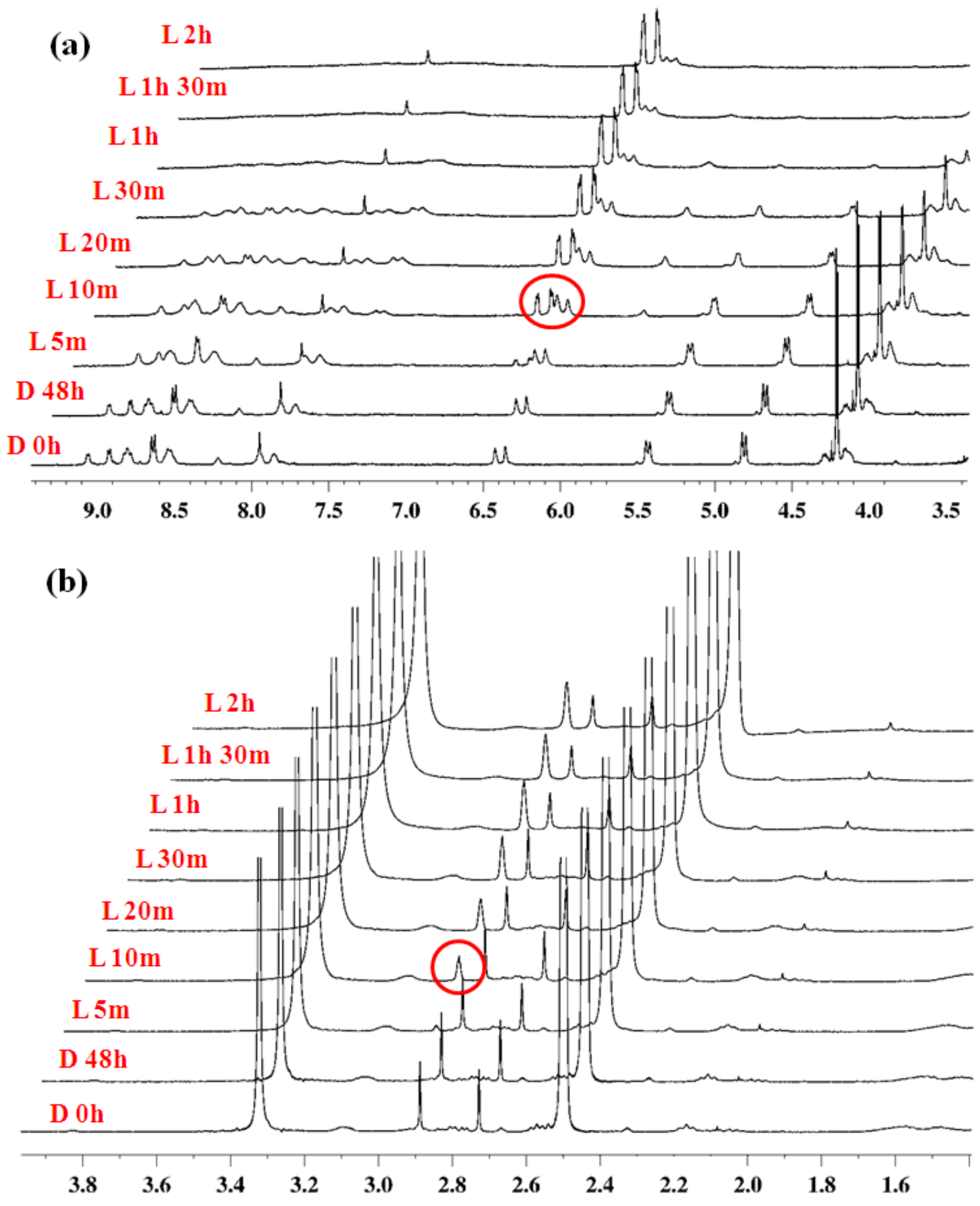

Figure S28. Changes in the ${ }^{1} \mathrm{H}$ NMR of complex 2 after photoexposure or kept in dark recorded at different time intervals as shown in $\mathrm{d}_{6}$-DMSO solvent. $\mathrm{D}=$ dark, $\mathrm{L}=$ light $(400-700 \mathrm{~nm}), \mathrm{m}=\mathrm{min}, \mathrm{h}=$ hour. 


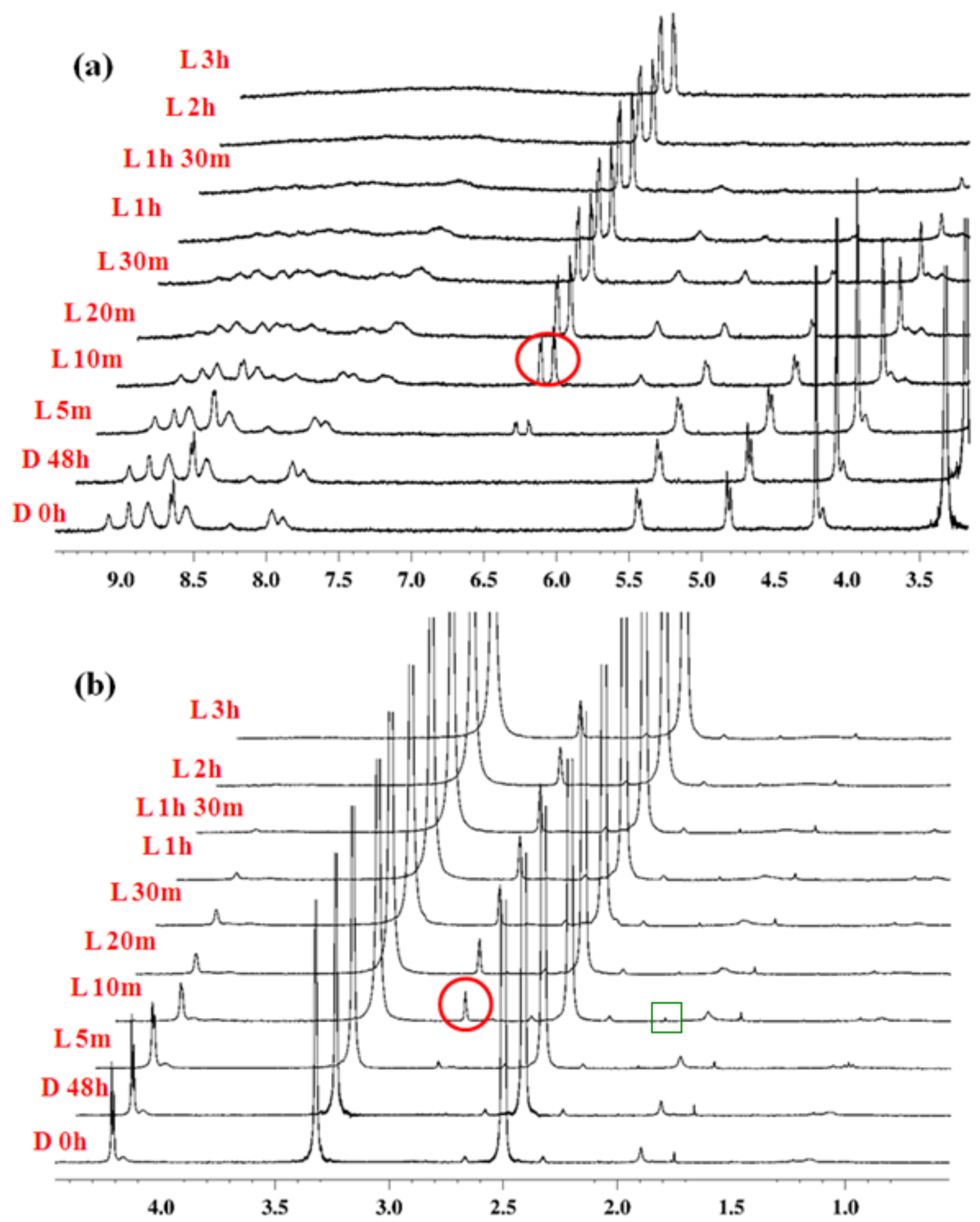

Figure S29. Changes in the ${ }^{1} \mathrm{H}$ NMR of complex 3 after photoexposure or kept in dark recorded at different time intervals as shown in $\mathrm{d}_{6}$-DMSO solvent. $\mathrm{D}=$ dark, $\mathrm{L}=$ light $(400-700 \mathrm{~nm}), \mathrm{m}=\min$, $\mathrm{h}=$ hour. Red circles show peak for released $\mathrm{Cp}$ ring, while the green square indicates the acetylenic proton at $2.2 \mathrm{ppm}$. 


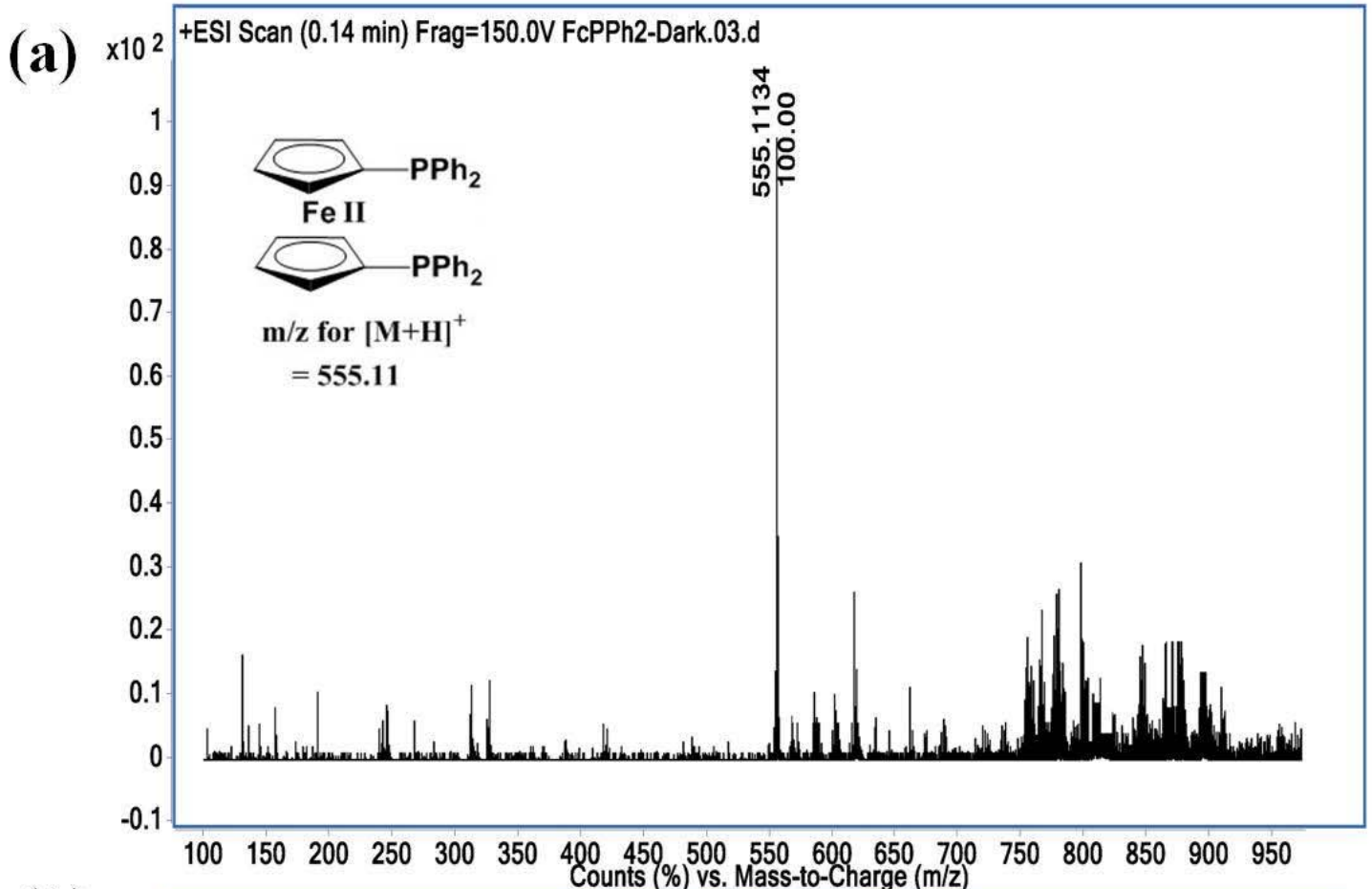

(b)

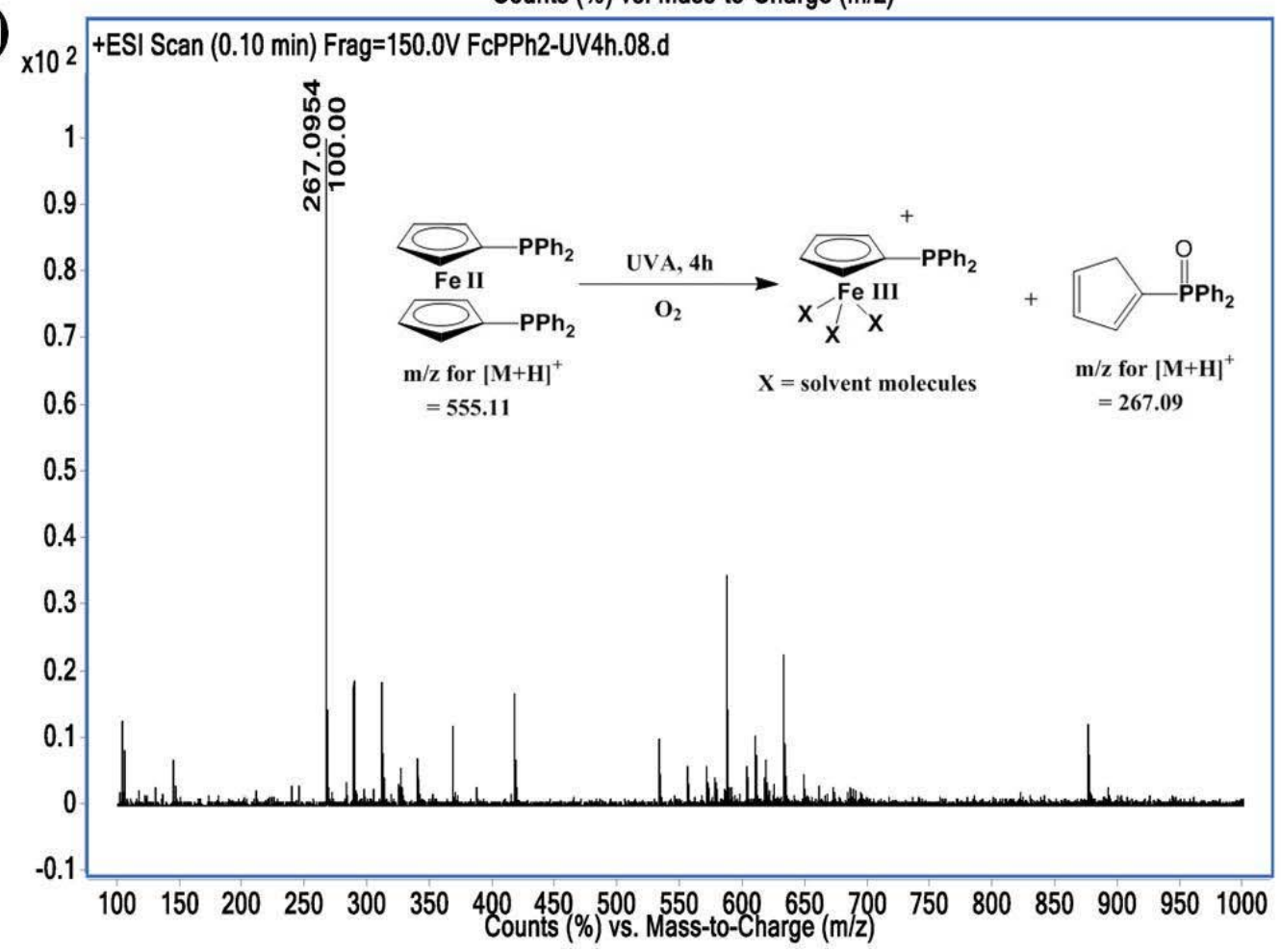

Figure S30. Changes in the mass spectra of 1,1-bis-(diphenylphophino)ferrocene recorded in diluted methanol solutions (a) in dark and (b) after photo-exposure for $4 \mathrm{~h}$ in UVA light, 395 $\mathrm{nm}$. 


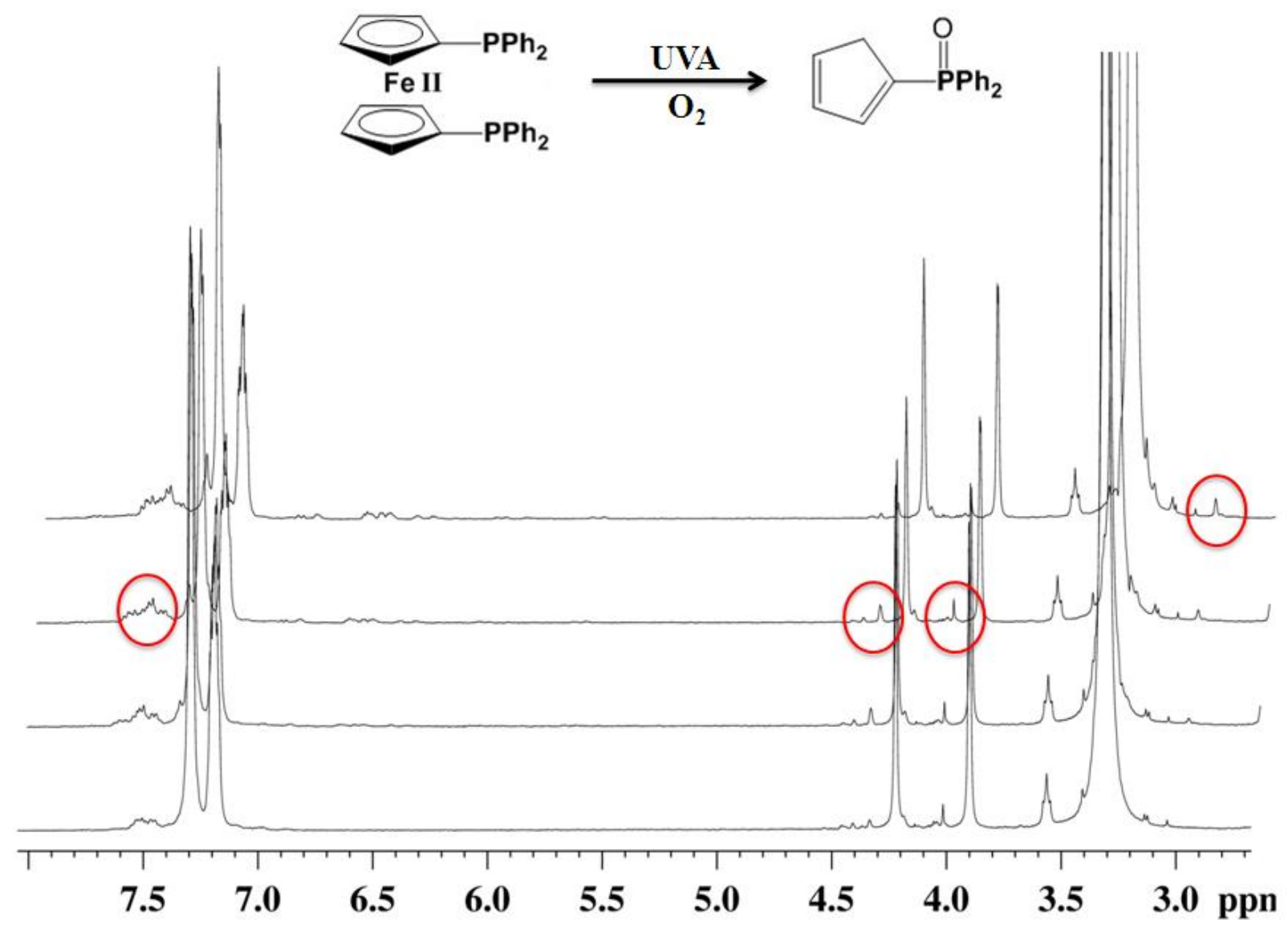

Figure S31. Changes in the ${ }^{1} \mathrm{H}$ NMR of 1,1-bis-(diphenylphosphino)ferrocene after photoexposure after photoexposure (UVA, $395 \mathrm{~nm}$ ) recorded at $2 \mathrm{~h}$ time intervals in $\mathrm{d}_{6}$-DMSO solvent. Red circles show peak for photo-released oxidized $\mathrm{Cp}$ moiety at 7.67-7.47 ppm (for Ph ring protons), 4.06 and $4.37 \mathrm{ppm}$ (for $\mathrm{C}=\mathrm{C}-\mathrm{H}$ protons of $\mathrm{Cp}$ ring) and at $2.98 \mathrm{ppm}$ (for $\mathrm{CH}_{2}$ protons of $\mathrm{Cp}$ rings). 

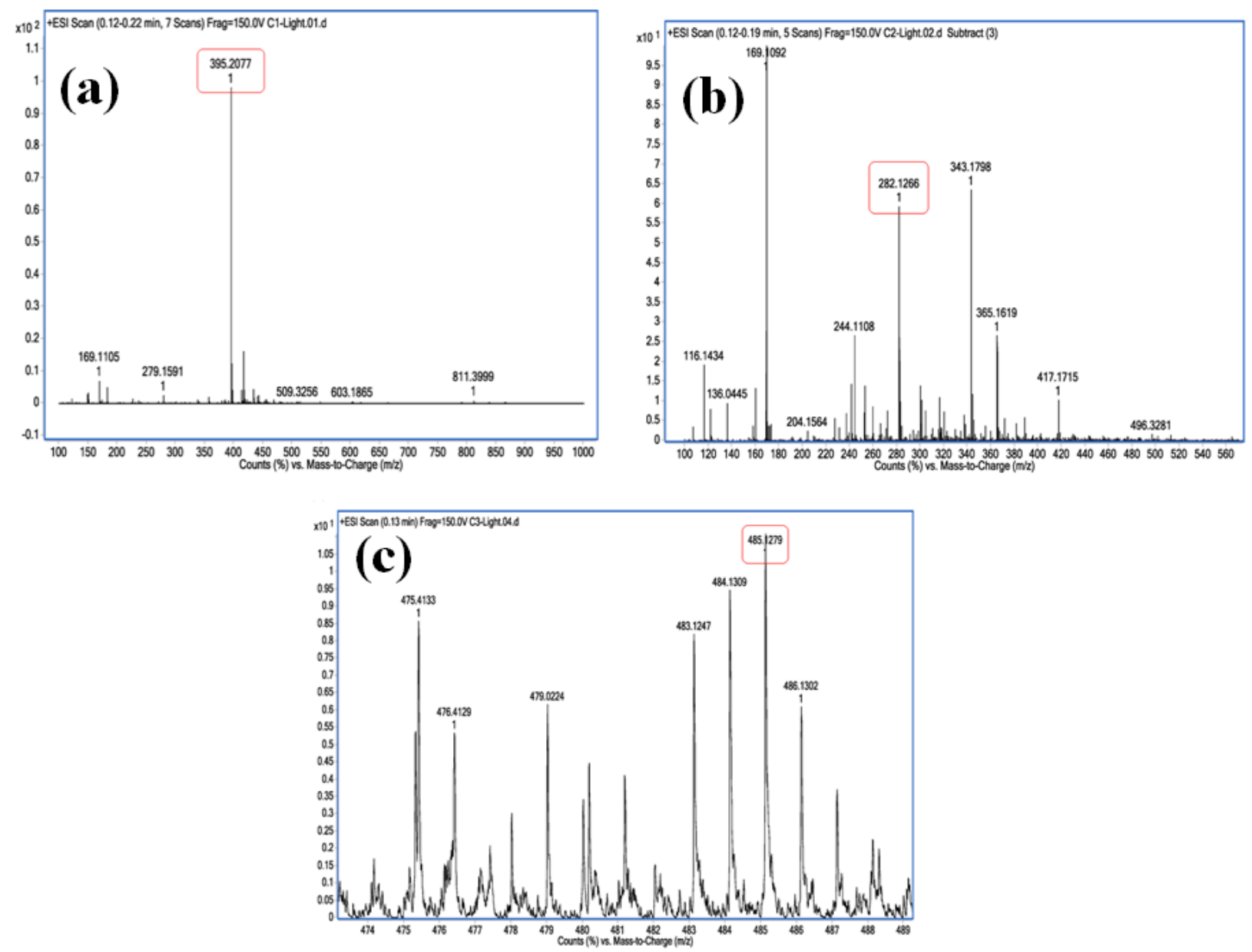

Figure S32. Mass spectra of irradiated samples of complex 1 (a), 2 (b) and 3 (c) showing the respective $\mathrm{m} / \mathrm{z}$ at 395.2077 for $\left[\mathrm{HL}^{1}+\mathrm{H}\right]^{+}, 282.1266$ for $\left[\mathrm{HL}^{2}+\mathrm{H}\right]^{+}$and 485.1279 for $[\mathrm{Pt}(\mathrm{tpy}) \mathrm{Cl}]^{+}$. 

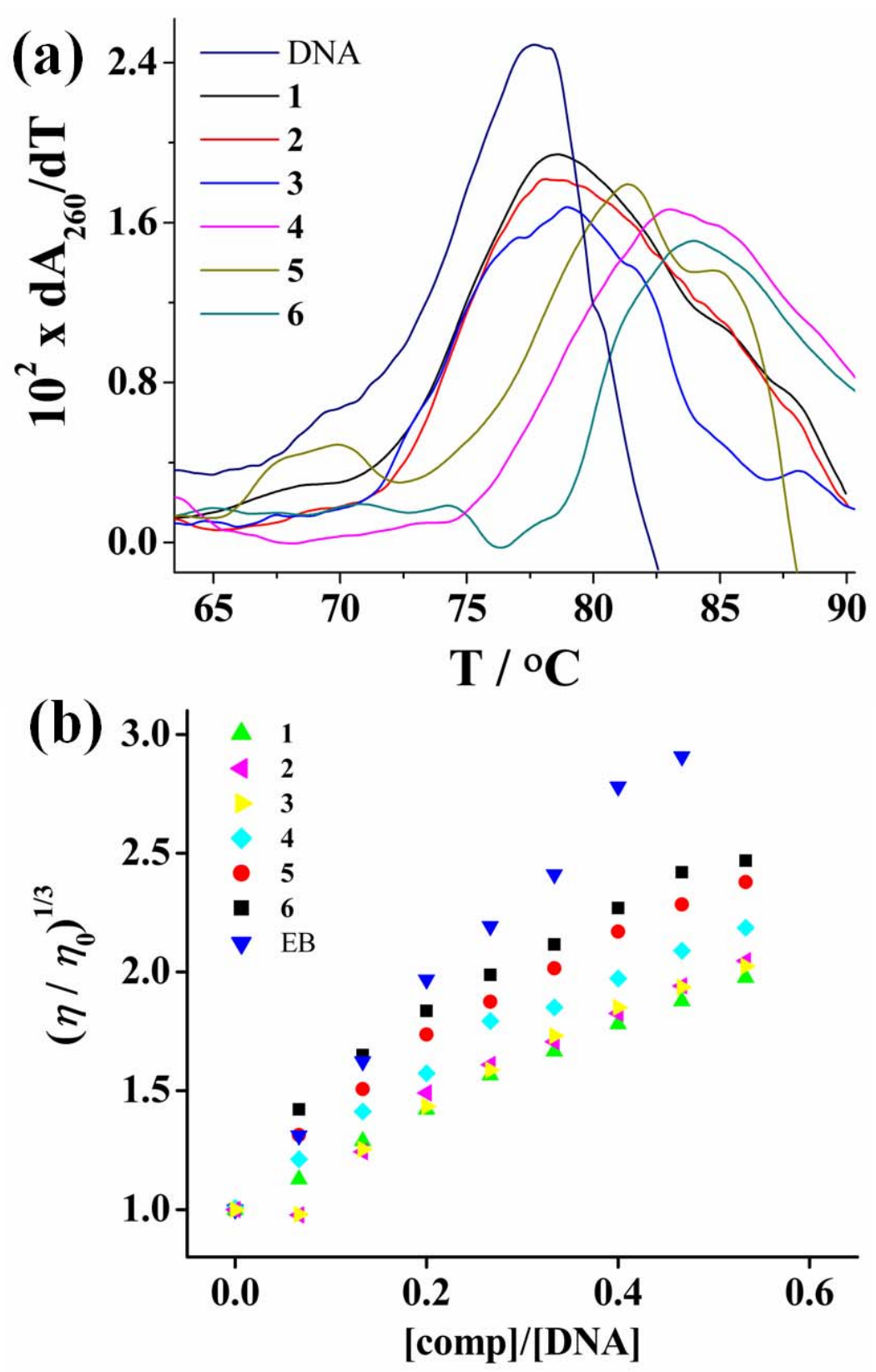

Figure S33. (a) Changes in ct-DNA $(100 \mu \mathrm{M})$ melting temperature in absence and presence of complexes $(10 \mu \mathrm{M})$ in 5\% DMSO-DPBS buffer $(\mathrm{pH}=7.2)$.(b) Changes in ctDNA $(100 \mu \mathrm{M})$ viscosity on addition of complexes in DMSO-DPBS buffer $(\mathrm{pH}=7.2)$. 


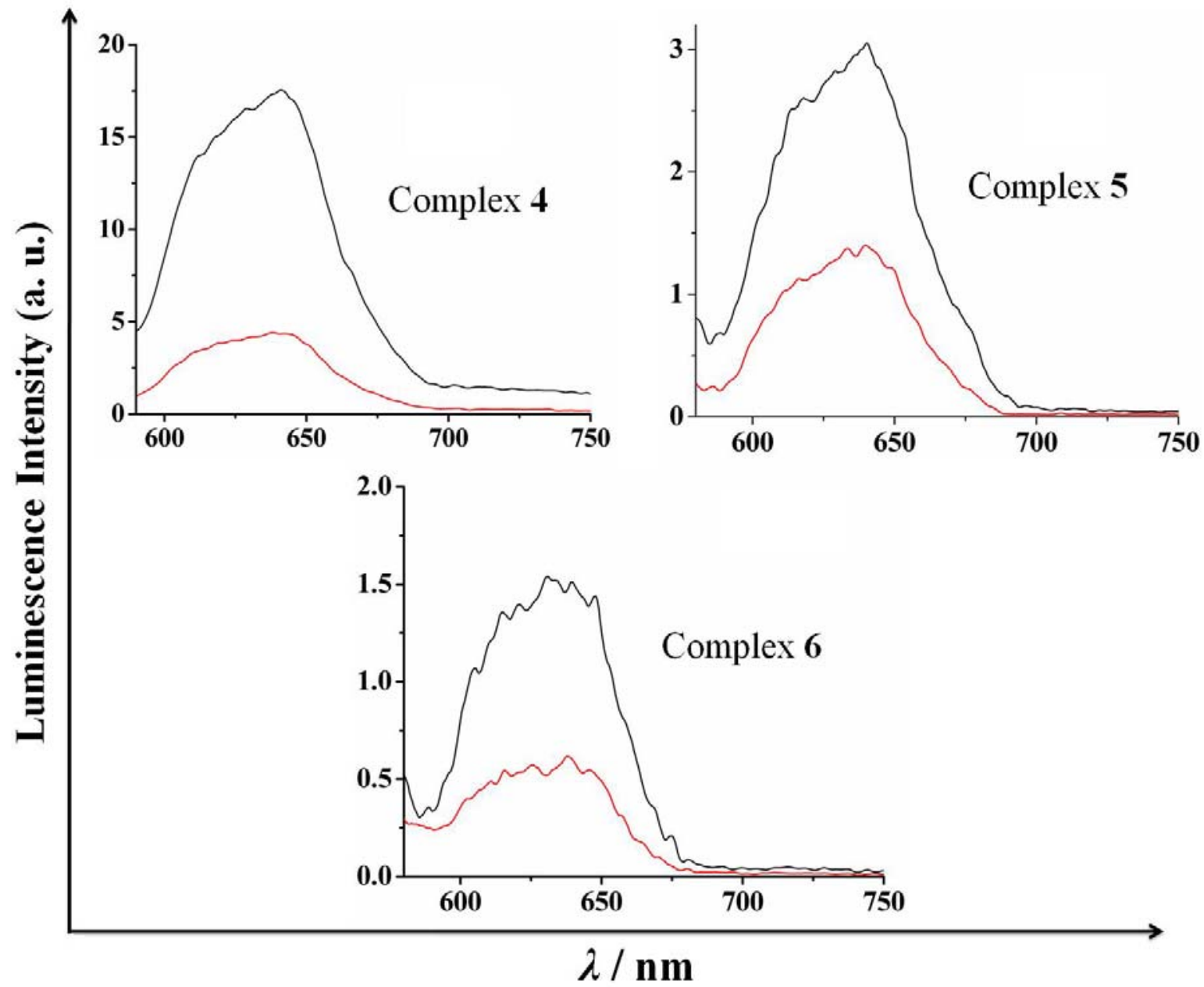

Figure S34. Changes in luminescence intensity of complexes 4-6 on addition of ct-DNA (200 $\mu \mathrm{M})$ to complexes $(50 \mu \mathrm{M})$ in $2 \%$ DMSO-DPBS buffer $(\mathrm{pH}=7.2)$. Red line is for complexes alone in buffer and black line is in presence of DNA. 


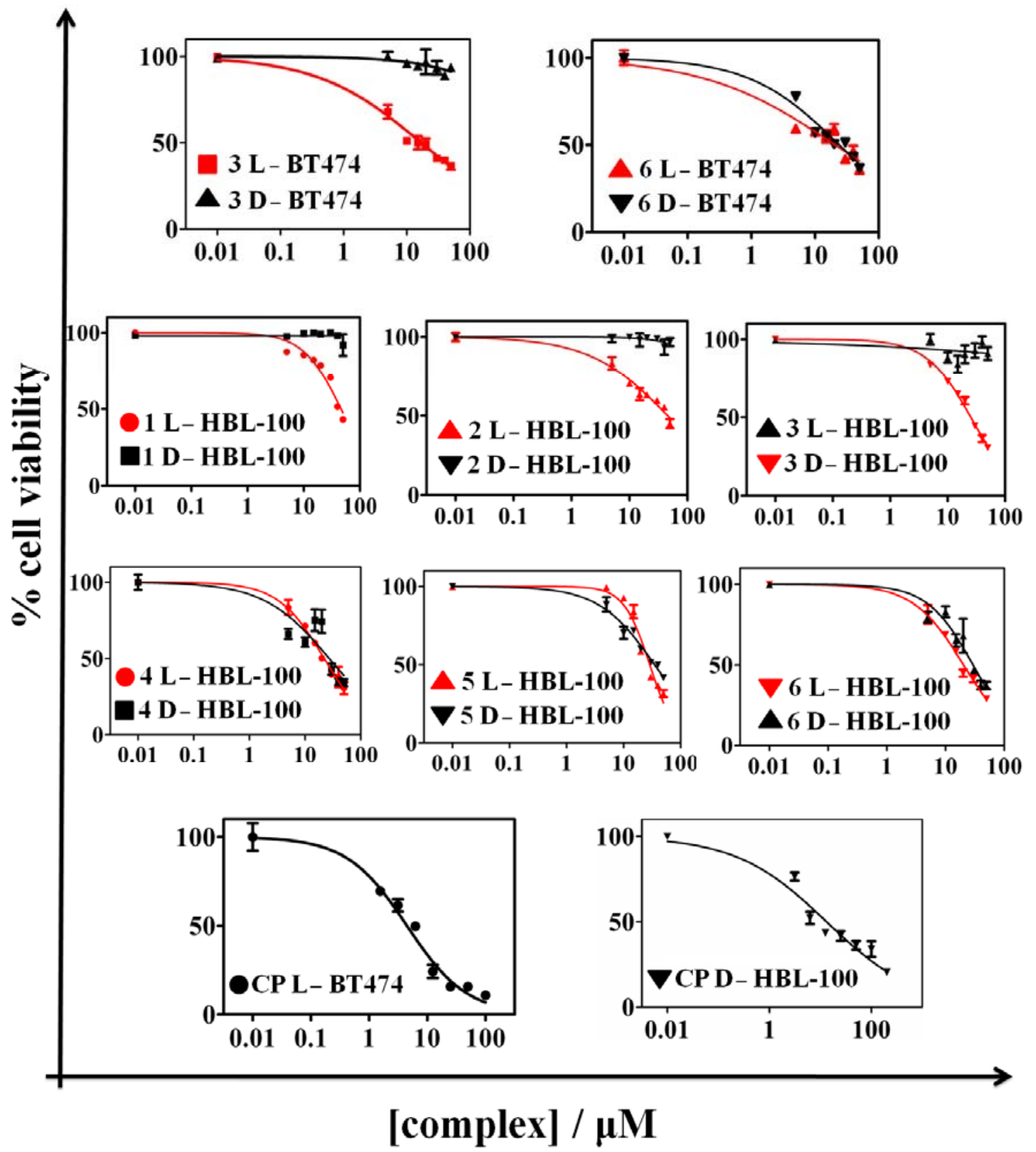

Figure S35. Cell viability plots obtained from the MTT assay of the complexes 1-6 on $24 \mathrm{~h}$ incubation showing cytotoxicity in BT474 and HBL-100 cells in visible light $(400-700 \mathrm{~nm}$, red symbols) and dark (black symbols) as shown in the figure. $\mathrm{L}=$ light, $400-700 \mathrm{~nm}, 10 \mathrm{~J} \mathrm{~cm}^{-2}$; D $=$ dark; $\mathrm{CP}=$ cisplatin . 

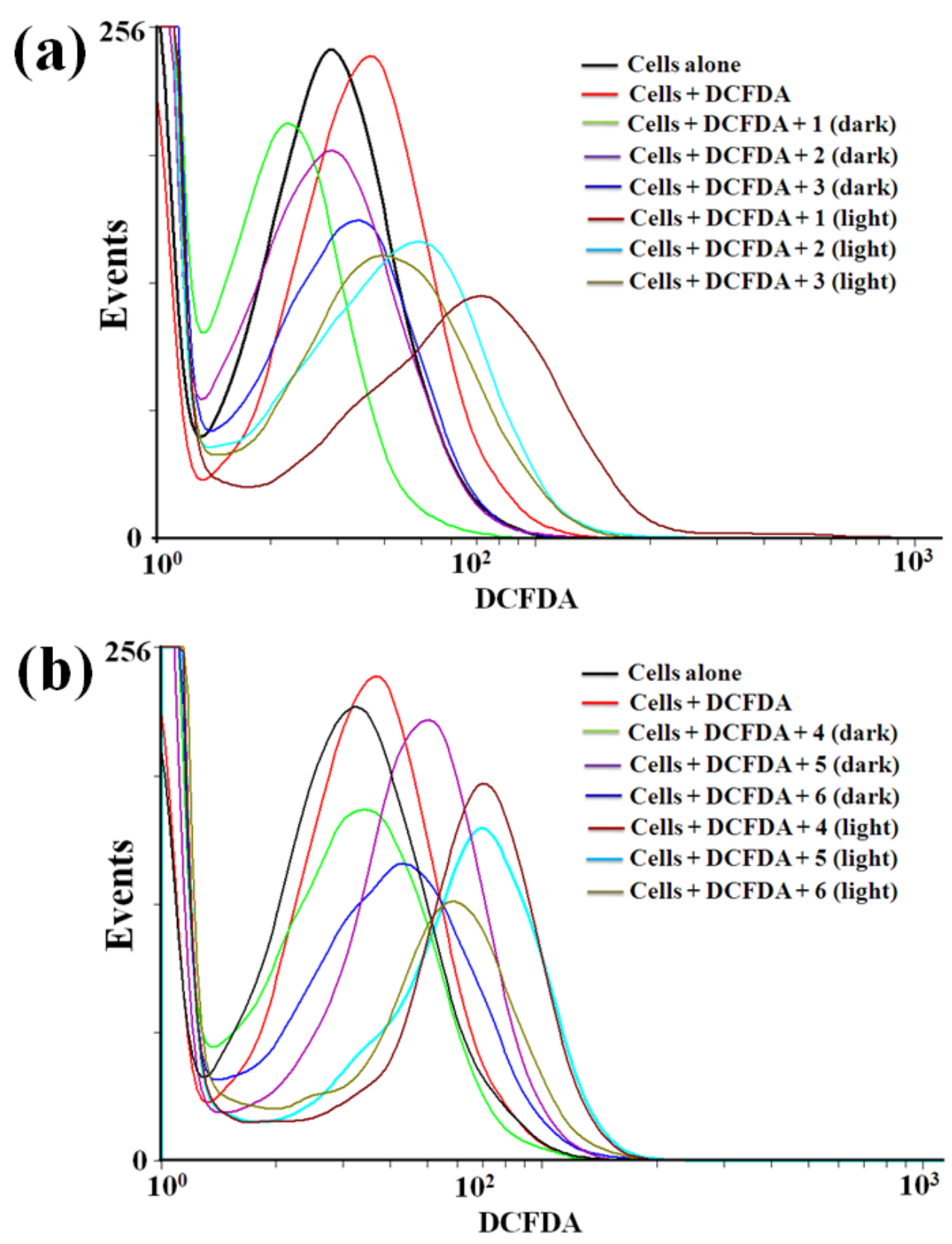

Figure S36. Cellular ROS generation by complexes 1-3 (a) and 4-6 (b) in BT474 cells in dark or light conditions as estimated by DCFDA assay [pre-incubation $=24 \mathrm{~h}$ in dark, light exposure (400$700 \mathrm{~nm}=1 \mathrm{~h})]$. 


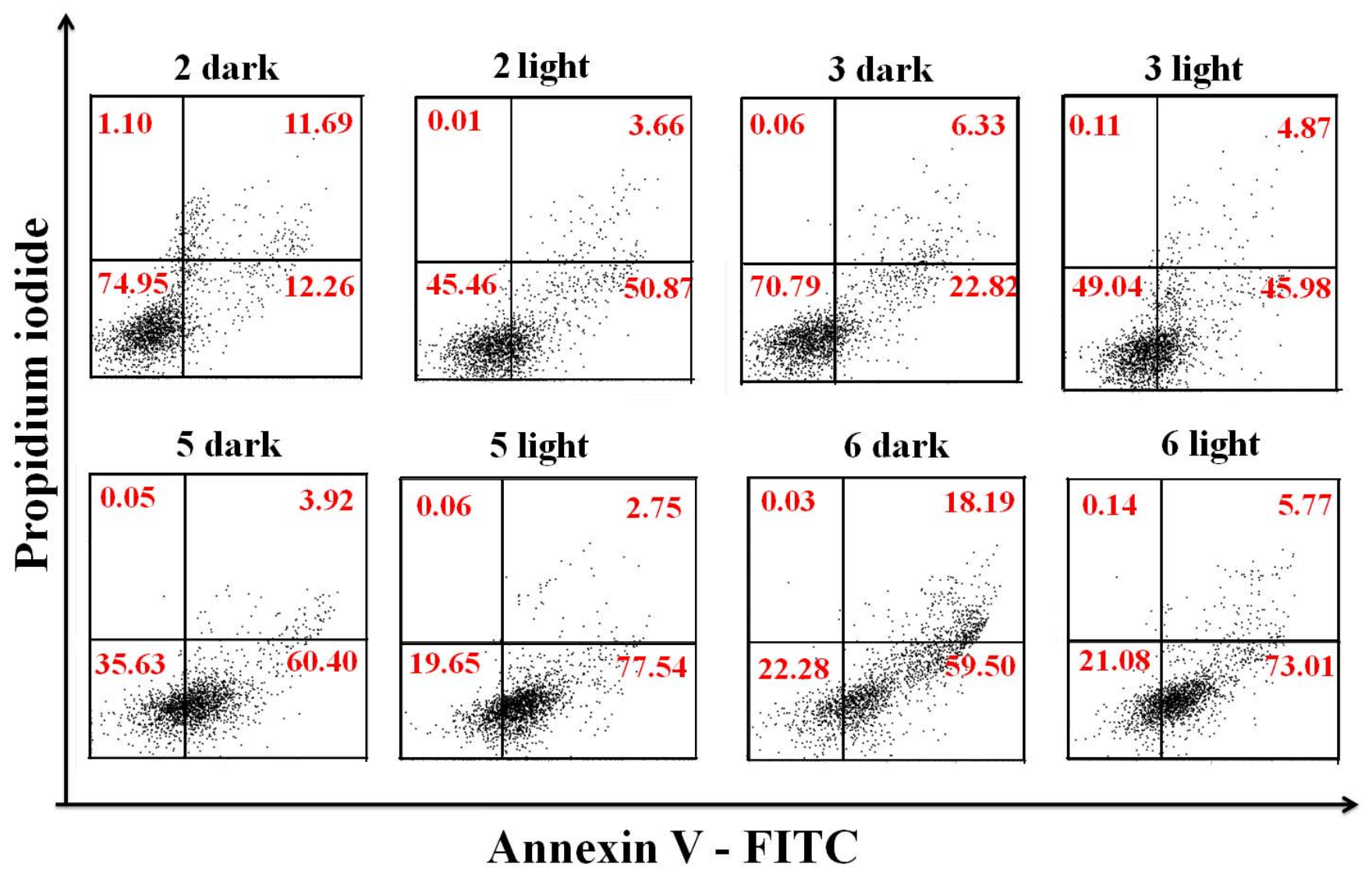

Figure S37. Dot plots of annexinV-FITC/PI assay on BT474 cells treated with complexes 2-6 either kept in dark or exposed to photoreactor $\left(400-700 \mathrm{~nm}, 10 \mathrm{~J} \mathrm{~cm}^{-2}\right.$ ) as labeled showing \% cell populations in respective quadrants: lower left (LL), live cells; lower right (LR), early apoptotic; upper left (UL), dead cells and upper right $(\mathrm{UR})$, late apoptotic [pre-incubation $=24 \mathrm{~h}$ in dark, light exposure $(400-700 \mathrm{~nm}=1 \mathrm{~h})$ ]. 


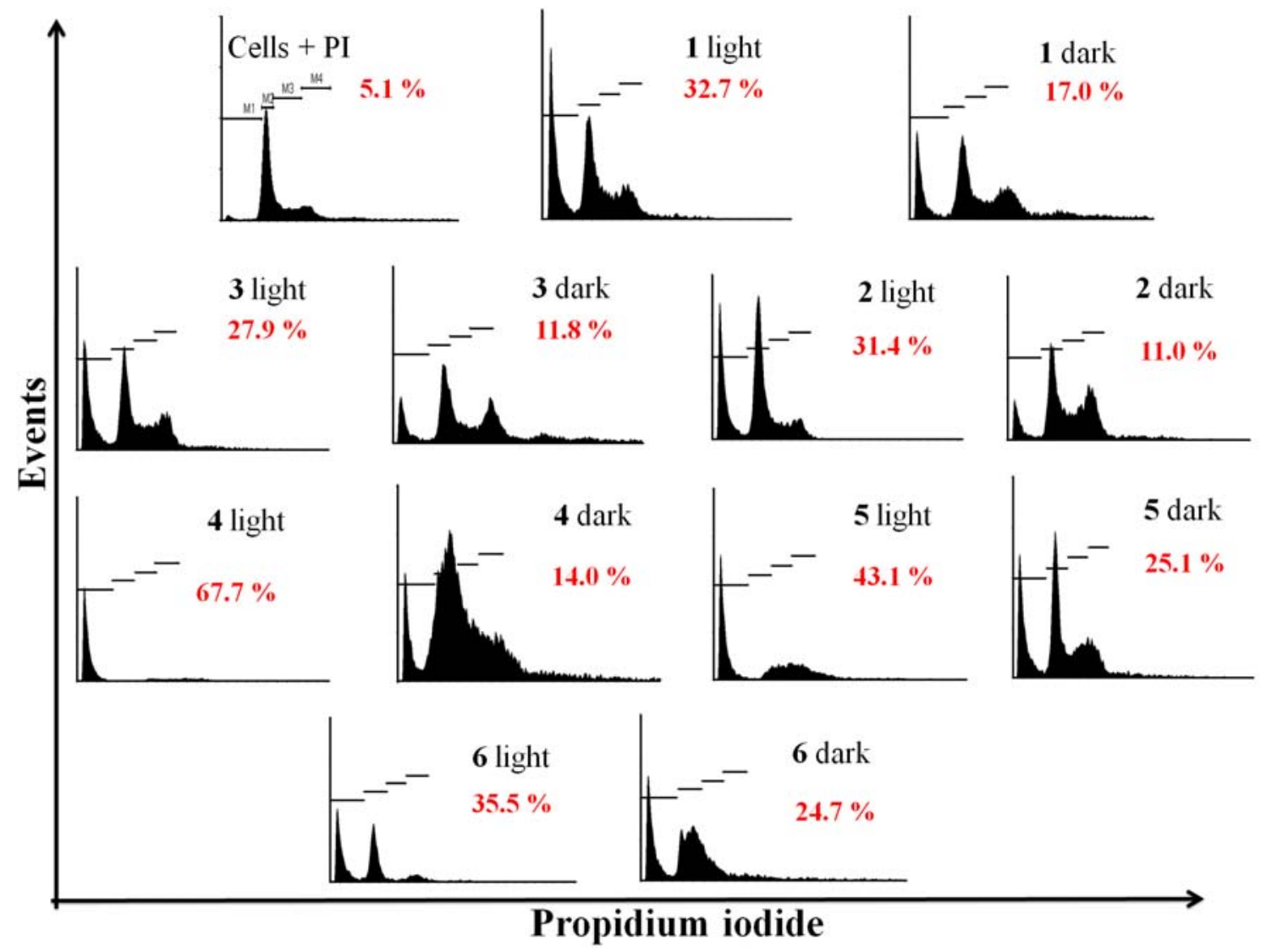

Figure S38. Cell cycle analysis was done on BT474 cells with complexes 1-6 in dark and light as shown in the figure using flow cytometry. The figure shows cell populations in different phases of cell cycle as denoted by M1-subG1, M2-G1, M3-S, M4-G2/M. [pre-incubation $=24 \mathrm{~h}$ in dark, light exposure $(400-700 \mathrm{~nm}=1 \mathrm{~h})]$. 
Table S1. Energy minimized coordinates

\section{COMPLEX 1}

\begin{tabular}{|lrrr|}
\hline 78 & -2.872761000 & -2.348428000 & 0.394178000 \\
26 & 4.595177000 & -2.950278000 & -0.888119000 \\
7 & -2.406229000 & -3.410489000 & 2.082623000 \\
7 & -1.042540000 & -2.970678000 & -0.092843000 \\
7 & -2.704593000 & -1.516021000 & -1.473626000 \\
6 & 4.952338000 & -1.641001000 & 0.740946000 \\
1 & 4.744960000 & -1.846007000 & 1.781631000 \\
6 & 6.193596000 & -1.912613000 & 0.055407000 \\
1 & 7.076832000 & -2.358736000 & 0.489091000 \\
6 & 6.058013000 & -1.468079000 & -1.308514000 \\
1 & 6.821032000 & -1.528862000 & -2.070943000 \\
6 & 4.733625000 & -0.917222000 & -1.471287000 \\
1 & 4.335163000 & -0.483997000 & -2.377765000 \\
6 & 4.050289000 & -1.020454000 & -0.202659000 \\
1 & 3.042672000 & -0.687600000 & 0.005837000 \\
6 & 3.863297000 & -4.799004000 & -0.171864000 \\
1 & 3.711077000 & -5.043398000 & 0.869702000 \\
6 & 5.075557000 & -5.031423000 & -0.902030000 \\
1 & 5.978167000 & -5.472688000 & -0.504674000 \\
6 & 4.885053000 & -4.565153000 & -2.253047000 \\
1 & 5.617123000 & -4.604725000 & -3.046574000 \\
6 & 3.556469000 & -4.036784000 & -2.363230000 \\
1 & 3.121049000 & -3.638652000 & -3.268359000 \\
6 & 2.896489000 & -4.189810000 & -1.073636000 \\
\hline & 1.535112000 & -3.773306000 & -0.738380000 \\
\hline & 0.759083000 & -2.998407000 & -1.648614000 \\
\hline
\end{tabular}

\begin{tabular}{|c|c|c|c|}
\hline 1 & 1.184040000 & -2.704892000 & -2.600690000 \\
\hline 6 & -0.535183000 & -2.601156000 & -1.302026000 \\
\hline 6 & -1.486383000 & -1.776617000 & -2.091740000 \\
\hline 6 & -1.229276000 & -1.265472000 & -3.370358000 \\
\hline 1 & -0.281242000 & -1.471542000 & -3.855297000 \\
\hline 6 & -2.202533000 & -0.482726000 & -4.023130000 \\
\hline 1 & -2.004017000 & -0.082368000 & -5.012514000 \\
\hline 6 & -3.425618000 & -0.227132000 & -3.380953000 \\
\hline 1 & -4.210191000 & 0.375857000 & -3.825551000 \\
\hline 6 & -3.642934000 & -0.767974000 & -2.104138000 \\
\hline 1 & -4.568459000 & -0.608302000 & -1.570796000 \\
\hline 6 & -3.206305000 & -3.591570000 & 3.163311000 \\
\hline 1 & -4.177932000 & -3.114438000 & 3.120446000 \\
\hline 6 & -2.789559000 & -4.355281000 & 4.264432000 \\
\hline 1 & -3.456846000 & -4.479934000 & 5.110010000 \\
\hline 6 & -1.513709000 & -4.944041000 & 4.244789000 \\
\hline 1 & -1.168358000 & -5.540967000 & 5.083072000 \\
\hline 6 & -0.685313000 & -4.753898000 & 3.123473000 \\
\hline 1 & 0.300725000 & -5.204048000 & 3.091609000 \\
\hline 6 & -1.139457000 & -3.984419000 & 2.044235000 \\
\hline 6 & -0.354736000 & -3.721010000 & 0.810132000 \\
\hline 6 & 0.943892000 & -4.139629000 & 0.505259000 \\
\hline 1 & 1.503260000 & -4.746055000 & 1.207046000 \\
\hline 6 & -4.679471000 & -1.671016000 & 0.815891000 \\
\hline 6 & -5.799966000 & -1.156453000 & 0.906413000 \\
\hline 6 & -7.099119000 & -0.457010000 & 0.752047000 \\
\hline 1 & -7.197173000 & 0.355730000 & 1.479391000 \\
\hline 1 & -7.936528000 & -1.140462000 & 0.933592000 \\
\hline 7 & -7.236894000 & 0.083540000 & -0.622023000 \\
\hline
\end{tabular}




\begin{tabular}{|c|c|c|c|}
\hline 1 & -7.540254000 & -0.574940000 & -1.336461000 \\
\hline 6 & -6.550224000 & 1.180335000 & -1.116601000 \\
\hline 8 & -6.334805000 & 1.282460000 & -2.358000000 \\
\hline 6 & -6.091723000 & 2.235746000 & -0.109664000 \\
\hline 1 & -5.415241000 & 1.764072000 & 0.619478000 \\
\hline 1 & -6.968943000 & 2.579153000 & 0.459060000 \\
\hline 6 & -5.388844000 & 3.433095000 & -0.775644000 \\
\hline 1 & -4.517725000 & 3.073713000 & -1.340564000 \\
\hline 1 & -6.061858000 & 3.886307000 & -1.514450000 \\
\hline 6 & -4.941764000 & 4.494219000 & 0.252370000 \\
\hline 1 & -4.303873000 & 4.021837000 & 1.018022000 \\
\hline 1 & -5.823686000 & 4.888856000 & 0.782248000 \\
\hline 6 & -4.171365000 & 5.660677000 & -0.402196000 \\
\hline 1 & -3.279972000 & 5.273411000 & -0.918005000 \\
\hline 1 & -4.796907000 & 6.133819000 & -1.173360000 \\
\hline 6 & -3.736003000 & 6.733233000 & 0.624383000 \\
\hline 1 & -4.627148000 & 7.153543000 & 1.110567000 \\
\hline 1 & -3.140143000 & 6.266431000 & 1.417127000 \\
\hline 7 & -2.972049000 & 7.840473000 & 0.031848000 \\
\hline 1 & -3.492024000 & 8.595601000 & -0.406996000 \\
\hline 6 & -1.599826000 & 7.954151000 & -0.090970000 \\
\hline 8 & -1.092582000 & 8.935882000 & -0.695208000 \\
\hline 6 & -0.739046000 & 6.857775000 & 0.549394000 \\
\hline 1 & -1.073390000 & 5.872578000 & 0.190954000 \\
\hline 1 & -0.908364000 & 6.865770000 & 1.637580000 \\
\hline 0 & 0.759744000 & 7.047624000 & 0.253680000 \\
\hline 1 & 0.914332000 & 7.065167000 & -0.833136000 \\
\hline 1 & 1.075103000 & 8.033643000 & 0.617373000 \\
\hline 6 & 1.624542000 & 5.941437000 & 0.892531000 \\
\hline 1 & 1.299909000 & 4.958471000 & 0.514610000 \\
\hline
\end{tabular}

\begin{tabular}{|llll|}
\hline 1 & 1.466189000 & 5.926963000 & 1.983174000 \\
6 & 3.127651000 & 6.131247000 & 0.598953000 \\
1 & 3.298397000 & 6.146229000 & -0.486482000 \\
1 & 3.443985000 & 7.116099000 & 0.980509000 \\
6 & 4.034849000 & 5.075841000 & 1.239755000 \\
16 & 3.624648000 & 3.279301000 & 0.531073000 \\
6 & 5.563524000 & 5.332052000 & 1.029860000 \\
6 & 5.391774000 & 2.910797000 & 0.722383000 \\
6 & 6.199926000 & 3.973233000 & 0.980361000 \\
1 & 3.824817000 & 4.971072000 & 2.309881000 \\
1 & 5.728740000 & 5.884679000 & 0.091275000 \\
1 & 5.931870000 & 5.961201000 & 1.851799000 \\
7 & 7.532110000 & 3.501768000 & 0.930801000 \\
6 & 7.550263000 & 2.121309000 & 0.658854000 \\
8 & 8.539553000 & 1.354469000 & 0.576706000 \\
7 & 6.186172000 & 1.777653000 & 0.516995000 \\
1 & 5.888785000 & 0.828934000 & 0.340663000 \\
1 & 8.378850000 & 4.018368000 & 1.121426000 \\
\hline
\end{tabular}

\section{COMPLEX 2}

\begin{tabular}{|cccc|}
\hline 78 & 0.751819000 & -2.558542000 & 0.347675000 \\
26 & 5.507145000 & 3.410817000 & -0.417501000 \\
7 & 1.765578000 & -2.690560000 & 2.122292000 \\
7 & 2.259821000 & -1.311069000 & -0.031010000 \\
7 & 0.267840000 & -1.993811000 & -1.564309000 \\
6 & 4.806465000 & 4.334679000 & 1.361385000 \\
1 & 4.934676000 & 3.958987000 & 2.366872000 \\
6 & 5.710417000 & 5.220098000 & 0.667721000 \\
1 & 6.641145000 & 5.609947000 & 1.055325000 \\
6 & 5.158250000 & 5.490014000 & -0.636323000 \\
1 & 5.603521000 & 6.116534000 & -1.396348000 \\
\hline
\end{tabular}




\begin{tabular}{|c|c|c|c|c|c|c|c|}
\hline 6 & 3.912406000 & 4.771090000 & -0.751564000 & 6 & 3.355715000 & -2.686900000 & 4.423206000 \\
\hline 1 & 3.253527000 & 4.777426000 & -1.608462000 & 1 & 3.973492000 & -2.686590000 & 5.315777000 \\
\hline 6 & 3.694601000 & 4.060160000 & 0.484484000 & 6 & 3.714608000 & -1.898315000 & 3.314659000 \\
\hline 1 & 2.843476000 & 3.433606000 & 0.714651000 & 1 & 4.610164000 & -1.287639000 & 3.347452000 \\
\hline 6 & 6.577424000 & 1.654628000 & 0.055535000 & 6 & 2.913029000 & -1.904924000 & 2.165631000 \\
\hline 1 & 6.743845000 & 1.259596000 & 1.047236000 & 6 & 3.194266000 & -1.114248000 & 0.939183000 \\
\hline 6 & 7.455000000 & 2.564048000 & -0.621862000 & 6 & 4.258600000 & -0.241621000 & 0.697786000 \\
\hline 1 & 8.369540000 & 2.976348000 & -0.220839000 & 1 & 5.012063000 & -0.074540000 & 1.457614000 \\
\hline 6 & 6.903627000 & 2.836544000 & -1.925924000 & 6 & -0.773638000 & -3.775404000 & 0.653535000 \\
\hline 1 & 7.331467000 & 3.490313000 & -2.672075000 & 6 & -1.784194000 & -4.487290000 & 0.667364000 \\
\hline 6 & 5.683058000 & 2.096547000 & -2.060775000 & 6 & -3.029324000 & -5.257454000 & 0.429415000 \\
\hline 1 & 5.054951000 & 2.096113000 & -2.939836000 & 1 & -3.821685000 & -4.941850000 & 1.116588000 \\
\hline 6 & 5.470835000 & 1.336852000 & -0.836746000 & 1 & -2.869231000 & -6.326865000 & 0.608277000 \\
\hline 6 & 4.356633000 & 0.433029000 & -0.554373000 & 7 & -3.486371000 & -5.091169000 & -0.971771000 \\
\hline 6 & 3.350985000 & 0.180067000 & -1.532111000 & 1 & -3.052418000 & -5.697972000 & -1.664056000 \\
\hline 1 & 3.404492000 & 0.668235000 & -2.497380000 & 6 & -4.027982000 & -3.927951000 & -1.493487000 \\
\hline 6 & 2.302365000 & -0.699404000 & -1.246923000 & 8 & -3.942437000 & -3.690184000 & -2.732067000 \\
\hline 6 & 1.165188000 & -1.088687000 & -2.120914000 & 6 & -4.710725000 & -2.974549000 & -0.513090000 \\
\hline 6 & 0.957182000 & -0.609483000 & -3.420582000 & 1 & -3.951074000 & -2.596373000 & 0.189167000 \\
\hline 1 & 1.658077000 & 0.093677000 & -3.857313000 & 1 & -5.433437000 & -3.542130000 & 0.091215000 \\
\hline 6 & -0.163853000 & -1.040685000 & -4.157505000 & 6 & -5.411944000 & -1.792612000 & -1.206971000 \\
\hline 1 & -0.329021000 & -0.668386000 & -5.163822000 & 1 & -4.702527000 & -1.294524000 & -1.880695000 \\
\hline 6 & -1.061089000 & -1.952403000 & -3.576739000 & 1 & -6.222259000 & -2.170773000 & -1.844452000 \\
\hline 1 & -1.946094000 & -2.314567000 & -4.088921000 & 6 & -5.965542000 & -0.776589000 & -0.185943000 \\
\hline 6 & -0.808105000 & -2.412166000 & -2.274958000 & 1 & -5.138624000 & -0.415121000 & 0.445429000 \\
\hline 1 & -1.462220000 & -3.119121000 & -1.785833000 & 1 & -6.680392000 & -1.273622000 & 0.488742000 \\
\hline 6 & 1.416956000 & -3.451069000 & 3.190423000 & 6 & -6.654178000 & 0.426153000 & -0.864376000 \\
\hline 1 & 0.510918000 & -4.034867000 & 3.081928000 & 1 & -5.960119000 & 0.904862000 & -1.569564000 \\
\hline 6 & 2.192275000 & -3.472352000 & 4.359950000 & 1 & -7.509277000 & 0.064199000 & -1.458700000 \\
\hline 1 & 1.882793000 & -4.093109000 & 5.193434000 & 6 & -7.180288000 & 1.482350000 & 0.114506000 \\
\hline
\end{tabular}




\begin{tabular}{|lrrr|}
\hline 16 & -5.696564000 & 2.262840000 & 1.149592000 \\
6 & -7.956727000 & 2.654417000 & -0.571366000 \\
6 & -6.623183000 & 3.824034000 & 1.115048000 \\
6 & -7.687249000 & 3.867465000 & 0.270141000 \\
1 & -7.810795000 & 1.027478000 & 0.886181000 \\
1 & -7.594970000 & 2.796571000 & -1.602592000 \\
1 & -9.021226000 & 2.388476000 & -0.629884000 \\
7 & -8.158352000 & 5.199502000 & 0.262534000 \\
6 & -7.390715000 & 5.994565000 & 1.135300000 \\
8 & -7.537722000 & 7.205079000 & 1.416066000 \\
7 & -6.414862000 & 5.102516000 & 1.645813000 \\
1 & -5.755055000 & 5.385891000 & 2.355389000 \\
1 & -8.971529000 & 5.566551000 & -0.210931000 \\
\hline
\end{tabular}

COMPLEX 3

\begin{tabular}{|lrrr|}
\hline 78 & 2.040915000 & 0.666960000 & -0.158450000 \\
26 & -5.535628000 & -0.595483000 & 0.298883000 \\
7 & 1.414383000 & 2.609313000 & 0.017103000 \\
7 & 0.085171000 & 0.418495000 & -0.453601000 \\
7 & 1.984896000 & -1.363019000 & -0.447112000 \\
6 & -5.711624000 & 0.222662000 & 2.251317000 \\
1 & -5.567907000 & 1.259337000 & 2.521857000 \\
6 & -6.959614000 & -0.383466000 & 1.855216000 \\
1 & -7.910418000 & 0.122008000 & 1.760774000 \\
6 & -6.716246000 & -1.781320000 & 1.600951000 \\
1 & -7.452533000 & -2.505453000 & 1.281608000 \\
6 & -5.317149000 & -2.041652000 & 1.838364000 \\
1 & -4.826759000 & -3.000514000 & 1.746051000 \\
6 & -4.697989000 & -0.803229000 & 2.243043000 \\
1 & -3.656317000 & -0.668225000 & 2.501120000 \\
6 & -5.090004000 & 0.935906000 & -1.086038000 \\
\hline
\end{tabular}

\begin{tabular}{|c|c|c|c|}
\hline 1 & -4.944823000 & 1.978930000 & -0.844229000 \\
\hline 6 & -6.347609000 & 0.342844000 & -1.436576000 \\
\hline 1 & -7.296171000 & 0.857434000 & -1.489011000 \\
\hline 6 & -6.128473000 & -1.058331000 & -1.697383000 \\
\hline 1 & -6.883486000 & -1.776432000 & -1.982670000 \\
\hline 6 & -4.735080000 & -1.337695000 & -1.507423000 \\
\hline 1 & -4.273091000 & -2.303288000 & -1.653388000 \\
\hline 6 & -4.065521000 & -0.097273000 & -1.141898000 \\
\hline 6 & -2.636309000 & 0.077108000 & -0.885310000 \\
\hline 6 & -1.743800000 & -1.033616000 & -0.915319000 \\
\hline 1 & -2.128321000 & -2.026667000 & -1.112676000 \\
\hline 6 & -0.377203000 & -0.840122000 & -0.693814000 \\
\hline 6 & 0.706701000 & -1.856858000 & -0.685132000 \\
\hline 6 & 0.517489000 & -3.228773000 & -0.894950000 \\
\hline 1 & -0.478153000 & -3.615702000 & -1.083496000 \\
\hline 6 & 1.621522000 & -4.104351000 & -0.859615000 \\
\hline 1 & 1.476612000 & -5.168403000 & -1.018958000 \\
\hline 6 & 2.904637000 & -3.586777000 & -0.616947000 \\
\hline 1 & 3.793850000 & -4.206540000 & -0.570664000 \\
\hline 6 & 3.047003000 & -2.204463000 & -0.418766000 \\
\hline 1 & 4.011861000 & -1.755519000 & -0.235344000 \\
\hline 6 & 2.201175000 & 3.686851000 & 0.262966000 \\
\hline 1 & 3.259037000 & 3.484806000 & 0.379719000 \\
\hline 6 & 1.664789000 & 4.980275000 & 0.356121000 \\
\hline 1 & 2.324475000 & 5.818057000 & 0.553008000 \\
\hline 6 & 0.280957000 & 5.160251000 & 0.190500000 \\
\hline 1 & -0.158444000 & 6.150627000 & 0.256804000 \\
\hline 6 & -0.532914000 & 4.041171000 & -0.064286000 \\
\hline 1 & -1.602262000 & 4.163808000 & -0.196243000 \\
\hline 6 & 0.042075000 & 2.766290000 & -0.149688000 \\
\hline
\end{tabular}




\begin{tabular}{|c|c|c|c|}
\hline 6 & -0.717398000 & 1.517195000 & -0.417381000 \\
\hline 6 & -2.090607000 & 1.369344000 & -0.632079000 \\
\hline 1 & -2.742585000 & 2.233992000 & -0.618206000 \\
\hline 6 & 3.989194000 & 0.834663000 & 0.119632000 \\
\hline 6 & 5.214447000 & 0.743256000 & 0.257539000 \\
\hline 6 & 6.645640000 & 0.363039000 & 0.346136000 \\
\hline 1 & 7.031507000 & 0.516138000 & 1.359416000 \\
\hline 1 & 7.258562000 & 0.981521000 & -0.319608000 \\
\hline 7 & 6.825726000 & -1.056406000 & -0.044189000 \\
\hline 1 & 6.820320000 & -1.249985000 & -1.043424000 \\
\hline 6 & 6.480098000 & -2.140735000 & 0.745108000 \\
\hline 8 & 6.169668000 & -3.244030000 & 0.211957000 \\
\hline 6 & 6.495422000 & -1.946153000 & 2.253385000 \\
\hline 1 & 7.458893000 & -1.547224000 & 2.591862000 \\
\hline 1 & 5.707369000 & -1.250779000 & 2.570575000 \\
\hline 1 & 6.323494000 & -2.914940000 & 2.726152000 \\
\hline
\end{tabular}


Table S2. Selected transitions and energies in the visible region of the complexes 1-3 as obtained from TDDFT calculations using B3LYP/LanL2DZ level of theory.

\begin{tabular}{|c|c|c|c|c|c|}
\hline $\begin{array}{l}\text { Complex } \\
\text { HOMO / LUMO }\end{array}$ & $\begin{array}{l}\text { Energy } \\
(\mathrm{eV})\end{array}$ & $\begin{array}{l}\text { Wavelength } \\
(\mathrm{nm})\end{array}$ & $\begin{array}{l}\text { Oscillator } \\
\text { Strength }\end{array}$ & $\begin{array}{l}\text { Major transitions } \\
\text { (\% contributions) }\end{array}$ & Nature \\
\hline \multirow{16}{*}{$\begin{array}{c}\mathbf{1} \\
{[\mathrm{HOMO}=211]} \\
{[\mathrm{LUMO}=212]}\end{array}$} & \multirow[t]{2}{*}{1.6390} & \multirow[t]{2}{*}{756.45} & \multirow[t]{2}{*}{0.0169} & $208 \rightarrow 212(34 \%)$ & LMCT \\
\hline & & & & $208 \rightarrow 219(26 \%)$ & ILCT \\
\hline & \multirow[t]{2}{*}{2.0942} & \multirow[t]{2}{*}{592.04} & \multirow[t]{2}{*}{0.0270} & $207 \rightarrow 218(49 \%)$ & ILCT \\
\hline & & & & $208 \rightarrow 212(42 \%)$ & LMCT \\
\hline & \multirow[t]{2}{*}{2.3035} & \multirow[t]{2}{*}{538.24} & \multirow[t]{2}{*}{0.0153} & $208 \rightarrow 212(21 \%)$ & ILCT \\
\hline & & & & $208 \rightarrow 213(27 \%)$ & ILCT \\
\hline & 2.3481 & 528.01 & 0.0159 & $208 \rightarrow 213(64 \%)$ & ILCT \\
\hline & \multirow{3}{*}{2.3838} & \multirow{3}{*}{520.12} & \multirow{3}{*}{0.0450} & $204 \rightarrow 212(41 \%)$ & L'MCT \\
\hline & & & & $205 \rightarrow 212(33 \%)$ & L'MCT \\
\hline & & & & $206 \rightarrow 212(24 \%)$ & L'MCT \\
\hline & \multirow[t]{2}{*}{2.3986} & \multirow[t]{2}{*}{516.90} & \multirow[t]{2}{*}{0.0176} & $204 \rightarrow 212(34 \%)$ & L'MCT \\
\hline & & & & $206 \rightarrow 212(25 \%)$ & L'MCT \\
\hline & \multirow[t]{2}{*}{2.4035} & \multirow[t]{2}{*}{515.84} & \multirow[t]{2}{*}{0.0281} & $204 \rightarrow 212(16 \%)$ & ILCT \\
\hline & & & & $207 \rightarrow 213(30 \%)$ & ILCT \\
\hline & 2.6630 & 465.58 & 0.0106 & $204 \rightarrow 213(83 \%)$ & L'MCT \\
\hline & 2.6806 & 462.53 & 0.008 & $202 \rightarrow 212(81 \%)$ & L'MCT \\
\hline \multirow{11}{*}{$\begin{array}{c}\mathbf{2} \\
{[\mathrm{HOMO}=180]} \\
{[\mathrm{LUMO}=181]}\end{array}$} & \multirow[t]{2}{*}{1.6387} & \multirow[t]{2}{*}{756.62} & \multirow[t]{2}{*}{0.0197} & $179 \rightarrow 181(36 \%)$ & LMCT \\
\hline & & & & $179 \rightarrow 188(27 \%)$ & ILCT \\
\hline & \multirow[t]{2}{*}{2.0935} & \multirow[t]{2}{*}{592.25} & \multirow[t]{2}{*}{0.0276} & $177 \rightarrow 187(42 \%)$ & ILCT \\
\hline & & & & $179 \rightarrow 181(40 \%)$ & LMCT \\
\hline & 2.2846 & 542.70 & 0.0100 & $179 \rightarrow 181(15 \%)$ & LMCT \\
\hline & & & & $179 \rightarrow 182(45 \%)$ & LMCT \\
\hline & 2.3348 & 531.03 & 0.0165 & $177 \rightarrow 182(15 \%)$ & LMCT \\
\hline & & & & $179 \rightarrow 182(47 \%)$ & LMCT \\
\hline & 2.3840 & 520.06 & 0.0948 & $175 \rightarrow 181(98 \%)$ & L'MCT \\
\hline & 2.6503 & 467.82 & 0.0113 & $175 \rightarrow 182(85 \%)$ & L'MCT \\
\hline & 2.6664 & 464.98 & 0.0070 & $173 \rightarrow 181(83 \%)$ & L'MCT \\
\hline & 1.6386 & 756.66 & 0.0194 & $137 \rightarrow 138(34 \%)$ & LMCT \\
\hline & & & & $137 \rightarrow 145(26 \%)$ & LLCT \\
\hline & 2.0979 & 590.99 & 0.0302 & $136 \rightarrow 144(46 \%)$ & LLCT \\
\hline & & & & $137 \rightarrow 138(41 \%)$ & LMCT \\
\hline & 2.2946 & 540.32 & 0.0161 & $137 \rightarrow 138(20 \%)$ & LMCT \\
\hline$[\mathrm{HOMO}=137]$ & & & & $137 \rightarrow 139(33 \%)$ & LMCT \\
\hline$[\mathrm{LUMO}=138]$ & 2.3510 & 527.37 & 0.0182 & $136 \rightarrow 139(12 \%)$ & LMCT \\
\hline & & & & $137 \rightarrow 139(50 \%)$ & LMCT \\
\hline & 2.3858 & 519.68 & 0.0766 & $135 \rightarrow 138(89 \%)$ & LMCT \\
\hline & 2.4034 & 515.87 & 0.0087 & $136 \rightarrow 139(29 \%)$ & ILCT \\
\hline & 2.6438 & 468.96 & 0.0060 & $133 \rightarrow 138(71 \%)$ & L'MCT \\
\hline & 2.6619 & 465.77 & 0.0161 & $135 \rightarrow 139(71 \%)$ & L'MCT \\
\hline
\end{tabular}


Table S3. Platinum content (pg Pt/ $\mu$ g of DNA) in ct-DNA $(500 \mu \mathrm{M})$ treated with complexes 1-6 $(50 \mu \mathrm{M})$.

\begin{tabular}{|c|c|c|}
\hline \multirow{2}{*}{ Complex } & \multicolumn{2}{|c|}{$\mathrm{pg} \mathrm{Pt} \mu \mathrm{g}_{\mathrm{of} \mathrm{DNA}}{ }^{a}$} \\
\cline { 2 - 3 } & Dark & 0 \\
\hline Untreated & 0 & $9742 \pm 72$ \\
\hline $\mathbf{1}$ & $428 \pm 55$ & $9850 \pm 53$ \\
\hline $\mathbf{2}$ & $657 \pm 25$ & $10514 \pm 109$ \\
\hline $\mathbf{3}$ & $400 \pm 32$ & $1828 \pm 50$ \\
\hline $\mathbf{4}$ & $1142 \pm 36$ & $1857 \pm 35$ \\
\hline $\mathbf{5}$ & $1200 \pm 50$ & $2542 \pm 82$ \\
\hline $\mathbf{6}$ & $1600 \pm 74$ & \\
\hline
\end{tabular}

${ }^{a}$ Samples either kept in dark or exposed to light for $1 \mathrm{~h}(400-700 \mathrm{~nm})$. 